\title{
International R\&D Roadmap for Fire Resistance of Structures Summary of NIST/CIB Workshop
}

\author{
Jiann C. Yang \\ Matthew Bundy \\ John Gross, \\ Anthony Hamins \\ Fahim Sadek \\ Anand Raghunathan
}

This publication is available free of charge from: http://dx.doi.org/10.6028/NIST.SP.1188

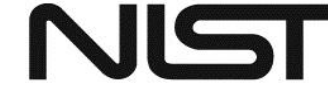

National Institute of Standards and Technology U.S. Department of Commerce 


\title{
International R\&D Roadmap for Fire Resistance of Structures Summary of NIST/CIB Workshop
}

\author{
Jiann C. Yang \\ Matthew Bundy \\ John Gross \\ Anthony Hamins \\ Fire Research Division \\ Engineering Laboratory
}

Fahim Sadek

Materials and Structural Systems Division

Engineering Laboratory

Anand Raghunathan

Energetics, Inc.

This publication is available free of charge from:

http://dx.doi.org/10.6028/NIST.SP.1188

March 2015

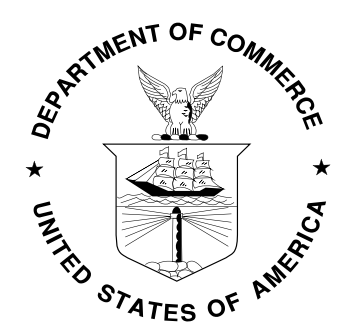

U.S. Department of Commerce

Penny Pritzker, Secretary

National Institute of Standards and Technology Willie May, Acting Under Secretary of Commerce for Standards and Technology and Acting Director 
Certain commercial entities, equipment, or materials may be identified in this document in order to describe an experimental procedure or concept adequately. Such identification is not intended to imply recommendation or endorsement by the National Institute of Standards and Technology, nor is it intended to imply that the entities, materials, or equipment are necessarily the best available for the purpose.

This report was prepared as an account of the International Workshop on the Fire Resistance of Structures hosted by NIST. The views and opinions expressed herein do not necessarily state or reflect those of NIST.

National Institute of Standards and Technology Special Publication 1188

Natl. Inst. Stand. Technol. Spec. Publ. 1188, 138 pages (March 2015)

CODEN: NSPUE2

This publication is available free of charge from: http://dx.doi.org/10.6028/NIST.SP.1188 
THIS PAGE LEFT INTENTIONALLY BLANK 


\begin{abstract}
This report summarizes the results of the global meeting to develop the International R\&D Roadmap for Fire Resistance of Structures (the Roadmap) held May 21-22, 2014, in Gaithersburg, Maryland. The workshop was sponsored by the National Institute of Standards and Technology (NIST) and the International Council for Research and Innovation in Building and Construction (CIB) and hosted by NIST. The workshop provided a forum to identify and discuss the research and development needs and programs to implement to advance technical solutions in order to improve the fire resistance of structures through greater use of existing technologies, development and deployment of emerging technologies, and development and implementation of standards and codes for performance-based engineering design. In preparation for the workshop, NIST commissioned three white papers-one on concrete structures, one on steel structures, and one on timber structures-written by topic experts in the respective fields. The white papers formed the basis for discussion at the workshop and provided a framework for the Roadmap, which is documented in this report.
\end{abstract}




\section{Acknowledgements}

Thanks are extended to Ms. Stéphanie Vallerent of Centre Scientifique et Technique du Bâtiment (CSTB) of France, Dr. Alec Lei of the Architecture and Building Research Institute (ABRI) of Taiwan, and Professor George Hadjisophocleous of Carleton University of Canada and the current Chair of CIB WI4 for their efforts in the initial planning of the workshop. Thanks also go to Energetics Incorporated's workshop team members Laurie Aldape, Stephanie Shuff, and Walt Zalis for their assistance in facilitating the workshop and preparing this report and to William Grosshandler, Lisa Choe and Matthew Hoehler of NIST for reviewing the initial draft report. Of course, this report would not have been possible without the specialized knowledge and insight contributed by the experts in various aspects of fire-resistant structures. These experts took time from their busy schedules to participate in the workshop and share their insight, which forms the basis of this document. These individuals are listed in Appendix A. 


\section{Table of Contents}

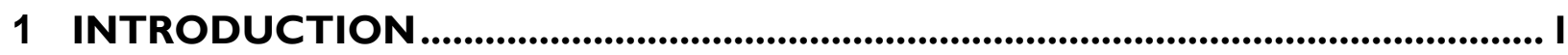

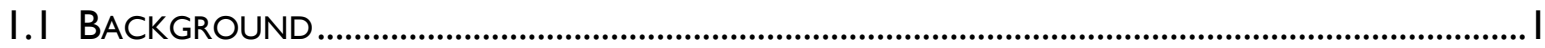

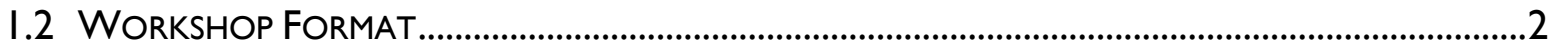

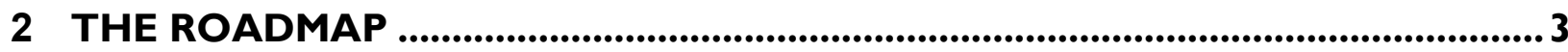

2.I CONCEPTUAL FRAMEWORK ................................................................................................

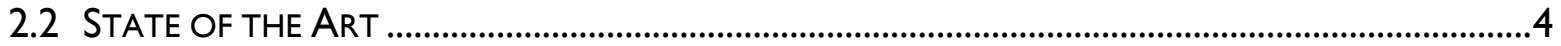

2.3 VISION

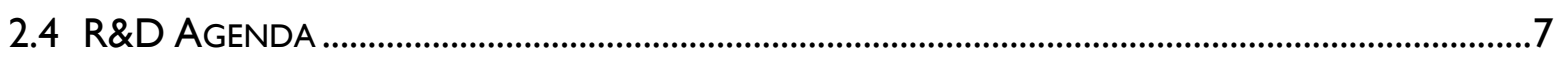

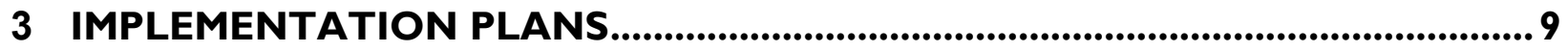

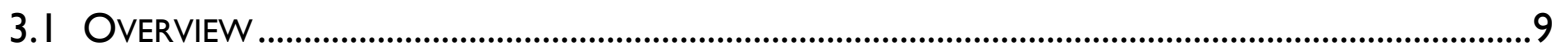

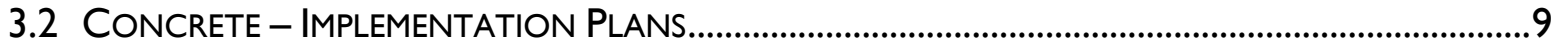

3.3 STEEL - IMPLEMENTATION PLANS....................................................................................... 15

3.4 TIMBER - IMPLEMENTATION PLANS......................................................................................... 20

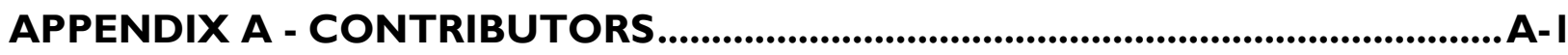

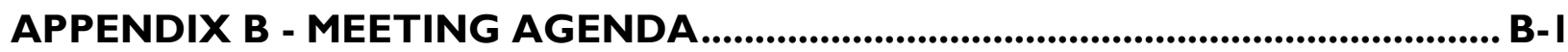

APPENDIX C - DEVELOPMENT STRATEGY ............................................................... C-I

APPENDIX D - LIST OF CURRENT R\&D NEEDS ..............................................

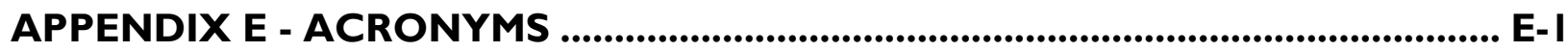

APPENDIX F - WHITE PAPERS................................................................................. I

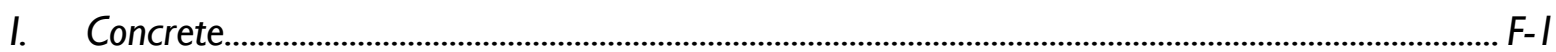

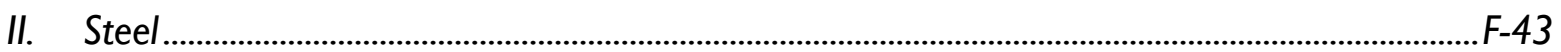

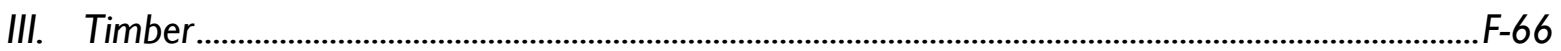




\section{TABLES}

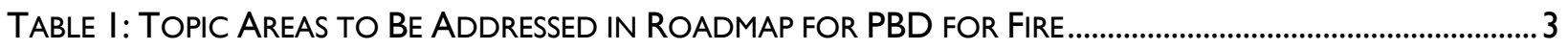

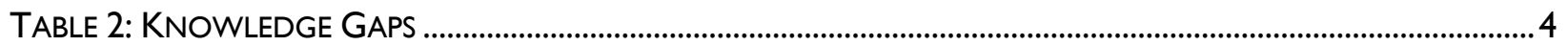

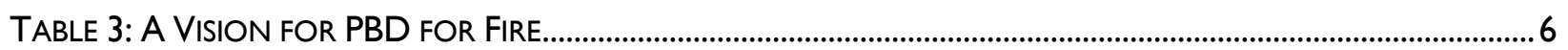

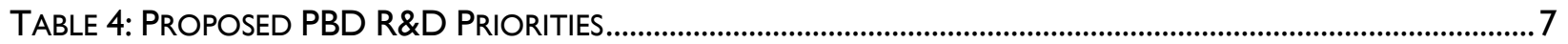

TABLE 5: WORLDWIDE EFFORTS TO SUPPORT THE PBD RESEARCH AGENDA ............................................................8

TABLE C.I: DEVELOPMENT STRATEGY FOR CONCRETE STRUCTURAL SYSTEMS ................................................. C-I

TABLE C.2: DEVELOPMENT STRATEGY FOR STEEL STRUCTURAL SYSTEMS.......................................................... C-I

TABLE C.3: DEVELOPMENT STRATEGY FOR TIMBER STRUCTURAL SYSTEMS..................................................... C-2

TABLE D.I: GENERAL R\&D NEEDS FOR CONCRETE STRUCTURAL SYSTEMS .................................................... D-I

TABLE D.2: GENERAL R\&D NEEDS FOR STEEL STRUCTURAL SYSTEMS .............................................................. D-2

TABLE D.3: GENERAL R\&D NEEDS FOR TIMBER STRUCTURAL SYSTEMS ………........................................... D-3

TABLE D.4: SPECIFIC R\&D NEEDS FOR CONCRETE STRUCTURAL SYSTEMS ................................................. D-4

TABLE D.5: SPECIFIC R\&D NEEDS FOR STEEL STRUCTURAL SYSTEMS ..........................................................

TABLE D.6: SPECIFIC R\&D NEEDS FOR TIMBER STRUCTURAL SYSTEMS .......................................................... D-6

\section{TOPIC TABLES}

\section{CONCRETE}

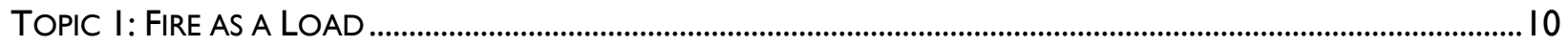

TOPIC 2: HIGH-TEMPERATURE STRAIN AND DEFLECTION MEASUREMENTS .................................................. I I

TOPIC 3: STAKEHOLDER EDUCATION AND CODE DEVELOPMENT .................................................................. 12

TOPIC 4: MULTI-SCALE CONDITIONS AND TESTING OF CONCRETE ELEMENTS AND SAMPLES ............................ I 3

TOPIC 5: SOCIETAL AWARENESS OF FIRE ISSUES............................................................................................ 14

\section{STeEL}

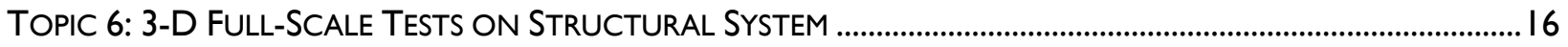

TOPIC 7: MATERIAL PROPERTIES FOR STEEL CONSTRUCTION ...........................................................................

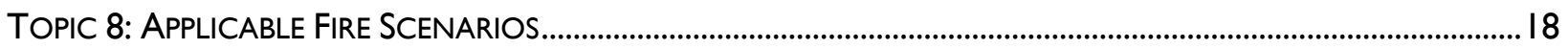

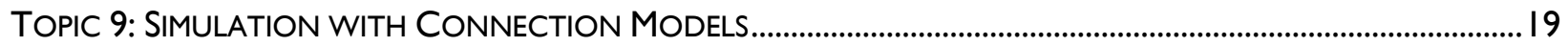

\section{TIMBER}

TOPIC I0: PREDICT THE RELIABILITY OF FIRE COMPARTMENTATION .................................................................... I

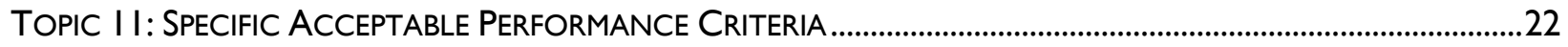

TOPIC I2: DEVELOPMENT OF STRUCTURAL MODELS FOR TIMBER FIRE RESISTANCE .............................................23

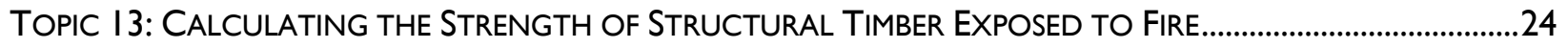

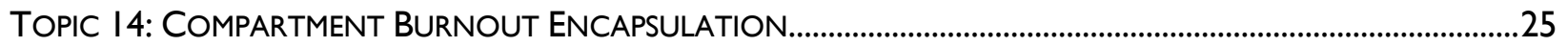

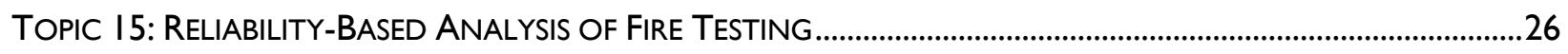

TOPIC I6: DESIGN FIRES BASED ON USE AND OCCUPANCY ............................................................................... 


\section{Introduction}

\subsection{Background}

Fire has a devastating and widespread impact on the built environment-including losses of human life, public and private property, and national treasure. Traditional approaches to fire protection for buildings and communities include construction restrictions (e.g., zoning and occupancy restrictions), measures to limit fire spread (e.g., passive fire protection and fire resistance rating requirements), and active fire suppression (e.g., sprinklers). Whereas these approaches have worked reasonably well, there are gaps in knowledge and understanding that preclude certainty in engineered structural fire protection design, and there remain instances of uncontrolled fires that have led to significant structural damage or collapse. A performance-based approach to building design goes beyond conventional methods of limiting fire spread by coupling realistic demand requirements with desired system performance.

Performance-based design (PBD) is possible today as a result of advances in predictive computational models used by the fire safety and structural engineering communities. These models may be used to characterize building fires and predict the thermal effects of a fire on a building's structural system. Advanced computational models can also predict the performance of a structural component, assembly, or system, as well as the effects of the thermal insult, including the diminishment of mechanical properties. The confluence of technological advances in three areas-characterization of building fires, prediction of thermal effects, and calculation of structural performance-makes possible the vision of a unified performance-based approach to structural fire safety and design.

Both the International Council for Research and Innovation in Building and Construction (Conseil International du Bâtiment, or [CIB]) ${ }^{\prime}$ and the National Institute of Standards and Technology (NIST) ${ }^{2}$ are working to enhance the knowledge and tools needed to improve the structural fire resistance of new buildings and retrofit of existing structures.

At the October 20II CIB meeting in Helsinki, Finland, CIB leadership agreed to convene a workshop to develop the International R\&D Roadmap for Fire Resistance of Structures (the Roadmap). The Roadmap would focus on development of a multi-year, multi-institution, large-scale experimental program to support advanced computational models and their application to standards development for performance-based engineering for structural fire resistance. This effort would be carried out under the umbrella of CIB with the intent to include key international organizations, including the International FORUM of Fire Research Directors and other appropriate U.S. and international research and development (R\&D), standards and codes development, and testing organizations. The workshop would focus on the following issues:

I. Identifying R\&D needs for large-scale experiments on fire resistance of structures to support performance-based engineering and structure-fire model validation

2. Prioritizing those needs in order of importance to performance-based engineering

3. Phasing the needed research in terms of a timeline; i.e., near term (less than 3 years), medium term ( 3 to 6 years), or long term (greater than 6 years)

4. Identifying appropriate international laboratory facilities available to address each need

5. Identifying potential collaborators and sponsors for each need

6. Identifying the primary means to transfer the results from each series of tests to industry through specific national and international standards, predictive tools for use in practice, and comprehensive research reports

\footnotetext{
' http://www.cibworld.nl/

${ }^{2}$ http://www.nist.gov/
} 
7. Identifying the means for the coalition of international partners to review progress and exchange information on a regular basis

In preparation for the roadmapping workshop, NIST commissioned three white papers-one on concrete structures, one on steel structures, and one on timber structures-written by topic experts in the respective fields. The white papers provided a basis for discussion at the workshop and helped develop a framework for the Roadmap. Each white paper focused on the following issues:

- Identification of R\&D needs for large-scale experiments on fire resistance of structures to support performance-based engineering and structure-fire model validation

- Prioritization of those R\&D needs in order of importance to performance-based engineering

- Identification of the needed research timeline (i.e., near term [less than 3 years], medium term [3 to 6 years], or long term [greater than 6 years])

These three white papers are included in their entirety in Appendix $F$ in this report:

- State-of-the-Art on Fire Resistance of Concrete Structures: Structure-Fire Model Validation ${ }^{3}$

- Fire Behavior of Steel Structures 4

- Fire Resistance of Timber Structures ${ }^{5}$

\subsection{Workshop Format}

NIST hosted the roadmapping workshop on its Gaithersburg campus in Maryland, USA, on May 2I-22, 2014. The workshop brought together more than 50 experts from academia, governments, industries, test laboratories, and standard and code development organizations from Asia, Australasia, Europe, and North America. A list of roadmapping workshop contributors is provided in Appendix A.

The workshop opened with an introduction by NIST on a PBD framework for the Roadmap, followed by presentations of the white papers. After these general presentations, the workshop participants divided into three groups (concrete, steel, and timber) to discuss the seven aforementioned issues. During these brainstorming sessions, participants opined on the white papers, the scope of a PBD framework, the current state of the art (SOA), development needs, development strategy, and the worldwide research agenda needs. The development needs were prioritized according to their importance in advancing PBD. Small groups within the breakout sessions selected high-priority tasks for which they developed more detailed implementation plans. The results of the breakout session discussions and the three white papers form the basis of this Roadmap.

The remainder of this report is organized as follows: Chapter 2 includes a discussion of the Roadmap's elements, including its conceptual design, the current SOA, a future vision for the PBD of structures, and the R\&D agenda. While common issues were identified for all structural materials, specific R\&D needs were also identified for each. With an emphasis on PBD, Chapter 3 presents prioritized implementation plans to improve the fire resistance of concrete, steel, and timber structures. Chapter 4 provides a synopsis of this report. Appendix A gives a list of workshop participants. Appendix B presents the workshop agenda. Appendix $C$ documents the key ideas from workshop participants regarding the Development Strategy. Appendix D contains a complete list of R\&D needs generated during the workshop, broken down by material type and system. Appendix $\mathrm{E}$ lists acronyms used in this report. Appendix $F$ provides final versions of the commissioned white papers.

\footnotetext{
${ }^{3}$ http://dx.doi.org/10.6028/NIST.GCR.15-983

${ }^{4}$ http://dx.doi.org//0.6028/NIST.GCR.15-984

${ }^{5}$ http://dx.doi.org// 0.6028/NIST.GCR.15-985
} 


\section{The Roadmap}

\subsection{Conceptual Framework}

Based upon the contents of the three white papers, the general scope of the workshop, and the particular expertise of the participants, specific topic areas for what should be addressed in the Roadmap were identified. These are shown grouped under general categories in Error! Reference source not found..

\section{TABLe I: TOPIC AREAS to Be ADDRESSED IN ROADMAP FOR PBD FOR FIRE}

Planning and Consensus Building

- Identify performance objectives for PBD/outcome-based design

- Identify drivers for scope and responsibilities for PBD

- Determine how PBD improves design and construction, facilitating construction job thoroughness and enabling builders/engineers to perform their jobs better

- Plan for implementation, outreach, and education

- Identify methods to educate authorities having jurisdiction (AHJs) and fire service community to be able to evaluate alternative PBDs

- Include cost in the conceptual framework

- Convey that PBD will ensure more uniform risks and more efficient uses of resources, but that losses are still possible

- Identify incentives for manufacturers to release more proprietary material properties/information for use with advanced heat transfer calculation methods under any time-temperature curves leading to a net reduction in the need for fire-proofing materials

\section{Fundamental Research Areas}

- Determine a methodology to characterize building fires

- Consider combustible load and compartment fire instead of simply fire

- Identify fire scenarios under which different structural materials are susceptible to fire

- Define a structural hazard fire, including mean temperature and temperature gradient

- Define performance objectives for property protection of structures to achieve the required property loss prevention levels

- Enable the use of material property data as input to methods

- Develop new materials, especially to resist non-standard fires

- Develop more reliable material models for use in finite element analysis

- Stress-strain response, rupture, and creep

- Characterize response of small individual bits of structure, such as bolts, reinforcing bars, and connections

- Develop high-temperature strain measurement methodologies

- Develop a probabilistic approach to determine uncertainties

- Reach agreement on clearly defined goals and objectives for any large-scale test

- Use component testing first to determine whether large-scale testing is needed

- Elucidate advantages and disadvantages of hybrid testing - partial frames with active load application devices designed to replicate forces coming from adjacent structure in a larger building

- Conduct testing to allow the validation of multi-physics simulations in design

- Determine the effects of real fires on the performance of "certified" products

- Determine the effects of suppression measures (i.e., fire hose streams and sprinkler spray) on compartment fires

- Determine the physical effect of the high-pressure water jets of fire hose streams on the physical fabric of the building during/after a fire

- Determine the integrity of egress routes (e.g., stairs, elevators) in structures 


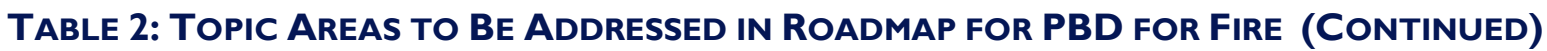

\section{Design Considerations}

- Ensure that appropriate design methodologies are developed to allow structural fire engineering to be undertaken on all kinds of building structures, including bridges and tunnels

- Consider that fire brigades act as drivers and constraints in PBD in that they attack fires but are often not aware of specific design PBD characteristics used during construction, thereby defeating the advanced design methodology

- Determine which performance criteria are needed for design

- Relate PBD required reliability to the design performance benchmark

- Provide clear articulation of "severity of fire" (i.e., means to describe and clearly articulate the relevant performance objectives related to structural performance)

- Develop criteria/guidance to determine when a prescriptive approach is inadequate

- Define the fire load based on various occupancies

- Clarify inclusion of fire dynamics or resistance

- Define performance levels to reduce the effects of fires and meet the performance objectives beyond life safety (e.g., property protection, swift repair, and sustainability)

- Define acceptable risk levels

- Determine the impact of ambient temperatures on fire development

- Determine the impact of wind-driven fires on fire development

- Base all structural designs on the best available models, consistent with structural mechanics and material behavior. Design scenarios should cover a range that models all possible "failures." Fire models should be realistic and cover the entire timeline

\subsection{State of the Art}

The three white papers in Appendix F provide comprehensive reviews of the current SOA on research, technology, testing, and best practices in PBD engineering for concrete, steel, and timber structural systems, and suggested areas where considerable gaps in knowledge exist. Additional knowledge gaps were identified by the workshop participants and are listed in Table 3.

\section{TABLE 3: KNOWLEDge GAPS}

\section{Performance Data}

- Lack of real performance data for existing building fires, including a database to assess probabilities and risk

- Limited material property (including geometry dependencies) data as a function of temperature

- Standardization for determining material properties at elevated temperature

- Need for material properties and performance during and after the fire

- Lack of high-temperature properties-especially permeability and pore structure-that influence spalling, which is often indeterminate (non-stochastic)

- Need more data on the applicability of the finite element codes to determine damage of wood/concrete/steel composite construction under fire, including both heating and cooling phases

- Understand the partition/protection variability in standard gypsum board when exposed to standard and real fires using probability methods

- Need to identify the conditions for self-extinguishing of charred wood

- Limited data on damage thresholds for structural systems at different fire exposure levels to develop methods for property protection

\section{Construction Designs}

- Instrumentation of buildings to assess performance after fire

- Building nonstructural components and system (BNCS) tests focused on earthquake and post-earthquake fire resilience 


\section{TABle 2: KNOWLedge GAPS (CONTINUED)}

- Fire response of post-installed reinforcement and anchoring

- Fire response of adhesive anchors

- Defining composite design

- Evaluation of the post-fire elements residual capacity

- Cascading impact on multiple system failures (and assembly failures)

- Indeterminate nature of spalling (not stochastic)

- Performance of base isolation systems in fire (or other pairing systems) under building fire conditions

- Considerations of exposure from/to neighbors' fire on nearby structures

- Need to determine if light frame construction fire results can be used to model heavy timber fire protection

- Fire safety effects of surrounding buildings around a fire building is not characterized

- Impact of interior design and furnishings on performance during a fire - information needed: where they are, where they are going, on the overall structural performance

- Need more on structural loading, compatibility/commonality of finite element computational fluid dynamic codes to characterize damage for wood/concrete/steel composite construction under fire heat loading and cool down

- Need to determine PBD impact and requirements for acceptance - transition from prescriptive to performance based design is a significant change

- Determine the fire performance of an as-built structure compared to as-tested construction

- Determine means to address variability in gypsum board in standard and real fires (probability based)

- Determine how PBD will be affected by current and evolving environmental laws, requirements, etc.

- Identify code hurdles-performance versus prescriptive codes, local versus model code acceptance

Modeling Capabilities

- Evaluation of light timber frame construction fires and their viability to model heavy timber fire protection

- Limited use of fire dynamics simulation for moving fires

- Uncertainties both in testing and modeling

- Probabilistic approach in simulations and translation in codes of PBD and application, with a transfer path to R\&D and then application

- Models for mechanical properties of materials at different fire-damaged levels after cool down

\section{Societal and Regulatory}

- Impact on PBD by current and evolving environmental laws, requirements, etc.

- Implementation of PBD in education, training, certification, standard fire scenarios, and test methods

- Identify hurdles anticipated when instituting performance versus prescriptive codes, local versus model code acceptance, and the translation challenges to assimilating PBD codes into building R\&D and design

\subsection{Vision}

The focus of the Roadmap is the development of a comprehensive, unified performance-based approach to structural fire safety and design. This goal will be realized through the creation of information and data, tools, guidelines, and standards for structural systems exposed to fire. The transformation to PBD to evaluate the fire performance of buildings and other structures will allow the community to move beyond the prescriptive procedures presently in use, and their attendant limitations. This vision will, for the first time, consider fire as a design condition in the structural design process and treat fire along with other hazards on a risk-consistent basis. The attributes of this transformation will include the following:

- Generation of a database of large-scale experiments documenting the performance of structural connections, components, subassemblies, and systems under realistic fire and loading conditions for validation of analytical models 
- Development of verified and validated simulation models and tools to predict structural fire performance, based on fire dynamics and thermal-structural modeling

- Use of risk- and reliability-based tools and models for the prediction and specification of the fire hazard, structural fire effects, and calculation of structural response

- Development of design guidance and standards on performance-based approaches for determining fire effects on structural systems

This broad vision of the future holds the promise of the following:

- A revolutionary transformation from the current prescriptive to new PBD

- Increased innovation and marketplace competition for new products, designs, and services

- Cost savings based on a rational and risk-consistent approach to design and the use of materials while achieving sustainability-related goals, such as reduced material use and more achievable construction programs

- Increased public safety through specific understanding of building response to severe compartment fires

Specific aspects that highlight the advantages of the PBD approach to structural fire safety and that will enable the broad vision previously outlined, as provided by the workshop participants, are summarized and categorized in Table 4.

\section{TABLE 4: A VISION FOR PBD FOR FIRE}

\section{Technologies}

- Buildings that are sensor-rich

- Reliable material property data for critical construction materials under a wide range of fire exposures

- Advanced measurement methods available to provide accurate characterization of evolving structural systems

- Reliable full-scale testing conducted and experimental results available in sufficient quantities to validate models; include a database of small and reduced-scale experiments including real conditions and fire load as available

- Impact of structural aging (e.g., sunlight, heat, and cold) on fire resistance of structural components established

- Methodology needed to account for changes in risk over time, as new combustible materials are introduced in developed buildings

- Methodology and data available for risk assessment and property protection of structures in fire

\section{Preferred Practices}

- Capability to design structures for fire to achieve not only life safety but also property protection objectives

- Capability to predict impacts of design on adjacent buildings and communities

- Capability to optimize design for multiple hazards (e.g., seismic and impact)

- Determination of specific performance levels/targets

- Capability to include fire-spread within the civil work along with fire structural performance

- Ability to address salvage value, reconstruction, reuse of components, etc.-building reclaiming

- Generally accepted methods for obtaining liability relief for registered design professionals

- Big-to-small versus small-to-big design criteria

\section{Implementation}

- Uncertainty on the entities to drive PBD into codes

- Interim approaches utilized en-route to a fully realized PBD

- Pathway to overcome uncertainty as to whether PBD will be used only to justify build-outs that are currently not permitted under prescriptive codes, and whether they provide, at least, the same level of safety

- AHJs and code officials sufficiently trained to evaluate and accept PBD approaches

Wide dissemination and education actions in place to support the transformation required for PBD approach in practice, not only in guidelines 


\subsection{R\&D Agenda}

The strategy for generating the R\&D agenda to move toward the vision outlined in Table 4 was discussed by the workshop participants, and the main ideas are captured in the tables in Appendix C. Appendix D contains the complete list of R\&D needs from the workshop, broken down by material type and system. The needs that garnered the greatest support from the participants are listed in order of priority in Table 5 below (highest priority at top).

\section{TABle 5: Proposed PBD R\&D PRIORITIES}

\section{Test Methodology}

- Fire as a load case

- High-temperature strain and deflection measurement methods

- Conduct three-dimensional (3-D) full-scale tests on structural systems

- Conduct reliability-based analysis of fire testing, especially standard testing

- Perform compartment burn-out encapsulation studies (full/partial)

- Identify and describe applicable fire scenarios

\section{Societal, Regulatory, and Performance}

- Stakeholder education and code development

- External demand for property protection, business continuity, and sustainability versus life safety-societal awareness of the fire "problem"

- Define acceptable performance criteria for a variety of all structures

Modeling and Simulation

- Multi-scale simulation-including heat transfer modeling in specific scenarios

- Develop connection models, including fracture for simulation of 3-D building structures under fire scenarios

- Predict the reliability of fire compartmentation

- Develop structural models for fire resistance of all structure types

- Develop models to determine the residual capacity of structures after a fire to evaluate property loss

\section{Materials Properties}

- Calculate the residual strength of structural timber exposed to fire

- Determine material properties of all new grades of building structural materials Determine material properties for different kinds of concrete during and after the cooling phase

Workshop participants also identified strategies to support the research for an international R\&D agenda. They noted that the effort should include science and technology development areas, required sequences of development, priorities for research, and international cooperation within the research community. Table 6 lists those efforts. 


\section{TABLE 6: WORLDWIDE EFFORTS TO SUPPORT THE PBD RESEARCH AgENDA}

\section{Testing and Testbeds}

- Build physical infrastructure to support small and large research needs

- Large-scale testing of systems - and their associated return on investment (ROI) analysis

- Unify procedures, processes methods, and goals

- Standardize tests methods and equipment across materials and assemblies

- Develop standard testing protocols for structural assembly/system level in real fires situations

- Conduct medium-scale testing, including compartments specific to decay and fire resistance

- Perform reliability-based analysis of fire testing

- Find a legal way to aggregate and provide testing data

Societal and Regulatory

- Develop a technical basis for building codes and standards

- Characterize reliability and strategies to improve it

- Acquire access to existing models

- Develop a suite of building information modeling programs, starting with drawing and ending at structural properties (e.g., integration of all of these models)

- Identify areas of practical application where PBD research can/should focus - such as design engineering

- Increase student involvement in courses and research and promote a course on fire resistance of structures as part of structural engineering programs in universities

- Determine the influence of sprinklers compared to passive prevention, especially in reliability

- Relate fire design with other pre-fire events such as floods and earthquakes

- Collaborate with concrete, steel, and timber to find "low-hanging fruit" (R\&D)

- Review literature and consolidate resources from CIB, the American Society for Testing and Materials (ASTM), the International Organization for Standardization (ISO), the Institution of Fire Engineers (IFE), the National Fire Protection Association (NFPA), and the Society of Fire Protection Engineers (SFPE)

- Conduct forensic studies to repurpose the National Construction Safety Team to look at smaller fire events

- Disseminate simulations and SOA papers more widely

- Define PBD on an international level

- Promote the importance of property loss prevention to achieve resilience

\section{Modeling and Simulations}

- Develop multi-scale simulations tools

- Create a blue ribbon panel to assess existing models

- Investigate compartment burnout (e.g., encapsulation, self-extinguishing, and flame spread)

- Convene testing experts to solicit ideas, experiences, and thoughts

- Collect all background data for inputs into models

\section{Material Properties and System Performance}

- Define the properties wanted in the databases

Establish design objectives and define performance levels, including use-specific performance criteria 


\section{Implementation Plans}

\subsection{Overview}

Implementation plans were developed based on the priority topic areas (from Table 5) for fire-resistant structures listed in standards development for performance-based engineering relevant to structural fire resistance. Priority topics were then expanded into implementation plans; when appropriate, some of these priorities were combined in the creation of the implementation plans. Workshop participants led this effort by providing a general description of the plan, a timeline, and programmatic information, including specific major tasks, milestones, performance targets, opportunities for research review, technology transfer issues, and roles and responsibilities of stakeholders. The result was 16 project plans, identification of potential collaborators, and the associated programmatic dependencies. This activity resulted in five action plans for concrete, four for steel, and seven for timber. The remainder of Section 3 comprises "topics" that describe these implementation plans, including an approximate scope, timeline, and approach for each topic. The reader should note that implementation plans proposed in a specific group (i.e., concrete, steel, or timber) may not be limited to that specific material, but could have general applicability across many structural building systems.

\subsection{Concrete - Implementation Plans}

Topics I through 5 correspond to the program implementation action plans for PBD for fire generated by the concrete breakout group. The plans focus on experimental conditions, measurement techniques, education and outreach, codes and standards development, and societal awareness, addressing the following:

- Topic I: Fire as a Load

- Topic 2: High-Temperature Strain and Deflection Measurements

- Topic 3: Stakeholder Education and Code Development

- Topic 4: Multi-Scale Conditions and Testing of Concrete Elements and Samples

- Topic 5: Societal Awareness of Fire Issues 


\section{TOPIC I: FIRE AS A LOAD}

\section{Description}

Fire should be treated as a load case similar to seismic, wind, weight of contents, etc. during the whole structure design. There are designed fire curves, but further development is required to determine a worse case for concrete PBD buildings.
Timeline

- Near term (3 years): Review current standards and information (e.g., SFPE S.0I, NFPA 557, ASOE7, Appendix E, and case studies)

- Near term (3 years): Develop guideline documents (e.g., roadmap for design fires)

- Medium term (3-6 years): Conduct experimentation as needed (to be determined post-"fire load roadmap")

\begin{tabular}{|c|c|}
\hline \multicolumn{2}{|c|}{ PROGRAM APPROACH } \\
\hline \multirow{6}{*}{ Major Tasks } & Solve the traveling fire problem \\
\hline & Determine method to account for "design for burnout" \\
\hline & Perform literature review \\
\hline & $\begin{array}{l}\text { Develop framework to determine probability of failure for a given load case, including guidance for } \\
\text { load usage }\end{array}$ \\
\hline & Establish basis for considering wind effects on fire load in mid- to high-rise structures \\
\hline & Develop fire load converting method to make use of available fire resistance test data in the PBD \\
\hline \multirow[t]{3}{*}{ Major Milestones } & Develop a model of traveling fires from room to room \\
\hline & Advance load cases of burnout \\
\hline & Establish guidelines to determine burring area (not for just one floor) \\
\hline \multirow{3}{*}{$\begin{array}{l}\text { Performance } \\
\text { Targets }\end{array}$} & Validate model of traveling fires \\
\hline & Revise current fire-load documents and new concerns documents \\
\hline & Achieve a certain number of buildings designed with these guidelines \\
\hline \multirow[t]{3}{*}{ Reviews } & Conferences and working groups \\
\hline & Journal papers \\
\hline & Central collection point for data and reports \\
\hline \multicolumn{2}{|l|}{ OTHER ISSUES } \\
\hline \multirow{4}{*}{$\begin{array}{l}\text { Technology } \\
\text { Transfer }\end{array}$} & Published peer-reviewed documents \\
\hline & Champion published reports in relevant codes/standards committees \\
\hline & Webinars and conference presentations \\
\hline & Share a representative potential building design with new guidelines/established research \\
\hline \multirow{2}{*}{$\begin{array}{l}\text { Roles and } \\
\text { Responsibilities of } \\
\text { Stakeholders }\end{array}$} & $\begin{array}{l}\text { Research laboratories (Edinburgh, National Research Council of Canada [NRCC], NIST, CIB, } \\
\text { Underwriters Laboratories [UL], and universities }\end{array}$ \\
\hline & Organizations attending this workshop and submitting the white paper \\
\hline \multirow{2}{*}{$\begin{array}{l}\text { Potential } \\
\text { Collaborators }\end{array}$} & American Society of Civil Engineers (ASCE), SFPE \\
\hline & Stakeholder organizations previously listed \\
\hline \multirow[t]{2}{*}{ Dependency } & $\begin{array}{l}\text { Incorporation of fire into the structural design of buildings (e.g., design of structures with added } \\
\text { fire protection features) }\end{array}$ \\
\hline & Fire exposure leads to structural response \\
\hline
\end{tabular}




\section{TOPIC 2: High-TeMPERATURE STRAIN AND DEFLECTION MEASUREMENTS}

\section{Description}

Improved measurement techniques and equipment are needed for strain, displacement, moisture, and crack development measurements.
Timeline

- Near term (approximately 3 years): Develop prototype

- Long term (greater than 10 years): Build off-theshelf sensors

\begin{tabular}{|c|c|}
\hline \multicolumn{2}{|c|}{ PROGRAM APPROACH } \\
\hline \multirow[t]{3}{*}{ Major Tasks } & Define the needs and parameters \\
\hline & Design prototype sensors \\
\hline & Transfer technology \\
\hline Major Milestones & $\begin{array}{l}\text { Obtain list of candidate technologies (e.g., optical strain, classic resistance strain gauges, and linear } \\
\text { variable differential transformers) }\end{array}$ \\
\hline \multirow{2}{*}{$\begin{array}{l}\text { Performance } \\
\text { Targets }\end{array}$} & Attain furnace temperature $\geq 1200^{\circ} \mathrm{C}$ in measurement equipment \\
\hline & Develop materials able to withstand temperature $\geq 500{ }^{\circ} \mathrm{C}$ within measurement environment \\
\hline \multirow[t]{2}{*}{ Reviews } & FORUM \\
\hline & NIST \\
\hline \multicolumn{2}{|l|}{ OTHER ISSUES } \\
\hline $\begin{array}{l}\text { Roles and } \\
\text { Responsibilities of } \\
\text { Stakeholders }\end{array}$ & Research community (e.g., NIST, optical fibers, University of London, and University of Ottawa) \\
\hline $\begin{array}{l}\text { Potential } \\
\text { Collaborators }\end{array}$ & Sensor manufacturers \\
\hline Dependency & Researcher feedback is crucial to success of these developments \\
\hline
\end{tabular}




\section{TOPIC 3: STAKEHOLDER EDUCATION AND CODE DeVELOPMENT}

\author{
Description
}

Development and implementation of PBD may be daunting because it is not universally defined and understood (objective-based design), and appropriate usage has not been defined.

\author{
Timeline
}

- Ongoing: More use in construction planning and execution

\begin{tabular}{|c|c|}
\hline \multirow[t]{6}{*}{ Major Tasks } & $\begin{array}{l}\text { Introduce fire discussion into more structural engineering and architecture programs (e.g., } \\
\text { Accreditation Board for Engineering and Technology [ABET] and National Council of Architectural } \\
\text { Registration Boards [NCARB]) }\end{array}$ \\
\hline & Develop risk management tools and techniques \\
\hline & Ensure that design standards contain clearly defined goals (high level) and objectives (specific) \\
\hline & Define objectives and allow PBD option \\
\hline & Establish third-party peer review (at owner's expense) to assist $\mathrm{AHJ}$ \\
\hline & $\begin{array}{l}\text { Develop check for safety values (e.g., check for missing input even if the model returns an } \\
\text { acceptable result) }\end{array}$ \\
\hline \multirow[t]{2}{*}{ Major Milestones } & Accreditation for PBD (e.g., credentials for fire protection engineers and structural engineers) \\
\hline & Certificate program for AHJs that incorporates specific information on PBD \\
\hline $\begin{array}{l}\text { Performance } \\
\text { Targets }\end{array}$ & $\begin{array}{l}\text { Medium term (within } 5 \text { years): explicit mention of PBD option in private-sector standards } \\
\text { development organizations (SDOs) }\end{array}$ \\
\hline Reviews & CIB, ISO, FORUM, Reactivate the "Concrete Fire Forum" \\
\hline \multicolumn{2}{|l|}{ OTHER ISSUES } \\
\hline $\begin{array}{l}\text { Technology } \\
\text { Transfer }\end{array}$ & $\begin{array}{l}\text { Develop a curriculum to be used in academic programs that is interchangeable between } \\
\text { college/university environments }\end{array}$ \\
\hline \multirow{4}{*}{$\begin{array}{l}\text { Roles and } \\
\text { Responsibilities of } \\
\text { Stakeholders }\end{array}$} & AHJs, building and construction code developers, fire protection engineers, structural engineers \\
\hline & ABET, NCARB, National Council of Examiners for Engineering and Surveying \\
\hline & Special inspection criteria (e.g., International Building Code, Chapter 18) \\
\hline & NIST to make available Fire Resistance Structures Workshop ideas to PhD students \\
\hline $\begin{array}{l}\text { Potential } \\
\text { Collaborators }\end{array}$ & None identified \\
\hline \multirow[t]{2}{*}{ Dependency } & Determine funding source \\
\hline & Determine the demand for PBD as \\
\hline
\end{tabular}




\section{TOPIC 4: MULTI-SCALE CONDITIONS AND TESTING OF CONCRETE ElementS AND SAMPLES}

\section{Description}

Multi-scale conditions and testing of concrete elements and samples need improvement. The design and development will include several issues, including developing system-level (subsystem) tests to capture the mechanics for modeling, multi-scale testing using alternative methods, determining the linkage between scale and test methods, establishing in situ and laboratory conditions that must be controlled (if achievable), understanding parameters at the micro level, and determining hightemperature strain property effects.

\section{Timeline}

- Start immediately and continue long term: Significant data to be collected and many methods to be developed ( 10 years and longer)

\begin{tabular}{|c|c|}
\hline \multicolumn{2}{|c|}{ PROGRAM APPROACH } \\
\hline \multirow[t]{4}{*}{ Major Tasks } & Develop full-scale (multi-scale) conditioning \\
\hline & Design multi-scale testing and hybrid testing \\
\hline & Perform in situ monitoring \\
\hline & Correlate resulting multi-scale and in situ data \\
\hline \multirow[t]{5}{*}{ Major Milestones } & Identify key material-scale behavior for structural response \\
\hline & Develop established testing guidelines for multi-scale testing \\
\hline & Identify methods to control and limit parameters \\
\hline & Correlate laboratory conditions with in situ field testing and monitoring \\
\hline & Creation of verifiable data sets appropriate for validation of numerical models \\
\hline \multirow[t]{2}{*}{$\begin{array}{l}\text { Performance } \\
\text { Targets }\end{array}$} & $\begin{array}{l}\text { Perform inexpensive small-scale tests to gather model input data that are correlated to full-scale } \\
\text { assemblies }\end{array}$ \\
\hline & Perform material tests to define thresholds for evaluating property damage levels due to fire \\
\hline \multirow{2}{*}{ Reviews } & Conduct literature and research review \\
\hline & Encourage use and reporting of consistent and constant parameters \\
\hline \multicolumn{2}{|l|}{ OTHER ISSUES } \\
\hline \multirow{3}{*}{$\begin{array}{l}\text { Technology } \\
\text { Transfer }\end{array}$} & Correlation of small-scale tests representing actual member performance \\
\hline & $\begin{array}{l}\text { Establishment of benchmark tests (working group) that report consistency of specific properties } \\
\text { and measurements }\end{array}$ \\
\hline & Open access and/or sharing experimental data \\
\hline \multirow{3}{*}{$\begin{array}{l}\text { Roles and } \\
\text { Responsibilities of } \\
\text { Stakeholders }\end{array}$} & $\begin{array}{l}\text { Concrete industry guidance on what are the best practices on testing procedures for all scales and } \\
\text { the related data sets }\end{array}$ \\
\hline & Modelers and researchers to identify systems and subsystems \\
\hline & Blind round robin among participating organizations to validate experimental data \\
\hline \multirow{2}{*}{$\begin{array}{l}\text { Potential } \\
\text { Collaborators }\end{array}$} & Researchers from the concrete and modeling industries \\
\hline & American Concrete Institute/Pankow or other industry foundations \\
\hline \multirow[t]{2}{*}{ Dependency } & Selection of the most appropriate parameters to consider to limit the amount of experimentation \\
\hline & Literature reviews, research reviews, and collaboration with researchers \\
\hline
\end{tabular}




\section{TOPIC 5: SOCIETAL AWARENESS OF FIRE ISSUES}

\section{Description}

Weighing the external demand for property protection versus life safety in a fire situation needs further examination. Several issues in the built environment will drive the discussion: climate change (e.g., more wildland-urban interface fires and weather extremes), sustainability (e.g., good corporate citizenship), and resilience (e.g., prepare, mitigate, survive, and recover).
Timeline

- Medium term (within 10 years): Begin project and achieve one or more milestones

\begin{tabular}{|c|c|}
\hline \multicolumn{2}{|l|}{ PROGRAM APPROACH } \\
\hline \multirow[t]{4}{*}{ Major Tasks } & Develop more risk-based business/loss models within the insurance industry \\
\hline & $\begin{array}{l}\text { Develop and define new performance criteria related to damage for property protection } \\
\text { rather than stability for life safety }\end{array}$ \\
\hline & Inventory firefighter safety issues \\
\hline & $\begin{array}{l}\text { Convince the business community and private sector that mission continuity is crucial to } \\
\text { success }\end{array}$ \\
\hline \multirow[t]{3}{*}{ Major Milestones } & $\begin{array}{l}\text { Recognition by the insurance industry on goals, objectives, property protection, and } \\
\text { mission continuity }\end{array}$ \\
\hline & $\begin{array}{l}\text { Determine the number of buildings and scope of PBD usage (e.g., whole buildings and } \\
\text { specific systems) }\end{array}$ \\
\hline & $\begin{array}{l}\text { Conduct a forensic study of fires in concrete structures (should be extended to other types } \\
\text { of structural materials) }\end{array}$ \\
\hline Performance Targets & $\begin{array}{l}\text { Verify hourly rating of concrete assembly for necessary evacuation time or for a specified } \\
\text { burn time with no adverse structural damage (should be extended to other types of structural } \\
\text { materials) }\end{array}$ \\
\hline \multirow[t]{2}{*}{ Reviews } & Technical articles \\
\hline & $\begin{array}{l}\text { More interaction between laboratories: the British Standard Institute, CSTB, FM Global } \\
\text { (FM), NIST, UL, and the Architecture and Building Research Institute (See the white paper } \\
\text { on concrete structures in Appendix F, Section I) }\end{array}$ \\
\hline \multicolumn{2}{|l|}{ OTHER ISSUES } \\
\hline \multirow[t]{3}{*}{ Technology Transfer } & $\begin{array}{l}\text { Academics-dissemination of knowledge in university classes or collaboration between } \\
\text { professors }\end{array}$ \\
\hline & Code and standards developers and processes \\
\hline & $\begin{array}{l}\text { Management and dissemination (either intentional/ unintentional) of proprietary } \\
\text { information }\end{array}$ \\
\hline \multirow{2}{*}{$\begin{array}{l}\text { Roles and Responsibilities of } \\
\text { Stakeholders }\end{array}$} & Open information exchange between all stakeholders \\
\hline & Carleton University and NRCC \\
\hline \multirow[t]{3}{*}{ Potential Collaborators } & Government \\
\hline & Insurance companies \\
\hline & SDOs \\
\hline \multirow[t]{3}{*}{ Dependency } & Determine funding source \\
\hline & Determine acceptable level of safety \\
\hline & $\begin{array}{l}\text { Develop method to capture forensic data on actual fires incorporating actual performance } \\
\text { and experience }\end{array}$ \\
\hline
\end{tabular}


International R\&D Roadmap for Fire Resistance of Structures: Summary of NIST/CIB Workshop

\subsection{Steel - Implementation Plans}

Topics 6 through 9 correspond to the program implementation plans for PBD for fire generated by the steel breakout group. The plans focus on experimental conditions, measurement techniques, material properties, and modeling and simulation, addressing the following:

- Topic 6: 3-D Full-Scale Tests on Structural Systems

- Topic 7: Material Properties for Steel Construction

- Topic 8: Applicable Fire Scenarios

- Topic 9: Simulation with Connection Models 


\section{TOPIC 6: 3-D FULL-SCALE TESTS ON STRUCTURAL SYSTEM}

\section{Description}

Most available test data are from standard fire exposure and individual component behavior. The establishment of structural system behavior in real fires will provide comprehensive information to develop PBD.
Timeline

- Long term (greater than 10 years)

\begin{tabular}{|c|c|}
\hline \multicolumn{2}{|c|}{ PROGRAM APPROACH } \\
\hline \multirow{5}{*}{ Major Tasks } & Establish test fire protocol to achieve structural limit states \\
\hline & Develop/implement technologies \\
\hline & Design parametric test series and identify parameters to be varied \\
\hline & Carry out tests \\
\hline & Validate test results, measurement technology, and hybrid testing method \\
\hline \multirow[t]{3}{*}{ Major Milestones } & Complete full-scale test series \\
\hline & Analyze data with aim to validate predictive models \\
\hline & Evaluate measurement technologies \\
\hline \multirow{3}{*}{$\begin{array}{l}\text { Performance } \\
\text { Targets }\end{array}$} & Tools/methods available for design profession \\
\hline & Comprehensive data made available (quality assured) \\
\hline & Guidance prepared for adoption by profession \\
\hline Reviews & Centralized database of large-scale test results \\
\hline \multicolumn{2}{|l|}{ OTHER ISSUES } \\
\hline \multirow{4}{*}{$\begin{array}{l}\text { Technology } \\
\text { Transfer }\end{array}$} & Conferences \\
\hline & Reports \\
\hline & Journal papers \\
\hline & Structures in Fire (SiF) movement \\
\hline $\begin{array}{l}\text { Roles and } \\
\text { Responsibilities of } \\
\text { Stakeholders }\end{array}$ & Refer to white papers \\
\hline $\begin{array}{l}\text { Potential } \\
\text { Collaborators }\end{array}$ & $\begin{array}{l}\text { International test houses with experience in large-scale structural testing, NIST, Efectis (France), } \\
\text { and CSTB }\end{array}$ \\
\hline \multirow[t]{2}{*}{ Dependency } & Adoption of PBD (e.g., fire included as design condition) \\
\hline & $\begin{array}{l}\text { Dependent upon material characterization, successful implementation of measurement } \\
\text { technologies, and small-scale component results }\end{array}$ \\
\hline
\end{tabular}




\section{Topic 7: MAterial Properties for Steel Construction}

\section{Description}

To predict the behavior of steel structures under fire conditions, accurate properties of all materials involved must be determined.
Timeline

- Near term (less than 3 years, assuming appropriate funding)

\begin{tabular}{|c|c|}
\hline \multicolumn{2}{|c|}{ PROGRAM APPROACH } \\
\hline \multirow[t]{3}{*}{ Major Tasks } & Develop database structure \\
\hline & Obtain complete properties through the heating and cooling cycle, including rapid quenching \\
\hline & $\begin{array}{l}\text { Complete known material database of relevant properties including creep, toughness, and interface } \\
\text { properties }\end{array}$ \\
\hline \multirow[t]{3}{*}{ Major Milestones } & Develop and populate database with existing data (Year I) \\
\hline & $\begin{array}{l}\text { Develop new test methods and obtain test data for heat-treated materials (e.g., bolts and welds) } \\
\text { (Year 2) }\end{array}$ \\
\hline & Obtain interface properties through new tests (Year 3) \\
\hline \multirow[t]{3}{*}{$\begin{array}{l}\text { Performance } \\
\text { Targets }\end{array}$} & $\begin{array}{l}\text { Have material properties sufficiently defined to produce very accurate models (from academic } \\
\text { stakeholders) }\end{array}$ \\
\hline & Advance the science of material testing standards (academic stakeholders) \\
\hline & Secure all propei \\
\hline Reviews & Crea \\
\hline \multicolumn{2}{|l|}{ OTHER ISSUES } \\
\hline \multirow{4}{*}{$\begin{array}{l}\text { Technology } \\
\text { Transfer }\end{array}$} & Websites \\
\hline & Industry publications (e.g., journals and technical reports) \\
\hline & Participation in standards organizations such as ISO and ASTM \\
\hline & $\begin{array}{l}\text { Participation in international meetings (e.g., ASCE, ASCE Engineering Mechanics Institute, ASCE } \\
\text { Structural Engineering Institute, and SiF movement) }\end{array}$ \\
\hline \multirow{2}{*}{$\begin{array}{l}\text { Roles and } \\
\text { Responsibilities of } \\
\text { Stakeholders }\end{array}$} & Testing distributed across academic entities, industrial entities, and national laboratories \\
\hline & $\begin{array}{l}\text { Possible website hosts: Federal Institute for Materials Research and Testing, Germany (BAM) } \\
\text { CSTB; NIST; and Tongji University }\end{array}$ \\
\hline \multirow{3}{*}{$\begin{array}{l}\text { Potential } \\
\text { Collaborators } \\
\text { Dependency }\end{array}$} & $\begin{array}{l}\text { BAM, Centre Technique Industriel de la Construction Métallique (CTICM) (France), NIST, Tongj } \\
\text { University, CSTB }\end{array}$ \\
\hline & Development of simplified models \\
\hline & Full-scale test models \\
\hline \multicolumn{2}{|c|}{ IDENTIFICATION OF MATERIALS AND TEST PROTOCOLS AND PROPERTIES } \\
\hline \multicolumn{2}{|c|}{$\begin{array}{l}\text { - Shear studs, welds, bolts, and different grades of steel } \\
\text { - Evaluate at range of temperatures up to } 1200^{\circ} \mathrm{C} \text { and subsequent cooling } \\
\text { - Thermal conductivity, specific heat, yield strength, creep coefficient of thermal expansion, high strain rate, and ductile } \\
\text { fracture } \\
\text { - Concrete/rebars }\end{array}$} \\
\hline \multicolumn{2}{|c|}{$\begin{array}{l}\text { - Thermal conductivity, specific heat, building properties at elevated temperatures, cohesion, adhesion, and shear for fire- } \\
\text { resistive coatings of various concentrations } \\
\text { - Internal certifications including critical aging/environmental resistance } \\
\text { - Gypsum wallboard }\end{array}$} \\
\hline
\end{tabular}




\section{TOPIC 8: APPLICABLE FIRE SCENARIOS}

\section{Description}

A framework is needed for developing specific fire scenarios depending on hazard, importance of structure, and characteristics of structural elements (e.g., compartment geometry, ventilation, and complexity of structural system). This framework could be a primary factor in the PBD of structural fire resistance.
Timeline

- Near term: Conduct research (less than 3 years)

- Medium term: Develop guidance and probabilistic basis for selecting fire exposure (Within 6 years)

\begin{tabular}{|c|c|}
\hline \multicolumn{2}{|c|}{ PROGRAM APPROACH } \\
\hline \multirow[t]{5}{*}{ Major Tasks } & Gather statistical data on fire hazards \\
\hline & Identify and evaluate existing fire models and identify gaps \\
\hline & Identify minimum design fire scenarios for life safety and other design objectives \\
\hline & Identify key input parameters depending on assessment method \\
\hline & Develop guideline or standard \\
\hline \multirow[t]{6}{*}{ Major Milestones } & Gather statistical data on fire hazards (Years I-2) \\
\hline & Identify and evaluate existing fire models and identify gaps (Year I) \\
\hline & Identify key input parameters depending on assessment method (Year I) \\
\hline & $\begin{array}{l}\text { Identify minimum design fire scenarios for life safety and other design objectives } \\
\text { (Years 2-3) }\end{array}$ \\
\hline & Develop guideline or standard (Years 3-6) \\
\hline & Issue draft for public review (Years 3-6) \\
\hline $\begin{array}{l}\text { Performance } \\
\text { Targets }\end{array}$ & Develop guideline or standard \\
\hline Reviews & IFE, ISO, NFPA, SFPE, etc. \\
\hline \multicolumn{2}{|l|}{ OTHER ISSUES } \\
\hline \multirow{2}{*}{$\begin{array}{l}\text { Technology } \\
\text { Transfer }\end{array}$} & The standard (a means for technology transfer) \\
\hline & Case studies \\
\hline \multirow{3}{*}{$\begin{array}{l}\text { Roles and } \\
\text { Responsibilities of } \\
\text { Stakeholders }\end{array}$} & Professional committees \\
\hline & Fire departments \\
\hline & International design guidelines/standards \\
\hline $\begin{array}{l}\text { Potential } \\
\text { Collaborators }\end{array}$ & Universities \\
\hline Dependency & Incomplete education might prevent widespread use \\
\hline
\end{tabular}




\section{TOPIC 9: SIMULATION WITH CONNECTION MODELS}

\section{Description}

Connection models that include fracture are useful for simulation of 3-D building structures under fire scenarios. After columns, the connections are the most vulnerable points in a structure, and avoidance of progressive collapse is the goal. Computer modeling is not advanced enough to use detailed 3-D modeling for design. The key will be component-based models with fracture that are configurable for different connections.

\section{Timeline}

- Medium term (6 years or more and possibly expanding to 10 years, depending on funding)

\begin{tabular}{|c|c|}
\hline \multicolumn{2}{|c|}{ PROGRAM APPROACH } \\
\hline \multirow[t]{6}{*}{ Major Tasks } & Characterize component behavior for different components and connections \\
\hline & Characterize coupling and interaction between different components \\
\hline & Characterize group effects and interactions \\
\hline & Include size/scale effect for components \\
\hline & Employ experimental verification for individual components and group effects \\
\hline & $\begin{array}{l}\text { Conduct large-scale testing for verification of macro models and to evaluate the effects of thermal } \\
\text { expansion as well as the redundancy of the structural system }\end{array}$ \\
\hline \multirow[t]{5}{*}{ Major Milestones } & Complete component models with coupling and interaction (Years I-3) \\
\hline & Complete component models with group effects and span effects (Years 3-5) \\
\hline & $\begin{array}{l}\text { Demonstrate the ability to model progressive collapse using connection models } \\
\text { (Years I-3) }\end{array}$ \\
\hline & Develop tool for generating the macro model for designers to obtain and input model (Years I-3) \\
\hline & $\begin{array}{l}\text { Conduct experimental verification at the individual component level (Years I-3) and at the large } \\
\text { scale (Years 3-5) }\end{array}$ \\
\hline \multirow{3}{*}{$\begin{array}{l}\text { Performance } \\
\text { Targets }\end{array}$} & Existence of component-based and macro models for fracture \\
\hline & Experimentally verified models \\
\hline & Tools for engineers to obtain macro models by inputting connection details \\
\hline \multirow[t]{3}{*}{ Reviews } & Additional workshops such as the Fire Resistance Structures Workshop \\
\hline & Travel funding to have meetings and workshops \\
\hline & Steel in Fire Forum meetings \\
\hline \multicolumn{2}{|l|}{ OTHER ISSUES } \\
\hline \multirow{3}{*}{$\begin{array}{l}\text { Technology } \\
\text { Transfer }\end{array}$} & Tools for engineers to obtain macro models by inputting connection details \\
\hline & $\begin{array}{l}\text { Standards that allow the use of connections models with fractures in advanced analysis for } \\
\text { progressive collapse }\end{array}$ \\
\hline & Publishing in industry magazines and relevant websites \\
\hline $\begin{array}{l}\text { Roles and } \\
\text { Responsibilities of } \\
\text { Stakeholders }\end{array}$ & NIST-National Fire Research Laboratory \\
\hline $\begin{array}{l}\text { Potential } \\
\text { Collaborators }\end{array}$ & CTICM, Efectis (France) \\
\hline Dependency & $\begin{array}{l}\text { Progressive collapse cannot be simulated at the 3-D level without being verified/benchmarked for } \\
\text { fracture }\end{array}$ \\
\hline
\end{tabular}




\subsection{Timber - Implementation Plans}

Topics 10 through 16 correspond to the program action implementation plans for PBD for fire generated by the timber breakout group. The plans focus on performance criteria, model development, material properties, reliability analysis, and design fires, addressing the following:

- Topic 10: Predict the Reliability of Fire Compartmentation

- Topic II: Specific Acceptable Performance Criteria

- Topic 12: Development of Structural Models for Timber Fire Resistance

- Topic 13: Calculating the Strength of Structural Timber Exposed to Fire

- Topic 14: Compartment Burnout Encapsulation

- Topic 15: Reliability-Based Analysis of Fire Testing

- Topic 16: Design Fires Based on Use and Occupancy 


\section{Topic 10: Predict the Reliability Of Fire COMPARTMENTATION}

\section{Description}

With greater understanding of fire compartmentation, PBD will be better able to prevent fire spread through voids and cavities, evaluate fire safety of insulating materials, evaluate fire resistance of service penetrations, evaluate fire performance of lining materials, and provide safe egress and firefighter access.
Timeline

- Medium term (within 6 years)

\begin{tabular}{|c|c|}
\hline PROGRAM APPRO & \\
\hline Major Tasks & Perform testing \\
\hline & Design models \\
\hline & Design guides \\
\hline Major Milestones & Perform medium-scale furnace tests \\
\hline & Perform large-scale verification of tests \\
\hline & Model material properties \\
\hline & Publish guidelines \\
\hline Performance & Adoption by building codes \\
\hline Targets & Reduced insurance premiums \\
\hline Reviews & None identified \\
\hline OTHER ISSUES & \\
\hline Technology & Conferences \\
\hline Transfer & Journals \\
\hline & Websites \\
\hline & Workshops \\
\hline & Industry manuals \\
\hline $\begin{array}{l}\text { Roles and } \\
\text { Responsibilities of } \\
\text { Stakeholders }\end{array}$ & None identified \\
\hline $\begin{array}{l}\text { Potential } \\
\text { Collaborators }\end{array}$ & Fire services and fire laboratories \\
\hline Dependency & None identified \\
\hline
\end{tabular}




\section{Topic I I: Specific Acceptable Performance CRITeRia}

\section{Description}

The performance relationship to occupancy (e.g., life safety and fire propagation) needs to be better defined for a variety of timber structures. The goal is to reduce life and property loss due to fire exposure.
Timeline

- Near term (within 3 years)

\begin{tabular}{|c|c|}
\hline \multicolumn{2}{|c|}{ PROGRAM APPROACH } \\
\hline \multirow[t]{3}{*}{ Major Tasks } & Determine the scope and nature of the types of occupancies/structures to be analyzed \\
\hline & Inform the development of the performance standards \\
\hline & Conduct case studies of fire experience in the identified occupancies and structures \\
\hline \multirow[t]{3}{*}{ Major Milestones } & Complete determining scope and nature of occupancies and structures \\
\hline & $\begin{array}{l}\text { Obtain acceptance of the performance-based standards by stakeholders in the industry (code } \\
\text { making and builders) }\end{array}$ \\
\hline & Define/identify fire experience in related structures and occupancies \\
\hline \multirow{2}{*}{$\begin{array}{l}\text { Performance } \\
\text { Targets }\end{array}$} & Industry acceptance \\
\hline & $\begin{array}{l}\text { Implementation and inclusion of the performance standards/criteria by code and standards } \\
\text { organizations }\end{array}$ \\
\hline \multirow[t]{3}{*}{ Reviews } & ISO \\
\hline & NFPA \\
\hline & ICC \\
\hline \multicolumn{2}{|l|}{ OTHER ISSUES } \\
\hline \multirow{3}{*}{$\begin{array}{l}\text { Technology } \\
\text { Transfer }\end{array}$} & Technical industry publications \\
\hline & Web-based reporting \\
\hline & Interaction with and participation in the code-making process \\
\hline $\begin{array}{l}\text { Roles and } \\
\text { Responsibilities of } \\
\text { Stakeholders }\end{array}$ & Building Research Institute, Japan (BRI); IBITS; NIST; and SDOs \\
\hline \multirow{4}{*}{$\begin{array}{l}\text { Potential } \\
\text { Collaborators }\end{array}$} & Industry \\
\hline & Vendors \\
\hline & Builders \\
\hline & Insurance companies and testing agencies \\
\hline \multirow[t]{2}{*}{ Dependency } & Industry acceptance \\
\hline & Validity of rationale and development of this work (performance criteria) \\
\hline
\end{tabular}




\section{TOPIC I 2: DEVELOPMENT OF STRUCTURAL MODELS FOR TIMBER FIRE RESISTANCE}

\section{Description}

Stakeholders could identify existing models and consider the need for new models and software necessary to understand and analyze timber performance in fire involvement or exposure.

\section{Timeline}

- Short term: Accessing existing models (within 3 years)

- Medium term: Extension and development of models (within 6 years)

\begin{tabular}{|c|c|}
\hline \multicolumn{2}{|c|}{ PROGRAM APPROACH } \\
\hline \multirow[t]{5}{*}{ Major Tasks } & Develop a library of experimental models \\
\hline & Develop and validate models of components and connections of timber construction \\
\hline & Model and understand all floors, walls, superstructures, and beams \\
\hline & Model the entire system \\
\hline & Validate the system against experimental and legacy experience \\
\hline \multirow{4}{*}{ Major Milestones } & Complete assembly of experimental library and existing software (Year I) \\
\hline & Develop new testing of models (Years I-3) \\
\hline & Complete system models (Years 3-5) \\
\hline & $\begin{array}{l}\text { Complete validation of system modeling against experimental and actual experience } \\
\text { (beyond } 5 \text { years) }\end{array}$ \\
\hline \multirow[t]{3}{*}{$\begin{array}{l}\text { Performance } \\
\text { Targets }\end{array}$} & $\begin{array}{l}\text { Complete robust, reliable, and validated models capturing the behavior of timber structures in fire } \\
\text { exposure }\end{array}$ \\
\hline & Establish the variability of timber as a natural resource and an engineered material \\
\hline & Create models that are consistent across repeatable testing \\
\hline \multirow[t]{3}{*}{ Reviews } & Email/video conferencing \\
\hline & Workshops \\
\hline & Technical publications \\
\hline \multicolumn{2}{|l|}{ OTHER ISSUES } \\
\hline \multirow{3}{*}{$\begin{array}{l}\text { Technology } \\
\text { Transfer }\end{array}$} & Send to code bodies for consideration in influencing code development and editing \\
\hline & Trade magazine publication \\
\hline & Web publication \\
\hline \multirow{2}{*}{$\begin{array}{l}\text { Roles and } \\
\text { Responsibilities of } \\
\text { Stakeholders }\end{array}$} & Institute for business and home safety \\
\hline & BRI and NIST \\
\hline \multirow{2}{*}{$\begin{array}{l}\text { Potential } \\
\text { Collaborators }\end{array}$} & Private builders' associations \\
\hline & Timber industry and government \\
\hline \multirow[t]{3}{*}{ Dependency } & Product demand \\
\hline & Health, safety, and welfare \\
\hline & Acceptance of the products with regard to safe, economical, high-performance building material \\
\hline
\end{tabular}




\section{TOPIC I 3: CALCULATING THE STRENGTH OF STRUCTURAL TIMBER EXPOSED TO FIRE}

\section{Description}

Determining the strength of structural timber is an essential need for PBD. This effort should include the examination of strength properties, clean rates, and protection methods for standard fires and realistic fires involving a wide range of wood products.
Timeline

- Medium term (5-6 years): Design guide

- Long term: Implementation (6 years and longer)

\begin{tabular}{|c|c|}
\hline \multicolumn{2}{|c|}{ PROGRAM APPROACH } \\
\hline \multirow[t]{4}{*}{ Major Tasks } & Test a wide range of wood products \\
\hline & Model heat transfer and charring \\
\hline & Develop design guides \\
\hline & Implement and gain acceptance of design guides \\
\hline \multirow[t]{5}{*}{ Major Milestones } & Finish small-scale testing of a wide range of products (Year I) \\
\hline & Develop heat transfer and charring model (Years I-2) \\
\hline & Perform medium-scale testing and modeling of protected wood (Years I-3) \\
\hline & Perform large-scale verification test (Years I-4) \\
\hline & Publish design guide (Years I-5) \\
\hline \multirow{3}{*}{$\begin{array}{l}\text { Performance } \\
\text { Targets }\end{array}$} & Acceptance and use of design guide by professionals \\
\hline & Large increase in construction of timber buildings \\
\hline & Adoption by building codes \\
\hline Reviews & Establish international working group with regular meetings \\
\hline \multicolumn{2}{|l|}{ OTHER ISSUES } \\
\hline \multirow{5}{*}{$\begin{array}{l}\text { Technology } \\
\text { Transfer }\end{array}$} & Present findings at national and international conferences \\
\hline & Publish in journals \\
\hline & Deliver short courses and workshops \\
\hline & Develop a website \\
\hline & Publish industry manuals \\
\hline \multirow{2}{*}{$\begin{array}{l}\text { Roles and } \\
\text { Responsibilities of } \\
\text { Stakeholders }\end{array}$} & Multiple small-scale facilities available \\
\hline & Large-scale: BRI, NIST, and NRCC \\
\hline $\begin{array}{l}\text { Potential } \\
\text { Collaborators }\end{array}$ & $\begin{array}{l}\text { Timber industry, adhesive industry, gypsum industry, engineered wood products, design } \\
\text { community, government (e.g., U.S. Department of Agriculture) }\end{array}$ \\
\hline Dependency & None identified \\
\hline
\end{tabular}




\section{TOPIC I 4: COMPARTMENT BURNOUT ENCAPSULATION}

\section{Description}

Tall buildings need to be capable of surviving burnout with minimal structural involvement and without intervention. The goal is to restrict or prevent spread to other compartments, both horizontally and vertically.
Timeline

- Medium term (3-6 years)

\begin{tabular}{|c|c|}
\hline \multicolumn{2}{|c|}{ PROGRAM APPROACH } \\
\hline \multirow[t]{5}{*}{ Major Tasks } & $\begin{array}{l}\text { Perform small-scale tests to determine the minimum heat flux needed to sustain combustion as a } \\
\text { function of char depth }\end{array}$ \\
\hline & $\begin{array}{l}\text { Perform thermal barrier-type testing of encapsulation materials under various temperature-time } \\
(\mathrm{T}-\mathrm{T}) \text { curves }\end{array}$ \\
\hline & Model the heat transfer in the wood to characterize changes/reduction in a cross section \\
\hline & $\begin{array}{l}\text { Model the room to determine conditions under which the wood structure will continue to sustain } \\
\text { combustion after contents are consumed }\end{array}$ \\
\hline & Model the fire resistance and fire safety of structures under construction \\
\hline \multirow[t]{5}{*}{ Major Milestones } & Quantify heat flux using small-scale tests (Year I) \\
\hline & Define the range of T-T exposures to be used (Year I) \\
\hline & $\begin{array}{l}\text { Perform fire-resistance tests of walls and floors with different T-T curves using various } \\
\text { encapsulation strategies (Years I-3) }\end{array}$ \\
\hline & Create and validate a heat transfer model for wood (Years 2-4) \\
\hline & Validate the model with full-scale burns (Years 3-6) \\
\hline $\begin{array}{l}\text { Performance } \\
\text { Targets }\end{array}$ & See “Major Milestones” \\
\hline \multirow[t]{2}{*}{ Reviews } & Quarterly web conferences \\
\hline & Face-to-face meetings/conferences as needed \\
\hline \multicolumn{2}{|l|}{ OTHER ISSUES } \\
\hline \multirow{2}{*}{$\begin{array}{l}\text { Technology } \\
\text { Transfer }\end{array}$} & Conference presentations and papers \\
\hline & NFPA standards \\
\hline \multirow{2}{*}{$\begin{array}{l}\text { Roles and } \\
\text { Responsibilities of } \\
\text { Stakeholders }\end{array}$} & $\begin{array}{l}\text { Forest Products Laboratory (FPL) and Technical Research Institute of Sweden (SP)-small } \\
\text { scale/medium scale }\end{array}$ \\
\hline & $\begin{array}{l}\text { Carlton/NRCC, Efectis, Exova, ITS, NGC, NIST, SP, Southwest Research Institute, and UL-fire- } \\
\text { resistance room burns }\end{array}$ \\
\hline \multirow{2}{*}{$\begin{array}{l}\text { Potential } \\
\text { Collaborators }\end{array}$} & National Research Council of Canada \\
\hline & FPL/NIST for model development \\
\hline Dependency & Design fire for input and for thermal barrier tests \\
\hline
\end{tabular}




\section{TOPIC I5: RELIABILITY-BASED ANALYSIS OF FIRE TESTING}

\section{Description}

Data generated worldwide, especially client testing data, have great potential to assist in PBD development. Complementary instrumentation, variability analysis methodology, up-to-date data for analysis, and reliability data are needed for PBD.

\section{Timeline}

- Near term: Initiate project and establish network and methods (within 3 years)

- Ongoing: Continue collection and analysis

\begin{tabular}{|c|c|}
\hline \multicolumn{2}{|c|}{ PROGRAM APPROACH } \\
\hline \multirow{4}{*}{ Major Tasks } & Develop a method to collect data \\
\hline & Set up an international structure to coordinate participants \\
\hline & Define additional instrumentation \\
\hline & Develop a method to analyze and incorporate in PBD \\
\hline \multirow{3}{*}{ Major Milestones } & Reach a defined number of participating laboratories \\
\hline & Identify organizations to coordinate participation \\
\hline & Develop and gain acceptance of the method \\
\hline \multirow{3}{*}{$\begin{array}{l}\text { Performance } \\
\text { Targets }\end{array}$} & Achieve participation of five or more laboratories \\
\hline & Achieve international participation of more than three continents \\
\hline & Publish the methodology \\
\hline \multirow{2}{*}{ Reviews } & Develop the website \\
\hline & Validate the database \\
\hline \multicolumn{2}{|l|}{ OTHER ISSUES } \\
\hline \multirow{2}{*}{$\begin{array}{l}\text { Technology } \\
\text { Transfer }\end{array}$} & Develop a guideline for the use of reliability-based analysis of fire testing data in PBD \\
\hline & Disseminate activities via the website \\
\hline $\begin{array}{l}\text { Roles and } \\
\text { Responsibilities of } \\
\text { Stakeholders }\end{array}$ & Building Research Establishment, BRI, CSTB, FM Global, NAFTL, SP, UL \\
\hline $\begin{array}{l}\text { Potential } \\
\text { Collaborators }\end{array}$ & Laboratories and trade associations \\
\hline Dependency & Industry participation to release data \\
\hline
\end{tabular}




\section{TOPIC I6: DESIGN FIRES BASED ON USE AND OCCUPANCY}

\section{Description}

Fire hazards and vulnerability will vary based on occupancy.

\section{Timeline}

- Near term (within 3 years)

\section{PROGRAM APPROACH}

\begin{tabular}{|ll|} 
Major Tasks & Review existing fire data \\
\cline { 2 - 2 } & Review existing design fire curves \\
\cline { 2 - 2 } Major Milestones & Research program to select design fires \\
\cline { 2 - 2 } & Draft the proposed fire design curves \\
\hline $\begin{array}{l}\text { Performance } \\
\text { Targets }\end{array}$ & Develop an international standard of design fires based on use and occupancy \\
\hline Reviews & (ISO/TC92) and FORUM \\
$\begin{array}{l}\text { OTHER IsSUES } \\
\text { Technology } \\
\text { Transfer }\end{array}$ & Develop an international standard \\
\hline $\begin{array}{l}\text { Roles and } \\
\text { Responsibilities of } \\
\text { Stakeholders }\end{array}$ & ISO/TC92 and FORUM \\
\hline $\begin{array}{l}\text { Potential } \\
\text { Collaborators }\end{array}$ & FORUM \\
\hline \begin{tabular}{l} 
Dependency \\
\hline
\end{tabular} & PBD development \\
\hline
\end{tabular}




\section{Appendix A - Contributors}

Farid Alfawakhiri

American Iron and Steel Institute (USA)

Hosam Ali

FM Global (USA)

\section{Amjad Aref}

University at Buffalo (SUNY) (USA)

Adam Barowry

Underwriters Laboratories (USA)

Luke Bisby

University of Edinburgh (UK)

\section{Andy Buchanan}

University of Canterbury (UK)

\section{Matthew Bundy}

National Institute of Standards and Technology (USA)

\section{lan Burgess}

University of Sheffield (UK)

\section{Lisa Choe}

National Institute of Standards and Technology (USA)

\section{Steve Croft}

U.S. Fire Administration (USA)

\section{Christian Dagenais}

FPI Innovations (Canada)

\section{John Danko}

Isolatek International (USA)

Mark Dietenberger

U.S. Department of Agriculture Forest Service

\section{Graeme Flint}

Ove Arup and Partners Ltd (UK)

John Gales

Carleton University (Canada)

\section{Richard Gann}

National Institute of Standards and Technology (USA)

\section{Maria Garlock}

Princeton University (USA)

\section{John Gross}

National Institute of Standards and Technology (USA)
William Grosshandler

National Institute of Standards and Technology (USA)

Kieth Grubb

American Institute of Steel Construction (USA)

Tuula Hakkarainen

VTT Technical Research Centre of Finland

Anthony Hamins

National Institute of Standards and Technology (USA)

Matthew Hoehler

National Institute of Standards and Technology (USA)

\section{Shanshan Huang \\ University of Sheffield (UK)}

\section{Morgan Hurley}

Society of Fire Protection Engineers (USA)

Rudy Jagnandan

Isolatek International (USA)

Ann Jeffers

University of Michigan (USA)

Venkatesh Kodur

Michigan State University (USA)

Joel Kruppa

Ismans Engineering School (France)

Francis Lavelle

Applied Research Associates, Inc. (USA)

Guo-Qiang Li

Tongji University (China)

Joe Main

National Institute of Standards and Technology (USA)

Samuel Manzello

National Institute of Standards and Technology (USA)

Mike Moore

Georgia Pacific (USA)

Birgit Ostman

SP Wood Technology (Sweden) 
International R\&D Roadmap for Fire Resistance of Structures: Summary of NIST/CIB Workshop

\section{Nicolas Pinoteau}

CSTB (Scientific and Technical Center for Building) (France)

\section{Keith Poerschke}

National Gypsum Co. (USA)

Kuldeep Prasad

National Institute of Standards and Technology (USA)

\section{Spencer Quiel}

Lehigh University (USA)

\section{Selvarajah Ramesh}

National Institute of Standards and Technology (USA)

\section{Darlene Rini}

Ove Arup and Partners Ltd (USA)

Vincent Roux

Efectis Group (USA)

\section{Fahim Sadek}

National Institute of Standards and Technology (USA)

\section{Kuma Samathipala}

American Wood Council (USA)

\section{Mina Seif}

National Institute of Standards and Technology (USA)

\section{Chris Smith}

National Institute of Standards and Technology (USA)

\section{Robert Solomon}

National Fire Protection Association (USA)

\section{James Sullivan}

Alexandria Fire Department (USA)

\section{Junichi Suzuki}

National Institute for Land and Infrastructure

Management (Japan)

\section{Stephen Szoke}

Portland Cement Association (USA)

\section{Amit Varma}

Purdue University (USA)

Robert Wessel

Gypsum Association (USA)

\section{Jiann Yang}

National Institute of Standards and Technology (USA)

\section{Chao Zhang}

National Institute of Standards and Technology (USA) 


\section{Appendix B - Meeting Agenda}

\begin{tabular}{|c|c|c|}
\hline 8:30-8:40 am & Welcome & $\begin{array}{c}\text { Howard Harary, } \\
\text { NIST Engineering Laboratory - } \\
\text { Acting Director }\end{array}$ \\
\hline $8: 40-9: 00$ & NIST Performance-Based Design - Vision Straw Man & John Gross, NIST \\
\hline 9:00-9:30 & White Paper Presentation - Concrete & Bisby \& Team \\
\hline $9: 30-10: 00$ & White Paper Presentation - Steel & Kruppa \& Team \\
\hline $10: 00-10: 30$ & White Paper Presentation - Timber & Buchanan \& Team \\
\hline $10: 30-10: 35$ & Breakout Sessions Instructions & $\begin{array}{l}\text { Anand Raghunathan, } \\
\text { Energetics }\end{array}$ \\
\hline $10: 30-10: 45$ & \multicolumn{2}{|l|}{ Break } \\
\hline $10: 45-10: 50$ & $\begin{array}{l}\text { Transition to Breakout Groups } \\
\text { (by material topics - Concrete, Steel, Timber) }\end{array}$ & $\begin{array}{c}\text { Steel - Room B245 } \\
\text { Concrete - Room 205/Bldg } 226 \\
\text { Timber - Room A3 I5 }\end{array}$ \\
\hline $\begin{array}{l}10: 50-12: 45 \\
\text { pm }\end{array}$ & $\begin{array}{c}\text { Introductions and Review of the White Paper Specifics } \\
\text { Development Needs - High-Level }\end{array}$ & Breakout Sessions \\
\hline $12: 45-1: 45$ & \multicolumn{2}{|l|}{ Lunch } \\
\hline $1: 45-3: 10$ & $\begin{array}{c}\text { Development Needs - Specific } \\
\text { R\&D Impact on Development Strategy }\end{array}$ & Breakout Sessions \\
\hline $3: 10-3: 25$ & \multicolumn{2}{|l|}{ Break } \\
\hline $3: 25-4: 00$ & Worldwide Research Agenda & Breakout Sessions \\
\hline $4: 00-4: 25$ & Idea Review and Prioritization & Breakout Sessions \\
\hline $4: 30-5: 00$ & Review of Prioritized Ideas by Topic & Plenary \\
\hline 5:00 pm & \multicolumn{2}{|c|}{ Tour of NIST National Fire Research Laboratory } \\
\hline
\end{tabular}

Thursday, May 22, 2014

\begin{tabular}{|c|c|c|}
\hline 8:30-8:45 am & Plenary - Review Day I and Adjourn to Breakout Groups & Plenary \\
\hline $8: 45-9: 00$ & Review of Day I Ideas, Identify New Ideas & Breakout Sessions \\
\hline $9: 00-10: 30$ & Small Group Work & Breakout Sessions \\
\hline 10:30-10:45 & Break \\
\hline 10:45-11:45 & Plenary to Review Selected Priority Development & Plenary \\
\hline 12:00 pm & \multicolumn{2}{|c|}{ Adjourn } \\
\hline
\end{tabular}

B-I 


\section{Appendix C - Development Strategy}

The strategy to identify R\&D needs focuses on knowledge, information, tools, concepts, and applications that would enable the respective systems, processes, and technologies to develop from the status quo toward a future vision for a comprehensive, unified performance-based approach to structural fire safety and design as described in Section 2.3 of this report. Table C.I, Table C.2, and Table C.3 provide categorized lists of ideas and concepts to be considered in the development strategies for concrete, steel, and timber structural systems, respectively.

\section{TABLe C. I: DeVelopment StRATEgy for ConCRETe Structural SYSTEMS}

\begin{tabular}{|c|c|}
\hline R\&D & Other \\
\hline $\begin{array}{l}\text { - Identify current capabilities } \\
\text { - Determine future design scenarios and } \\
\text { philosophy } \\
\text { - Develop risk assessment tools, including } \\
\text { consequences of uncontrolled fires and post- } \\
\text { mortem analysis } \\
\text { - Test results that challenge current sense of } \\
\text { comfort or present economic opportunities } \\
\text { - Obtain consensus on verification and validations } \\
\text { - Prioritize coordination sensitivity studies and } \\
\text { cost-benefit analysis } \\
\text { - Generate the necessary knowledge, skills, tools, } \\
\text { and attitudes to serve as drivers }\end{array}$ & $\begin{array}{l}\text { - Incorporate political and economic considerations } \\
\text { (e.g., insurance and cost savings) } \\
\text { - Introduce fire hazards as a topic in civil engineering } \\
\text { curriculum } \\
\text { - Encourage cross-pollination of engineering disciplines } \\
\text { in colleges and universities } \\
\text { - Educate architects on fire issues and the variety of } \\
\text { choices in fire-compliant designs }\end{array}$ \\
\hline
\end{tabular}

\section{TABle C.2: DeVelopment Strategy for Steel Structural SyStems}

- For steel construction development, focus on survey of fire load and practical techniques to be used for design

- Conduct full-scale tests of a steel frame/composite slab structure subject to real fires to investigate behavior/failure modes and the influence of such factors as the degree of composite action, span lengths connections, etc.

- Assess the range of fire exposures (e.g., local, travel, and post-flash) to structural response

- Develop a comprehensive, hybrid simulation environment (architecture of a program)

- Measure the load and deflection throughout a structural system during a fire up to a collapse

- Increase knowledge of structural behavior when exposed to a wild fire

- Develop knowledge/research on fire as a secondary event (e.g., initial damage in structure and non-structure)

- Validate temperature-dependent models for connection components including fracture

- Publish well-documented data on the web

- Provide feedback to education

- Create a centralized database of test data and knowledge sharing

- Establish small-to-big or big-to-small design criteria

- Develop better instrumentation

- Advance test methods to better quantify measurement uncertainty

- Advance material models for fire

- Quantify a safety factor for structural fire collapse or other performance criteria 


\section{TABLE C.3: DeVELOPMENT StRATEgy for Timber Structural SyStemS}

- Convene focus groups to define acceptable levels of performance

- Prioritize most critical research needs produced by this process

- Develop building material database for thermal mechanical behavior

- Define specific database needs for desired thermo-physical/mechanical fire properties

- Consider use of innovative, scale modeling concepts to reduce costs for validating different designs

- Develop computer prediction capability

- Validate models using test results, and perform uncertainty analyses of both testing and modeling

- Locate, instrument, and burn buildings slated for demolition to define specific design fire loads

- Determine R\&D requirements for medium-scale testing and modeling

- Research and define appropriate scale for various tests and their goals

- Determine the effects of environment (e.g., wind, snow, humidity, and ice) on testing

- Fund several different demonstration buildings; use each one as a case study for PBD, fire testing, performance modeling, and new materials

- Compose R\&D research teams to develop highly controlled experiments on a small scale to develop material properties and relevant test methods

- Coordinate and prioritize internationally, encouraging continued contribution of resources (preferably from influential sources) and leveraging of those resources

- Ensure the maximum numbers of risks or material assemblies can be performance-tested simultaneously Carry out small-scale, room-scale, and building-scale fire tests and modeling 


\section{Appendix D - List of Current R\&D Needs}

The number of dots associated with each need in the tables represents the resulting prioritization by the workshop participants in the breakout sessions.

\section{TABLe D. I: General R\&D NeEdS FOR CONCRETE Structural SYSTEMS}

\section{\begin{tabular}{l|l|l} 
Knowledge & Drivers & Design
\end{tabular}}

- Develop plan for fire as a load case $\cdots \cdots \cdots(9)$

- Improve code development process and education (e.g., of fire protection engineers, structural engineers, and AHJs) $\cdots \cdots \cdots(7)$

- Define what the fire service should expect from PBD buildings $\bullet(2)$

- Characterize the exemplar concrete buildings of the future $\bullet$ (I)

- Investigate interactions (e.g., seismic and fire) $\bullet(I)$

- Expand knowledge of fire performance of retrofitted or strengthened concrete structures

- Establish a fragility framework (e.g., intensity measure, response measure, damage measure, and cost measure)

- Relate construction technique and PBD (e.g., design/build and modular)
- Conduct further examination of external demand for property protection versus life safety with concrete structures $\cdots \cdots(5)$

- Develop accreditation and education for PBD $\cdots$ (3)

- Increase understanding of societal awareness and expectations of fire "problem"
- Decide whether PDB design should be big versus small or small versus big $\bullet(2)$

- Develop an industry-accepted design framework and standard that allows for a formal process to change the framework and standards as appropriate 
TABle D.2: General R\&D NeedS for Steel Structural SyStemS

\begin{tabular}{|c|c|c|c|}
\hline Knowledge & Information & Concepts & Tools \\
\hline $\begin{array}{l}\text { Determine material } \\
\text { behavior at elevated } \\
\text { demperatures and } \\
\text { - Identify and describe } \\
\text { applicable fire } \\
\text { scenarios } \bullet \bullet(5) \\
\text { - Define failure with } \\
\text { respect to structural } \\
\text { integrity, serviceability, } \\
\text { and cost to } \\
\text { repair/restore •• (2) } \\
\text { - Test data on "reactive" } \\
\text { coating systems (i.e., } \\
\text { material properties a } \\
\text { means/technique to } \\
\text { evaluate) • (I) } \\
\text { - Determine properties } \\
\text { of materials (e.g., steel } \\
\text { and fire protection) }\end{array}$ & $\begin{array}{l}\text { - Perform 3-D full- } \\
\text { scale tests on } \\
\text { structural systems, } \\
\text { including multi-hazard } \\
\text { scenarios, and } \\
\text { nonstructural and, } \\
\text { hybrid tests } \\
\text { (9) } \\
\text { - Generate } \\
\text { experimental data for } \\
\text { lower-probability } \\
\text { scenarios (e.g., fire } \\
\text { after earthquake or } \\
\text { blast followed by fire } \\
\text { - (I) } \\
\text { - Test methods and } \\
\text { instrumentation to } \\
\text { gather data for } \\
\text { validation } \\
\text { - Use finite element } \\
\text { modeling to develop } \\
\text { fire curves for } \\
\text { particular fuel loads } \\
\text { and verify through } \\
\text { testing }\end{array}$ & $\begin{array}{l}\text { - Conduct uncertainty } \\
\text { quantification } \bullet \bullet(4) \\
\text { - Measure robustness of } \\
\text { steel structure varieties } \\
\text { in fire } \bullet(2) \\
\text { - Develop fire risk and } \\
\text { performance rankings } \\
\text { for structures } \bullet(2) \\
\text { - Determine the } \\
\text { appropriateness of } \\
\text { different model } \\
\text { hierarchies, material } \\
\text { models for modeling, } \\
\text { acceptance criteria, and } \\
\text { codes that are less } \\
\text { prescriptive and more } \\
\text { explanatory }(1) \\
\text { - Develop a consistent } \\
\text { framework for } \\
\text { performance-based fire } \\
\text { engineering }\end{array}$ & $\begin{array}{l}\text { - Measure assessment } \\
\text { technologies (e.g., } \\
\text { sensors and information) } \\
\text { - Build a hierarchy of } \\
\text { predictive models } \\
\text { - Design an holistic life } \\
\text { cycle }(3) \\
\text { - Design real fire tests, } \\
\text { including which } \\
\text { temperature to measure } \\
\text { in a structure with } \\
\text { thermal gradient, how to } \\
\text { determine the } \\
\text { measurement points, and } \\
\text { how to assess the fire } \\
\text { resistance of structures } \\
\text { in real fires (e.g., use } \\
\text { time and thermal } \\
\text { temperature) } \\
\text { - Standardize blast testing }\end{array}$ \\
\hline
\end{tabular}


TABle D.3: General R\&D Needs fOr Timber Structural SyStemS

\begin{tabular}{l|l} 
Design & Testing
\end{tabular}

- Define designed and real fire based on occupancy and structural materials; include a wide range of building sizes, fire loads, ventilation, living materials, etc. $\bullet \bullet \bullet \bullet \bullet \bullet \bullet \bullet \bullet \bullet \bullet \bullet \bullet \bullet \bullet \bullet$ (20)

- Analyze the effects of real fires on compartmentation $\cdots \cdots \bullet \bullet$ (6)

- Understand applicability of PBD to existing buildings, particularly for insurance purposes (e.g., lower rates if an old building meets a new design standard)

- Understand the difference between standard and real fires on charring rates

- Identify the conditions for stopping charring in decay phase

- Determine the past performance of assemblies in real-fire conditions

- Evaluate known emerging wood/wood hybrid materials

- Ensure PBDs are relevant to all interior and exterior finishes

- Understand fire's impact on nonstructural components

- Define and mitigate auto-exposure problems

- Determine whether water sprinkler requirements can be removed if fire-resistant approaches, such as encapsulation, become sufficiently effective

- Understand inter-relationships between components used in conjunction with each other as installed and during a fire

\section{Technical}

- Determine material properties at increasing temperatures $\bullet(I)$

- Understand performance of variations in materials-different wood species, fastener types, room size, etc.

- Understand behavior of and heat transfer in complex systems (wood/concrete/steel)

\section{Standards}

- Define acceptable performance levels $\bullet \bullet \bullet \bullet \bullet \bullet(10)$

- Identify performance requirements for life safety in tall buildings $\cdots(3)$

- Develop test standards for full-scale testing-fire load, structural, etc. $\bullet(2)$

- Determine standards for postearthquake fire performance $\bullet$ (2)

- Develop guidelines for the whole PBD process, taking into account all parties and going to a sufficiently detailed level • (I)
- Conduct real-scale experiments of various systems, ventilation conditions, and fuel load $\bullet(2)$

- Test to burnout without structure failure and define what to test $\cdot(I)$

- Determine how to show limited encapsulation approaches without doing extensive testing $\bullet(I)$

- Determine where to test parameters for location, interior air flow, etc.

- Understand the difference between prescribed, modeled, and actual fire; incorporate information into standard tests and models

- Correlate small-scale testing to PBD

\section{Other}

- Include firefighter safety in PBD requirements $\bullet(2)$

- Develop a responsible safety culture but without materialbased prejudices (e.g., wood burns) • (I)

- Address needs for staff and funding for platforms

- Address loading requirements per code

- Provide technical education to building authorities (and other stakeholders) 
TABle D.4: SpeCific R\&D NeEdS FOR CONCRETE Structural SyStemS

\section{\begin{tabular}{l|l|l} 
Measurement and Test Methods & Design & Tools
\end{tabular}}

- Develop high-temperature strain and deflection measurement techniques $\cdots \cdots \cdots(7)$

- Develop models for heat transfer in specific

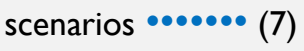

- Determine methods for measuring fire intensity $\bullet \bullet$ (4)

- Correlate small-scale and full-scale performance under various exposures and test methods $\bullet \bullet \bullet$ (4)

- Design test methods to derive needed material properties (e.g., spalling) $\bullet$ (3)

- Create bench-scale measurement apparatus • (I)

- Measure pore pressure in concrete $\bullet(I)$

- Test components (e.g., beam and column) - (I)

- Test worst-case thermal load, beyond "typical" fire case $\bullet(I)$

- Aggregate the type of file performance $\bullet(I)$

- Perform a study of service moisture

- Perform hybrid testing (e.g., proof of viability)

- Ascertain spalling speed during fire

- Strengthen R\&D efforts (not just for conventional reinforced concrete)

- Determine effects of aging (i.e., weathering) on fire-resistive performance

- Document the effect of suppression tactics preand post-flashover

- Piggyback on other tests and programs

- Include spalling prevention, not only prediction $\bullet$ (I)

- Design for structurally significant fires (worst-case scenario)

- Create guidelines on the effect of cracking on reduced fire resistance of concrete

- Design for fire load case (e.g., comparative tests)

- Define "high-impact" test structures
- Design multi-scale simulations $\bullet \bullet \bullet \bullet(6)$

- Validate computational models with necessary mechanics $\bullet(2)$

- Build sensors for assessment of building during fire 
TABLe D.5: Specific R\&D Needs for Steel Structural SyStemS

\begin{tabular}{|c|c|c|c|}
\hline Knowledge & Information & Concepts & Tools \\
\hline $\begin{array}{l}\text { - Understand how } \\
\text { natural fires interact } \\
\text { with structures (e.g., } \\
\text { experiment of } \\
\text { traveling fire) } \bullet(2) \\
\text { - Evaluate cellular beams } \\
\text { - (I) } \\
\text { - Evaluate } \\
\text { composite/hybrid } \\
\text { systems } \\
\text { - Quantify fire-induced } \\
\text { restrain depending on } \\
\text { various types of } \\
\text { connectors }\end{array}$ & $\begin{array}{l}\text { - Develop connection models, } \\
\text { including fracture } \\
\text { - Develop simple fire models and } \\
\text { calculation methods to predict } \\
\text { the temperature of structural } \\
\text { components in real fires, as well } \\
\text { as tools to model global } \\
\text { structures in real fires } \bullet \bullet(4) \\
\text { - Develop concrete fracture } \\
\text { models } \\
\text { - Shear stud behavior } \\
\text { - Fracture criteria for steel •• } \\
\text { (2) } \\
\text { - Study temperature-dependent } \\
\text { load-displacement behavior of } \\
\text { shear stud connectors }{ }^{\circ}(1) \\
\text { - Understand fire-thermal- } \\
\text { structure cycles } \\
\text { - Develop no-creep steel models }\end{array}$ & $\begin{array}{l}\text { - Determine how to } \\
\text { exploit scaling for } \\
\text { structural fire } \\
\text { testing } \bullet(3) \\
\text { - Examine plate } \\
\text { buckling } \\
\text { - Auxial } \\
\text { - Flexural } \\
\text { - Shear } \\
\text { - Combined }-(I) \\
\text { - Study thermal } \\
\text { properties of } \\
\text { interment }(I) \\
\text { - Study sheet time } \\
\text { and rate dependent } \\
\text { behavior (creep, } \\
\text { etc.) }\end{array}$ & $\begin{array}{l}\text { - Develop post-fire } \\
\text { damage } \\
\text { assessment tools } \\
\text { - Explore fiber } \\
\text { optic } \\
\text { temperature, } \\
\text { strain, and } \\
\text { displacement } \\
\text { measurement } \\
\text { technology } \\
\text { - Fire-structure } \\
\text { interaction } \\
\text { impact on spalling } \\
\text { of fire protection } \\
\text { coatings }\end{array}$ \\
\hline
\end{tabular}


TABLE D.6: SPECIFIC R\&D NeEdS FOR TIMBER STRUCTURAL SYSTEMS

\section{Knowledge \\ Information}

- Determine temperature- and moisture-dependent thermal and mechanical properties of timber and charred wood, at the molecular level if needed; cooperate as needed with experts outside of fire industry $\bullet \bullet(3)$

- Obtain statistical data on fire loads in different occupancies, real building fires, rescue service operations, and other situations $\cdots(3)$

- Gain new knowledge on fire dynamics of rooms lined with thermally thick (i.e., massive) wood structure (e.g., external heat flux versus sustainable combustion versus charring rate) $\bullet(I)$

- Determine the minimum heat flux required to sustain combustion as a function of char depth $\bullet$ (I)

- Determine the mechanical properties of different species and grades of wood and engineered wood products, in both cold and fire conditions

- Establish fall-off times for protective boards (e.g., gypsum) at testing

- Investigate the influence of wood façade claddings on exterior fire-spread flames coming out from a broken window after flashover

- Explore the long-term effects of weather, age, and environmental conditions, both internal to the building and external

- Determine relevant fire exposure conditions for fire stops in voids

- Study fire performance of cellulosic insulation and influence on fireresistance risk for smoldering

\section{Tools}

- Model post-flashover compartment fires and compare results to tests $\cdots \cdots \cdots(5)$

- Develop new measurement technologies or methodologies for fire resistance and cooling periods to incorporate into current testing practices $\cdots(3)$

- Develop finite element modeling that can do coupled thermal and mechanical analysis, particularly for the orthotropic properties of wood, and the fundamental wood material properties themselves $\bullet$ (2)

-Write computer software to predict whole-building fire performance

- Incorporate design fire exposure properties in finite element modeling for thermal properties

- Build a database of timber component properties, both for ideal and as-installed situations $\cdots(3)$

- Design encapsulation by gypsum board test methods - (I)

- Study the influence of poor construction skills on construction tolerance

- Consider how gaps between structural elements affect charring and fire resistance in joints

\section{Standards}

- Address regulatory issues, including incorporation of new standards into existing standards without creating overlap, double standards, or competing standards between prescriptive codes and PBD
- Build industry-wide, generic manufacturing specifications/ properties

- Design standardspecific performance criteria 


\section{Appendix E - Acronyms}

3-D

ABET

$\mathrm{AHJ}$

AISI

ASCE

ASTM

BAM

BNCS

BRE

BRI

CIB

CSTB

CTICM

FM

FORUM

FPL

ICC

IFE

ISO

NCARB

NFPA

NAFTL

NIST

NRCC

PBD

R\&D

Roadmap

SDO

SFPE

SFRM

$\mathrm{SiF}$

SOA

$S P$

T-T

UL

VTT three-dimensional

Accreditation Board for Engineering and Technology

authority having jurisdiction

American Iron and Steel Institute

American Society of Civil Engineers

American Society for Testing and Materials

Federal Institute for Materials Research and Testing, Germany

building nonstructural components and systems

Building Research Establishment

Building Research Institute, Japan

Conseil International du Bâtiment

Centre Scientifique et Technique du Bâtiment or Scientific and Technical Centre for Building

Centre Technique Industriel de la Construction Métallique

FM Global

the International Forum of Fire Research Directors

Fire Products Laboratory

International Code Council

Institution of Fire Engineers

International Organization for Standardization

National Council of Architectural Registration Boards

National Fire Protection Association

North American Fire Testing Laboratories

National Institute of Standards and Technology

National Research Council of Canada

performance-based design

research and development

International R\&D Roadmap for Fire Resistance of Structures

standards development organization

Society of Fire Protection Engineers

sprayed fire-resistive materials

Structures in Fire

state of the art

Technical Research Institute of Sweden

temperature-time

Underwriters Laboratories

VTT Technical Research Centre of Finland

E-I 


\title{
Appendix F - White Papers
}

I. Concrete

\author{
WHITE PAPER
}

\section{FIRE RESISTANCE OF CONCRETE STRUCTURES}

A report for the National Institute of Standards and Technology

by

Professor Luke Bisby, Arup Chair of Fire and Structures, University of Edinburgh, UK

Dr Hossein Mostafaei, FM Global Research Division (formerly with National Research Council of Canada)

Dr Pierre Pimienta, Centre Scientifique et Technique du Bâtiment, France

Final report

18 June 2014

F-I 
International R\&D Roadmap for Fire Resistance of Structures: Summary of NIST/CIB Workshop

THIS PAGE LEFT INTENTIONALLY BLANK

F-2 


\section{Contents}

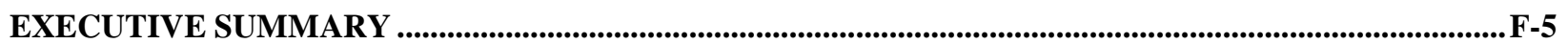

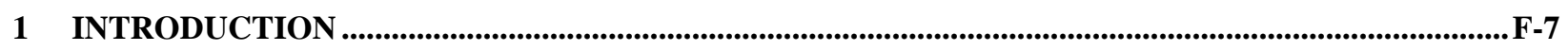

2 CURRENT STATE-OF-THE-ART IN STRUCTURAL FIRE ENGINEERING FOR

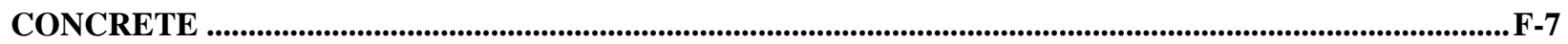

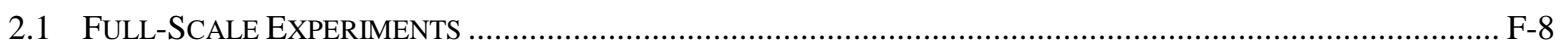

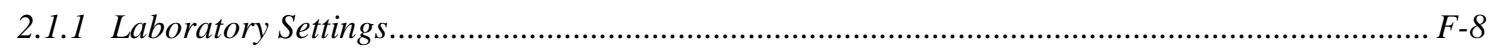

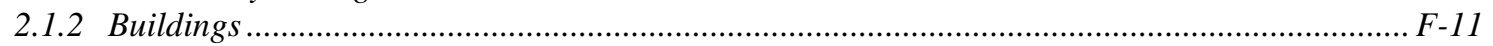

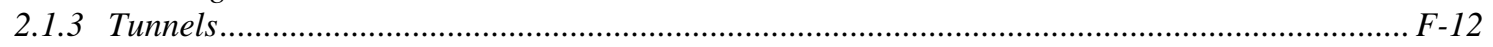

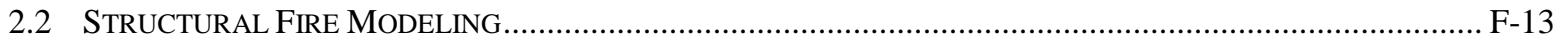

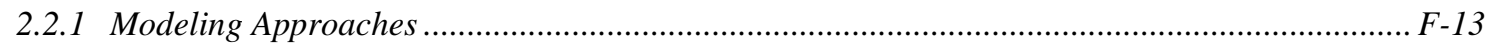

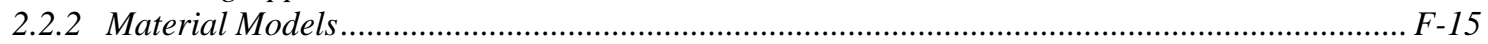

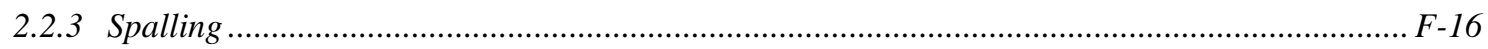

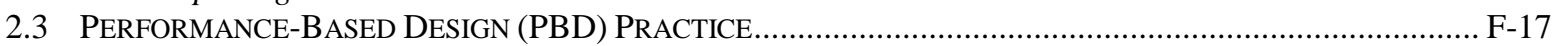

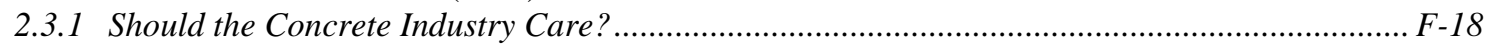

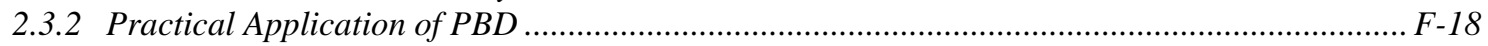

2.3.3 Regulatory Hurdles ................................................................................................... F-18

3 KNOWLEDGE GAPS ....................................................................................................................................19

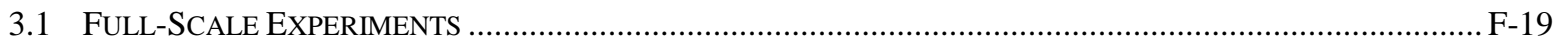

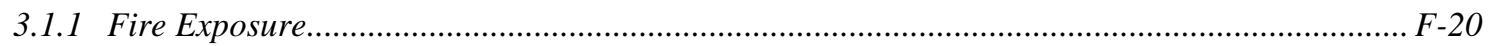

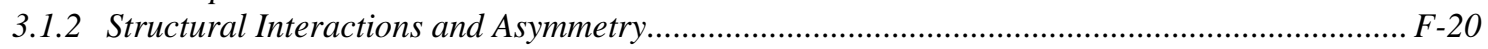

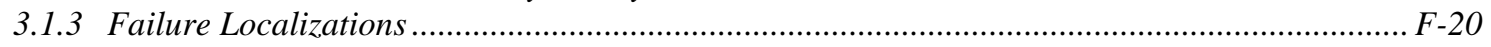

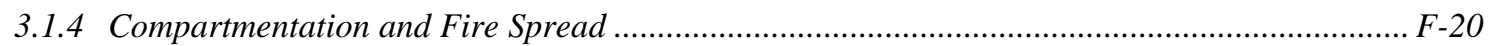

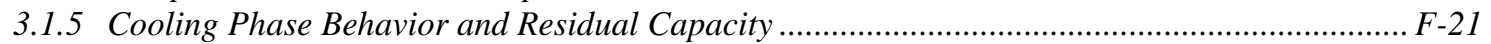

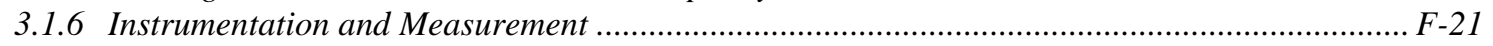

3.1.7 Data for Model Calibration, Validation and Verification..................................................... F-21

3.1.8 Structural Optimization and the Use of New Materials and Systems......................................... F-21

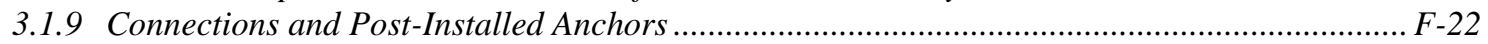

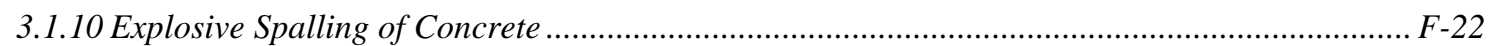

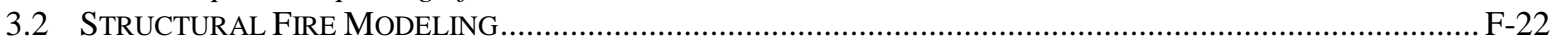

3.2.1 Material Models and Numerical Modeling ...................................................................... $F-22$

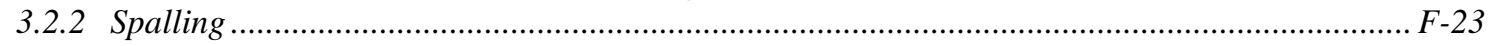

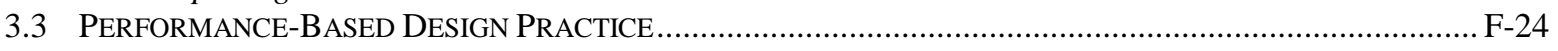

4 ACTIONS AND PRIORITIZATION FOR PBD OF CONCRETE STRUCTURES .................................F-25

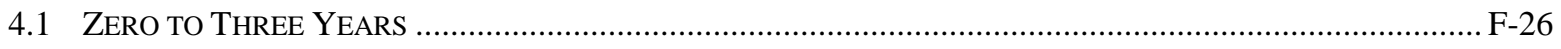

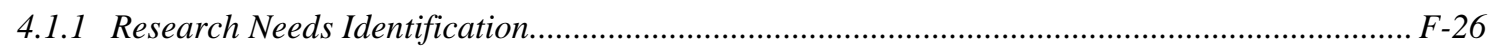

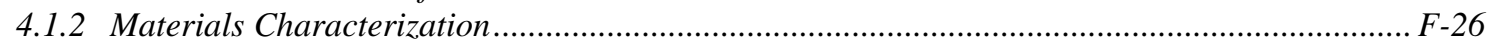

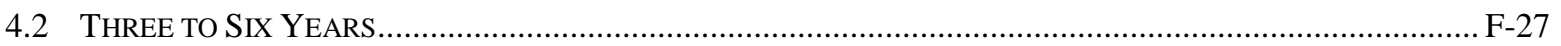

4.2.1 Small Scale Structural Elements ……………............................................................... F-27

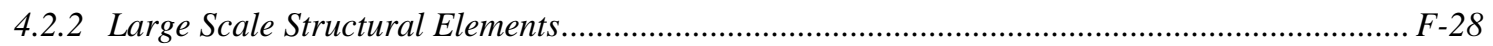

4.3 SIX TO NINE YEARS ..................................................................................................................... F-29

4.3.1 Whole Structure Testing and Modeling............................................................................... F-29

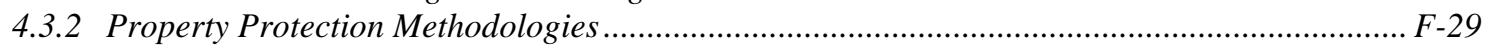

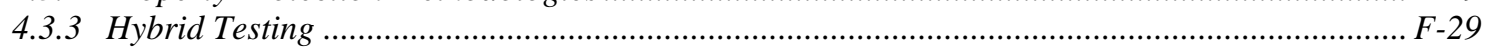

4.3.4 Test-Model Based Certification Protocols …….................................................................... F-30

5 OPPORTUNITIES AND SPONSORS FOR COLLABORATION …....................................................30

5.1 Possible PARTNERS IN THE AMERICAS (POSSIBLE FIRST CONTACT NAMES IN BRACKETS) ..................... F-31 
International R\&D Roadmap for Fire Resistance of Structures: Summary of NIST/CIB Workshop

5.2 POSSIBLE PARTNERS IN EUROPE (POSSIBLE FIRST CONTACT IN BRACKETS) ………….......................... F-32

5.3 POSSIBLE PARTNERS IN ASIA AND AUSTRALASIA (POSSIBLE FIRST CONTACT IN BRACKETS) .................. F-33

6 TECHNOLOGY TRANSFER AND INFLUENCING PRACTICE ...........................................................F-34

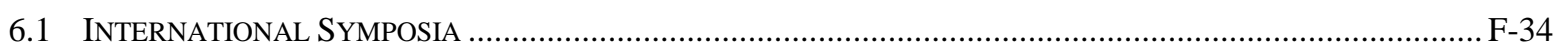

6.2 RESEARCH-ACTIVE CODES AND STANDARDS GROUPS (ALPHABETICAL) ……….................................... F-34

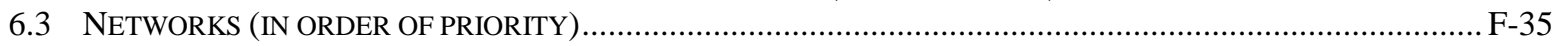

7 MEANS FOR COALITION OF INTERNATIONAL RESEARCH PARTNERS .....................................F-35

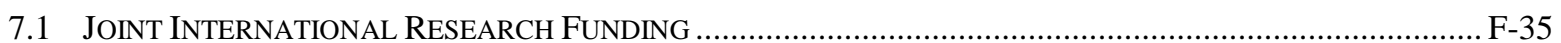

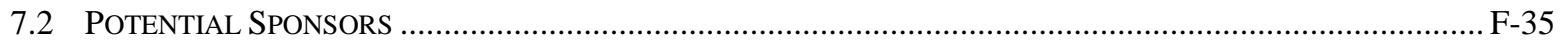

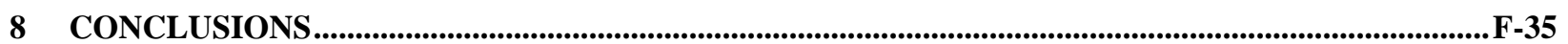

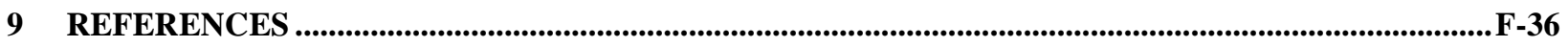




\section{Executive Summary}

This white paper presents the current, international, state-of-the-art large-scale experimental, modeling, and performance-based design (PBD) efforts related to structural fire resistance of concrete structures. The paper addresses these topics with emphasis on research and development needs for large-scale experiments on fire resistance of structures to support performance-based engineering and structure-fire model validation; prioritizing those needs; phasing the needs in terms of near, medium and long term; identifying the most appropriate international laboratory facilities and collaborators available to address each need; identifying possible means to transfer the results of research to industry; and identifying a means for the coalition of international partners to review progress and exchange information on a regular basis.

Any future research strategy in this area relies on demonstrating suitable drivers; these may be based either on safety or property protection concerns, or on economic, sustainability, or optimization goals. It will also be necessary for the international concrete construction, fire testing, research, and regulatory communities to work together and acknowledge the relevant unknowns regarding the performance of concrete structures in fire, as well as the limitations of current approaches to structural fire testing and design. The following key research needs are highlighted herein:

- Enhanced material thermal and constitutive models are needed as inputs to future computational modeling activities.

- A credible, repeatable, representative, and temporally and economically efficient test method for characterization of different concrete mixes' propensity for spalling in fire is needed.

- Small-scale tests are needed on concrete materials and reinforced concrete structural elements to provide basic validation data for computational modeling.

- Spalling tests and associated modeling must be developed to account for and/or understand as many of the known spalling risk factors as possible. Numerical models for spalling need to be improved and validated. The structural scenarios in which spalling causes no concern (if any) should be elucidated.

- Large-scale structural tests are needed which sequentially ramp up the complexity of structural fire testing assemblies, eventually leading to whole structure testing. These tests should be carefully planned to address as many of the relevant thermal and structural issues as possible, rather than to simulate/demonstrate the response of a real concrete building.

- Once computational modeling capability is developed and validated against an appropriate range of tests, numerical parametric modeling studies should be undertaken to understand and interrogate the overall whole structure response of various types of concrete structures. Large-scale whole structure tests of 'exemplar' reinforced concrete buildings are needed to credibly validate and corroborate testing and modeling of structural materials and small scale and large scale structural elements.

- Tests and models are needed to allow engineers to quantify fire damage to concrete structures after different fire exposure levels. Such testing and modeling would support the development of intensity measures, damage indices, performance limits, and 
International R\&D Roadmap for Fire Resistance of Structures: Summary of NIST/CIB Workshop

quantification of consequences of damage; these are needed in support of PBD of concrete structures for fire.

\section{DISCLAIMER}

The potential collaborators listed herein are given for the purposes of this review and are based on the information available in the literature and from comments made during public review. In no case does such identification imply recommendation or endorsement by the authors, nor does it imply that the collaborators identified are the only available for the stated purposes. 


\section{Introduction}

The U.S. National Institute of Standards and Technology (NIST) conducted a building and fire safety investigation of the World Trade Center (WTC) disaster of September 11, 2001; the Final Report included 30 recommendations that address: (1) specific improvements to building standards, codes, and practices; (2) changes to, or the establishment of, evacuation and emergency response procedures; and, (3) research and other appropriate actions needed to help prevent future building failures. As part of NIST's plan to implement the report's recommendations regarding new methods for fire resistance design of structures, an international research and development $(\mathrm{R} \& \mathrm{D})$ roadmap on the fire resistance of structures is being developed. NIST commissioned three white papers to be used as the basis for technical discussions at an international workshop. This report is one of three independent white papers on the current, international, state-of-the-art large-scale experimental, modeling, and performancebased design (PBD) efforts related to structural fire resistance. The paper addresses reinforced concrete structures and deals with:

1. highlighting research and development needs for large-scale experiments on fire resistance of structures to support performance-based engineering and structure-fire model validation;

2. prioritizing the needs in order of importance to performance-based engineering;

3. phasing the needs in terms of near ( $<3$ yrs), medium (3-6 yrs) and long term (6-9 yrs);

4. identifying candidate international laboratory facilities available to address each need;

5. identifying potential collaborators and sponsors for each need;

6. identifying means to transfer the results from each series of tests to industry through specific national and international standards, predictive tools for use in practice, and comprehensive research reports; and

7. identifying a means for coalition of international partners to review progress and exchange information.

\section{Current State-of-the-Art in Structural Fire Engineering for Concrete}

In general, concrete structures perform well in building fires [Bailey and Khoury, 2011]. Because concrete is non-combustible and has a relatively low thermal conductivity, and provided that the concrete cover to the internal steel reinforcement remains in place during heating (i.e. there is no cover spalling), heat flow to the interior of a reinforced concrete element in fire occurs slowly. Concrete structures are therefore widely presumed to possess 'inherent fire resistance'; this is typically treated in structural design by prescribing minimum overall member dimensions and minimum concrete cover to the steel reinforcement. Historical evidence suggests that these simple, prescriptive approaches have provided an acceptable level of performance of concrete structures in building fires. 
For a variety of technical and economic reasons (briefly discussed in Section 2.3.1), large-scale structural fire testing, computational analysis, and PBD of concrete structures for fire has received only a fraction of that given to steel-framed structures.

It is noteworthy that a number of state-of-the-art reviews on structural fire engineering testing, analysis and design are available in the literature [e.g. British Steel, 1999; Grosshandler, 2002; Grosshandler, 2003; Almand et al., 2004; Beyler et al., 2007; Kodur et al., 2007; Beitel and Iwankiw, 2008; Kodur et al., 2011; Wald, 2011; Vassart and Zhao, 2011; Bisby et al., 2013]; however none of these has focused exclusively on concrete structures. A review of large scale structural fire testing was also recently published by Bisby et al. [2013].

\subsection{Full-Scale Experiments}

\subsubsection{Laboratory Settings}

Since the mid-1900s, a number of large-scale standard fire resistance tests have been performed on reinforced concrete structural elements in standard fire testing furnaces [e.g. ISO, 1999; ASTM, 2011]. Various prior research needs assessments (noted above) have highlighted a number of deficiencies associated with such tests and have identified a range of general structural fire engineering research needs, which have yet to be properly addressed; some of these are discussed in Section 3.1.

In addition to standard furnace tests, a smaller number of ad-hoc, non-standard structural fire tests performed in laboratories have also been presented in the literature. Several authors have presented results from fire tests on concrete elements or assemblies using custom made or modified standard furnaces to study specific structural response issues or specific types of concrete structures, which cannot be easily investigated using a standard 'single element' approach. For instance, Van Herberghen and Van Damme [1983] used a modified standard floor furnace to study the fire resistance of post-tensioned continuous (unrestrained) flat floor slabs with unbonded prestressing tendons in standard fire conditions; Kordina [1997] used a modified floor furnace to investigate the punching shear behavior of reinforced concrete flat slabs in standard fire conditions; Kelly and Purkiss [2008] used an oversized floor furnace to study the fire resistance of simply-supported, partly-restrained, long-span, post-tensioned concrete slabs under standard fire exposure; Li-Tang et al. [2008] studied the structural fire behavior of modelscale, three-span continuous unbonded post-tensioned concrete slab strips in a custom built furnace subject to a standard fire; Zheng et al. [2010] performed a series of standard fire tests on two-span, continuous post-tensioned concrete slabs in a furnace with a central support built inside the heating chamber; and Annerel et al. [2011] used a modified standard floor furnace to perform punching shear tests on concrete slabs subjected to a standard fire. Several other examples are available in the literature; however, an exhaustive summary is avoided here.

Only one large-scale test of a 'real' multi-story concrete building exposed to a real fire appears to have ever been performed. Bailey [2002] presents the results of a real fire test on a full-scale, seven-story cast in-place concrete building that was performed at the UK Building Research Establishment (BRE) Cardington test site. The full-scale building was a concrete frame three bays by four bays. It had two cores that incorporated cross bracing for lateral load support, and the floor slab was $250 \mathrm{~mm}$ thick. The main aim of the test was to investigate the behavior of a 
full-scale concrete building during a realistic compartment fire, under sustained design load. Bailey [2002] stated that the test aimed to:

- investigate how the whole building resisted or accommodated large thermal expansions from the heated parts of the structure (lateral thermal expansion of the floor slab in particular);

- identify both beneficial and detrimental modes of whole building behavior that cannot be observed through standard furnace tests on isolated structural elements;

- investigate the effects of concrete spalling and its possible significance on whole building response; and

- compare test results and observations from large-scale fire tests with current methods of structural fire engineering (SFE) design.

A fire compartment was built into an edge bay of the building with an area of $225 \mathrm{~m}^{2}$ between the ground and first floor. One internal column was exposed to the fire and eight additional columns were partially exposed to the fire. The columns were made from high strength concrete (103 MPa cube strength), incorporating $2.7 \mathrm{~kg} / \mathrm{m}^{3}$ of polypropylene (PP) fibers (of unspecified type) to prevent explosive spalling. The cover to the steel reinforcement was $20 \mathrm{~mm}$. The structure was loaded using sand bags and the fire load was timber cribs with a load of $40 \mathrm{~kg} / \mathrm{m}^{2}$. Key observations and conclusions relevant to the current report were that [Bailey, 2002]:

- gas temperatures were reduced early in the fire due to explosive spalling of the soffit of the floor slab; slab soffit spalling was extensive, reduced the severity of the fire throughout the test, and exposed the bottom reinforcing bars; spalling was explosive and probably exacerbated by high in-plane compressive stresses in the slab caused by lateral restraint to thermal expansion;

- vertical displacements toward the edge of the building were larger than the displacements near the center and showed no signs of a stabilizing plateau;

- the slab remained stable and supported the load 'by compressive membrane action at small slab vertical displacement'; such action can only occur at small vertical displacements, and thus if the slab's vertical displacements were greater or lateral restraint surrounding the heated slab were less, 'it is difficult to see how the slab could have supported the static load' [Bailey, 2002]; and

- thermal expansion of the floor slab resulted in significant lateral displacement of the external columns.

Two further large-scale non-standard structural fire tests were also performed at BRE to study the performance of hollow core concrete slabs resting on steel beam flooring systems [Bailey and Lennon, 2008]. These were performed after worrying results from tests and incidences of failures of hollow core slabs during real building fires in Europe [e.g. Van Acker, 2003; de Feijter and Breunese, 2007]. The tests were intended to demonstrate that tying together and grouting of hollow core slabs could prevent premature shear failure (this having been observed in smaller scale tests on hollow core slabs). 
The fire compartment was $7.0 \mathrm{~m} \times 17.8 \mathrm{~m}$ in plan with a height of $3.6 \mathrm{~m}$. Fifteen $1200 \mathrm{~mm}$ wide $\times 200 \mathrm{~mm}$ hollow core slabs, with concrete compressive strength of $85 \mathrm{MPa}$ and moisture content of $2.8 \%$ by mass, were placed in a single row to form the compartment roof. The slabs were loaded with sandbags and exposed to a natural fire using $32.5 \mathrm{~kg} / \mathrm{m}^{2}$ of wooden cribs; the intent being to follow the ISO 834 [ISO, 1999] standard fire for the first 60 minutes. Observations and conclusions were that (Bailey and Lennon, 2008):

- properly designed and detailed hollow core floor systems behave well when subjected to severe fire scenarios, as well as during the cooling phase of the fire;

- edge units fractured during the cooling phase, however, this did not lead to loss of load bearing capacity;

- no significant spalling of the units was observed;

- different end restraint conditions did not affect the measured vertical displacement, however, restraint conditions kept outer portions of the edge slab in place when it fractured along its length; and

- there was evidence of a lateral compressive strip forming at the ends of the units caused by restraint to thermal expansion; thus may have enhanced the flexural and shear capacities of the slabs.

Large-scale non-standard fire tests on unloaded and loaded concrete columns and unloaded posttensioned concrete slabs in real fires have also been reported by Wong and $\mathrm{Ng}$ [2011] and CCAA [2010]. The CCAA tests aimed to assess the magnitude and extent of spalling for various types of Australian aggregates in a real fire, and to provide guidance on possible measures to limit its effects.

Ring et al. [2011] present limited results of four large-scale non-standard fire tests on 'framelike' concrete structures performed to investigate redistribution of loading within reinforced concrete structures subjected to fire. These tests were designed to provide data for the development, assessment, and validation of numerical tools for predicting the structural response of concrete tunnels in fire. Triangular tubular frames were constructed on slope and loaded to simulate a soil overburden. Two of these frames incorporated PP fibers in their concrete mix. Oil burners were used to heat the atmosphere inside the tubes to $1200^{\circ} \mathrm{C}$ in nine minutes and remaining at $1200^{\circ} \mathrm{C}$ for three hours. These tests provide data for validation of computational models and they clearly demonstrate the benefits of PP fibers in preventing heat-induced spalling.

In general, the available non-standard testing of concrete structures presented above shows that the behavior of concrete in fire is considerably more complicated than would be assumed on the basis of the available prescriptive guidance, which typically prescribes only overall member dimensions and minimum concrete cover. This may present possible benefits and/or risks for concrete structures in fire. Whole building response has not been widely investigated for concrete buildings.

Some laboratories, such as BAM (Germany), NRC (Canada) and CERIB (France) are able to carry out Hybrid Fire Testing (HFT). HFT couples physical tests on part of a structure with realtime computational simulation of the rest of the structure [Mostafaei, 2013]. HFT allows 
reproduction, in a more realistic way, of the boundary conditions and the applied external loads during a fire. However, HFT is not yet widely accepted or properly validated for whole frame reinforced concrete structures.

\subsubsection{Buildings}

Relatively few detailed technical analyses of the performance of concrete buildings during and after real fires are available in the literature. A 2008 report by the Concrete Society [2008] on assessment, design and repair of fire damaged concrete structures provides summary information on a number of real fires that have been reported in concrete buildings by Ingham [2007], Berry [1991], Srinivasan et al. [2007], Sivagnanam [2002], Nene and Kavle [1992], Morales [1992], Smart [2006], Dilek [2005, 2007], Taerwe et al. [2006], Peker and Pekmezci [2003], Boam and Copper [1994], Cabrita Neves et al. [1997], and Calavera et al. [1992]. A Recent report by Meacham et al. (2012) is also relevant. Consistent observations from these studies are that:

- concrete buildings subjected to real fires (as opposed to 'standard' fires) generally perform well, and structural failure (i.e. local or global collapse) is rare;

- in many cases fire-damaged structures can be brought back into use by removal and replacement of damaged concrete and internal steel reinforcement;

- considerable structural damage and irrecoverable deformation are observed in concrete slabs and beams due to differential thermal gradients, thermal bowing, and discrete cracking in regions not explicitly designed for the stresses and deformations experienced under these thermal actions;

- cracking and spalling can be severe, particularly for modern concrete mixes and for elements with thin concrete webs (as in many precast concrete elements); widespread spalling of slab soffits was observed in many fires, although in general this did not lead to structural failure; and

- relaxation of prestressing tendons was observed in both bonded and unbonded posttensioned construction; prestressing tendons are particularly sensitive to high temperature [Gales et al., 2011a, b].

Fletcher et al. [2006] discuss the performance of the Windsor Tower, a high rise building in Madrid, Spain, which was partly constructed from concrete and which experienced a severe fire resulting in major structural collapse in 2005. Due to the complexity and uncertainty of response of this structure, the only relevant conclusion from this report is that the steel portions of the structure suffered considerably more damage than those made from concrete. Reasons for this are not given, other than the typical 'inherent' fire resistance of concrete. Fletcher et al. [2006] also discuss the performance of the CESP Buildings in Sao Paolo, Brazil, during a fire in 1987. These were concrete frames with concrete ribbed slab floors and experienced a major fire exceeding two hours in duration. The concrete core of one of the buildings collapsed during the fire; attributed to lateral thermal expansion of the concrete floor beams resulting in secondary bending moments and lateral shear forces for which the columns were not designed.

de Feijter and Breunese [2007] describe the aftermath of a severe fire in a multi-story car park constructed partly from precast prestressed hollow core concrete slabs, which spanned from a central core to a load-bearing precast concrete façade. The structure was severely damaged 
during the fire and total structural collapse was a serious concern. Excessive crack formation was observed in the hollow core slabs, including horizontal cracks between the individual cores and vertical cracks from the cores to the slabs' bottom surfaces; these resulted in total separation of the bottom half of the hollow core elements (along with the internal prestressed reinforcement) over a large portion of the structure. Spalling to a depth of several centimeters was widespread in both the slab soffit and the concrete façade elements, exposing steel reinforcement in many places. de Feijter and Breunese [2007] concluded that for concrete structural elements that are exposed to exterior environments it cannot be taken for granted that spalling will not occur during fire. They also concluded that differential thermal cracking is a particular concern for concrete structures with small amounts of internal reinforcement (e.g. precast elements prestressed only in the longitudinal direction) and that consideration should be given to the connection between structural elements, both to account for compressive stresses developed due to lateral restraint during heating, and for tensile stresses developed due to thermal contraction on cooling. It is clear based on the above that it is essential for structures to be considered not as separate parts, but rather as a connected whole.

A notable fire event in another concrete car park structure was the 2004 Gretzenbach fire, reported by Muttoni et al. [2005]. In this case, an underground cast-in-place concrete flat slab structure collapsed in punching shear during the cooling phase after a 'rather small and localized fire' [Annerel et al., 2013]. Full details of this collapse are not widely available; however, a forensic structural fire analysis presented by Annerel et al. [2013] suggests the need for additional work on punching shear of concrete slabs in fire.

Gales et al. [2011a, b] present detailed reviews of available test data and case studies of real fires in unbonded post tensioned (UPT) concrete buildings. They show that multiple case studies and much of the available furnace test data show that the response of real UPT buildings in fire is more complicated than suggested by the available prescriptive guidance, particularly with respect to cover spalling and prestressed tendon rupture under localized heating. It is shown that concrete spalling of some form has occurred in all reported real fires in UPT buildings, and that in more than $65 \%$ of these cases tendons have ruptured as a result. Spalling has occurred in more than half of available furnace tests on UPT elements. Tendon rupture or release of prestress occurred in the majority of real fires, leading to both partial and progressive failure of UPT buildings. Tendon rupture has been observed in 33\% of reported furnace tests, and is more likely in a real building than a furnace test; localized heating of tendons is particularly problematic and can rapidly lead to tendon rupture. Gales et al. [2011b] highlight two fundamental inadequacies of available test data for UPT structures in particular: (1) that the total anchor-to-anchor length of UPT tendons in standard furnace tests is always much shorter than in real UPT structures, and (2) standard furnace tests are designed to provide uniform heating, thus failing to simulate spatially non-uniform, travelling, and/or localized fires in real buildings. The result of both factors is that furnace tests cannot capture the conditions most likely to result in unbonded prestressing tendon rupture in fire.

\subsubsection{Tunnels}

Several dramatic fires in tunnels have occurred during the past two decades, including: the Channel tunnel (1996 and 2008), Mont Blanc (1999) and Frejus (2005) between France and Italy, Storebealt (1994) in Denmark, Tauern (1999) in Austria, and Gothard (2001) in Switzerland and Baltimore (2001) in the USA. 
Very high temperatures were reached in all of these tunnel fires (probably more than $1000^{\circ} \mathrm{C}$ ) and it is likely that these temperatures were reached during the first $15 \mathrm{~min}$ of the fires [Voeltzel and Dix, 2004; Abraham and De Robert, 2003]. Similarly, high levels of temperature and heating rate have been measured in tunnel fire tests such as the EUREKA 499 fire tests and the Memorial Tunnel Fire Test Program [Lönnemark and Ingason, 2005]. High temperatures and heating rates often result in considerable spalling and damage to tunnel linings and structures. These have potentially serious consequences for the safety of users and of fire and rescue teams. Fire damage to tunnels also typically necessitates time-consuming and costly refurbishment of the tunnel prior to re-opening. In addition to direct economic losses from repair activities, indirect economic losses associated with tunnel closure are often substantial. Whereas spalling of concrete in fire has been known for more than a century and occurs frequently in building fires, these more recent examples in tunnel fires have clearly highlighted a significant problem; spalling of modern concrete materials.

Adequately addressing the spalling problem is now a primary requirement in any new tunnel design. Fire resistance tests on large-scale concrete elements are required in most tunnelling projects. National authorities have introduced temperature versus time curves in various tunnel fire testing regulations. Three of the most commonly used curves in Europe (the RWS, HCinc, and RABT fires) were designed to represent the maximum envelope for all possible fire events in road or rail tunnels. These curves reach 1200 to $1300^{\circ} \mathrm{C}$ in less than 10 minutes [World Road Association, 1999; Taillefer et al., 2013].

Heat induced spalling phenomena remain relatively poorly understood from a fundamental perspective [Maluk, 2014] and depend on a large number of factors, including the geometry of the concrete elements and the externally applied loads [Guerrieri and Fragomeni, 2013; Jansson and Bostrom, 2013; Carre et al., 2013]. Other factors influencing spalling are discussed in Section 2.2.3. So that laboratory tests provide results that are as representative as possible of the credible worst case fire situation, large elements (close to full scale) are generally tested for compliance with anti-spalling design requirements. These are generally slabs or walls with sections larger than $4 \mathrm{~m}^{2}$. The elements are typically mechanically loaded in an attempt to reproduce the externally applied in-service loads [Taillefer et al., 2009; Pimienta et al., 2010; Jansson and Bostrom, 2013] despite the fact these loads are not well known in practice.

\subsection{Structural Fire Modeling}

\subsubsection{Modeling Approaches}

Experimental studies on the behavior of full-scale reinforced concrete structures in fire have shown that designers "need to (better) understand the behaviour of entire structures in fire to ensure that premature collapse will not occur" [Bailey 2002]. Performing full-scale structural fire tests is expensive, and historically they have been infeasible. A potentially cost-effective alternative approach to evaluate the behavior of entire concrete structures in fire is to employ validated computational modeling approaches.

Two main modeling approaches may be used for concrete structures in fire: (1) sequentially coupled thermal-stress analysis and (2) fully-coupled thermal-stress analysis. In the sequentially coupled thermal-stress analysis approach, the heat transfer analysis is carried out first to determine temperature distributions within the concrete elements throughout the duration of fire 
exposure. The structural analysis is then performed for the structure under the applied load, and the changes in the mechanical properties and thermal deformations of the structure due to changes in temperatures, are accounted for as the structural analysis proceeds in time. In this approach, the thermal field is assumed not to be influenced by the structural response to heating. Most current numerical modeling tools customized for fire use this sequentially coupled approach. A key issue in this method is that, because the interactions between thermal and structural analysis are ignored, if spalling occurs during fire this is not accounted for despite the considerable changes in temperature (and mechanical stress) distributions that result. In fully coupled thermal-stress analysis, both heat transfer analysis and structural analysis are carried out at each time step for the duration of the fire exposure. This method can thus capture the thermal/mechanical interaction effects; however, this is a much more computationally expensive approach and it is rarely used in practice (and it is not currently possible to credibly predict heatinduced spalling in any case).

Critically, computational modeling approaches for concrete structures in fire need to be validated using experimental data that adequately represent the behavior of real structures in real fires; such validation data are effectively non-existent at present, even at reduced scale. Furthermore, despite considerable efforts expended in developing numerical models and computational tools for concrete structures' response to fire, such tools have not become easily accessible to the practicing engineers, particularly as compared to the available numerical models used for analysis of concrete structures' behavior at the ambient temperature. Computational tools for concrete are much less developed and have far inferior validation than those used for structural fire analysis of steel structures (possible reasons for this are noted in Section 2.3.1).

One of the existing computational tools customized for response evaluation of structures in fire is the SAFIR numerical analysis code [Franssen, 2011]. SAFIR applications have been partially validated for different structural systems, including some validation using results of tests on concrete structural elements [SAFIR, References 2014]. SAFIR has also been employed in simulations used during hybrid fire testing [Mostafaei, 2013], wherein an entire 6-story concrete structure was simulated in fire using a substructuring approach by coupling a physical substructure (an isolated test specimen within a standard column fire resistance furnace) and a numerical model substructure (real-time computational model built within SAFIR). Another customized computer program for structural modeling in fire is Vulcan [Huang et al., 2003a, b, c]. Vulcan is mainly employed for numerical analysis of steel-concrete composite slabs constructed within steel framed structures, although it has also been used in research of concrete structures in fire [e.g. Huang, 2010].

In recent years, Kodur and colleagues [e.g. Kodur and Dwaikat, 2011; Dwaikat and Kodur, 2010; Kodur et al., 2009] have published a number of papers applying a 'macroscopic finite element model' for the analysis of concrete structural elements of various types in fires. Included in many of these studies is a purely hygro-thermal concrete spalling model, which is used to study the impacts of spalling on the structural response of concrete elements in fire. The spalling model is useful for purposes of illustration but clearly needs further work to include the latest understanding on factors influencing spalling (see below).

Custom computational analysis codes have also been developed to model individual concrete structural elements reinforced or strengthened with FRP materials in standard furnace tests [e.g. 
Bisby et al. 2005], however these are research tools and are not suitable for use in design. Furthermore, such models are element based and have not generally been incorporated into numerical modeling to obtain the entire structural response. Commercial finite element computational modeling tools such as ABAQUS [Abaqus FEA, 2010] or ANSYS [2014] have also been used by various researchers and practicing engineers to simulate the response of concrete structures in fire.

The main shortcoming of all of the above numerical tools is a lack of proper validation against data from full-scale whole structure tests. Currently available validation data are based almost exclusively on single-element standard fire resistance tests, and as already noted such tests do not simulate whole structures.

\subsubsection{Material Models}

Concrete displays complex behavior under load at elevated temperatures. To perform accurate computational analysis of concrete structures in fire, validated material models are required for both thermal and mechanical properties of all materials involved.

Many studies have been performed over several decades in an attempt to understand and characterize the thermal properties of concrete at high temperatures; for instance concretes' thermal conductivity and specific heat [e.g. Schneider, 1986; Bazant and Kaplan, 1996; Neville, 1997; Harmathy, 1993; Flynn, 1999]. The thermal properties of concrete are highly temperaturedependent and vary widely depending on concrete density, moisture content, and aggregate type. Eurocode 2 [CEN, 1992] provides detailed variable thermal property models for concrete that have been widely used in computational fire analysis of concrete and steel-concrete composite elements and structures [Franssen, 2011], and a summary of available thermal models for concretes of different types has been presented by Flynn [1999].

Determining the variations in mechanical properties of concrete at elevated temperature is essential for computational modeling of concrete structures. Most important are the stress-strain relationships (in tension and compression) of the concrete and reinforcing (or prestressing) steel at different temperatures. For reinforcing and prestressing steels reliable mechanical properties and high temperature constitutive models are available from various sources [e.g. Harmathy, 1993; Buchanan, 2002; Gales et al., 2009; CEN, 2004]. For instance, Eurocode 3 [CEN, 2005] provides stress-strain models for structural steel materials that are used in most current numerical modeling tools. Some authors [e.g. Gales et al., 2009] have suggested a need to explicitly account for creep straining of steel at elevated temperatures in computational structural fire modeling. The research community appears divided on this issue, with most researchers appearing to feel that it is sufficient to implicitly include creep strains (as in the relationships provided in the Eurocodes [CEN, 2003, 2004]) when modeling the response of steel at elevated temperatures.

For concrete materials, numerous studies have been carried out to understand the variations in mechanical properties at elevated temperature [Schneider, 1985; Fletcher et al., 2007; Buchanan, 2002; Khoury 2000, Youssef and Moftah, 2007; Bamonte and Gamarova, 2014]. A unique mechanical property of concrete at high temperatures is its so-called 'transient strain,' which applies to concrete only when loaded and heated for the first time [Mindeguia et al., 2013; Khoury et al., 1985]. Ignoring transient strain in numerical modeling of concrete, particularly for 
elements under compressive stress may result in erroneous results [Khoury, 2000; Lange et al., 2014], although again the research community appears to be divided on this issue. Stress-strain relationships for concrete at elevated temperature are mainly dependent on the concrete temperature, initial concrete compressive strength, density of concrete (e.g. lightweight or normal weight), type of aggregates (e.g. siliceous versus carbonate), and the initial applied stress. A recent summary is given by Bamonte and Gambarova [2014].

Of particular interest are material models for describing the tensile behavior of concrete at elevated temperature, since this is not well known and presents significant computational challenges. Most computational modeling approaches for concrete in fire make use of 'smeared cracking' models, which are unable to precisely describe the formation and widening of discrete concrete cracks. Such models are, by definition, unable to precisely predict steel reinforcement strains in the area of discrete cracks, which in practice could lead to tensile rupture of reinforcement or to reductions in shear carrying capacity due to loss of aggregate interlock. Considerable additional research is needed to better understand the properties of concrete in tension at elevated temperature, and to develop computational models that can credibly capture the necessary behaviors and reliably predict failures.

Recovery and retention of mechanical properties of concrete both during and after cooling are also not well known; these have particular importance for modeling the response of concrete structures in real fires, where properly accounting for cooling phase contractions and structural interactions is essential [Concrete Society 2008].

The variation in thermal and mechanical properties of high strength concrete and high performance concrete have also been studied at elevated temperatures [e.g. Kodur and Sultan, 2003; Phan, 1996; Kulkarni et al., 2011]. This work has highlighted that spalling is the main problem for high strength concretes during fire.

\subsubsection{Spalling}

Spalling, in its most general form, is defined as the violent breaking off of pieces from the surface of concrete elements when exposed to rising temperatures. Spalling takes several different forms and can severely affect the load carrying capacity of a concrete structure due to a reduction of cross section, changes in the mechanical load distribution, and a reduction in or the overall loss of the thermal protection to the steel reinforcement or prestressing. It is a complex phenomenon involving time and temperature dependent mechanical stresses, temperature diffusion, and differential thermal stresses, moisture movement, and microstructural and chemical changes with increasing temperature. A given concrete's propensity for spalling depends not only on its material parameters (e.g. concrete mix composition, the nature of the mix constituents and their specific material properties), but also on structural parameters (e.g. geometry, boundary conditions, restraint) and applied mechanical and thermal loads.

Heat-induced spalling appears to exhibit a stochastic nature and experimental results are regularly contradictory. Whether this is due to genuine randomness or to insufficiently controlled testing methods remains unclear. However, major trends in factors increasing the risk of spalling can generally be stated. Spalling risk tends to increase (however with some exceptions in the literature) with increases in compressive strength, compactness of the concrete, rate of heating, moisture content, and imposed compressive load [Meyer-Ottens, 1972; Copier, 1979; Jensen et 
al., 1987; Connoly, 1995; Ali et al., 2001; Mindeguia, 2009; Jansson and Bostrom, 2013]. An exhaustive list of factors which are known to influence propensity for heat induced spalling has been presented by Maluk [2014] and is reproduced later in Section 3.2.2.

Many research studies have also shown that the addition of a small amount of PP microfibers into the fresh concrete mix decreases spalling risk, although the mechanisms by which the fibers reduce propensity for spalling are not well known [Diederichs et al., 1995; Shuttleworth, 2001; Bilodeau and al., 2004; Salomao and Pandolfelli, 2007].

Two main mechanisms promote spalling and are considered in the literature; these are used in most computer simulations to predict spalling. The first mechanism considers the thermal stresses induced by thermal gradients, differential thermal expansion, and the induced restrained deformations in heated concrete. The second mechanism attributes spalling to a build-up of pore pressure due to evaporation of free moisture within the concrete microstructure; this is sensitive to the compactness (density, permeability, porosity) of the concrete and its moisture content [Harmathy, 1965; Kalifa et al. 2001]. Harmathy [1965], among others, has proposed that the pore pressure level in heated concrete is increased by the formation of a liquid water saturated layer termed the 'moisture clog'. This clog results from moisture transport (due to pressure gradients induced by heating) and condensation in the inner cooler zones within the concrete. More recently, a third mechanism has been proposed [Jansson 2008]. This mechanism considers that spalling takes place within the moisture clog layer due to a combination of a reduction of the concrete strength (due to its wet, hot state) and the absence of drying creep.

Several coupled thermo-hygro-chemo-mechanical codes attempting to simulate the stress state as a consequence of both thermo-hygral and thermo-mechanical processes are described in the literature [e.g. Gawin et al., 2006; Zeiml et al., 2008; Lottman et al., 2013; Ožbolt and Bošnjak, 2013]. However, even these advanced models, which take into account a large number of factors using a number of mass and energy balance equations, are unable to accurately predict spalling for a given mix under a given mechanical stress and heating regime.

Since spalling depends not only on material parameters but also on structural parameters, it is necessary to repeatably and accurately reproduce realistic conditions (e.g. geometry, boundary conditions, applied mechanical and thermal loads, etc.) when experimentally studying spalling of different concrete mixes.

\subsection{Performance-Based Design (PBD) Practice}

Structural design for fire is currently concerned primarily with the provision of 'fire resistance' to protect against loss of life and spread of fire to adjacent buildings. Fire resistance has historically been defined as the time of exposure to the standard fire [e.g. ASTM, 2011; ISO, 1999] during which an isolated structural element tested in a standard fire testing furnace can resist failure due to loss of load bearing capacity under service loads, unacceptable temperature rise at the unexposed face, or passage of flames or hot gas through the element. This approach to fire resistance design based on furnace testing is unrealistic and irrational for reasons too numerous to discuss here [Bisby et al., 2013]. During the 1990s, the emergence of performancebased structural fire design codes, most notably in Europe [e.g. CEN, 2004, 2005], enabled the use of more rational approaches to fire resistant structural design. This allows designers to take any approach they wish to meet the performance objectives for the structure, and thus both the 
fire and the structural response can be rationally assessed and structural performance quantified and compared against performance objectives. In practice this often means that structures are engineered to perform 'at least as good' as structures that meet the historical prescriptive guidance (however problematic this might be in many cases).

\subsubsection{Should the Concrete Industry Care?}

Beginning in the early 1990s, the European steel industry devoted considerable funding and effort to understanding the whole structure response of steel buildings in fire; the goal was to demonstrate the ability to performance engineer (primarily through the development of validated computational modeling tools) steel structures for fire, and to permit reductions in passive fire protection of steel structures. A large number of large-scale non-standard fire tests (see Bisby et al., 2013) led to the development and validation of structural fire design software specific to steel-framed buildings (e.g. www.vulcan-solutions.com).

The most significant result of this dedicated research effort has been development of an ability to justify (sometimes using computational modeling) removal of passive fire protection from steel framed structures, leading to market advantages in building construction as compared with alternative building materials and systems. Conversely the concrete industry has made little effort to capitalize on PBD in structural fire engineering and has not devoted similar resources to research in this area. This is likely because - as already noted and notwithstanding the problematic structural responses noted above that are sometimes observed for concrete structures in fires - in the absence of heat induced cover spalling, concrete structural elements tend to perform well in furnace tests as compared with unprotected steel elements.

One result of the above is that there is little obvious economic benefit from PBD for fire for concrete structures. Hence there is little incentive to invest in detailed and costly testing programs to investigate and/or demonstrate the possible benefits of rationally accounting for full structure interactions and alternative load carrying mechanisms in reinforced or prestressed concrete structures during fire. Research on concrete in fire tends to receive support only when potential problems are identified (as in the case of funding to study heat induced cover spalling in the wake of the 1999 Mont Blanc and 1996 Channel Tunnel fires); rarely in support of more rational or optimized structural design.

\subsubsection{Practical Application of PBD}

For the reasons noted above, practical application of PBD for fire for reinforced concrete structures appears not to be widely implemented. Indeed, the authors are not aware of any reinforced, prestressed, post-tensioned or precast concrete structures that have ever been designed on the basis of a true PBD for fire approach. Specific cases of PBD of concrete structures in fire appear to occur only very rarely and in cases where existing concrete structures fail to meet the simplified prescriptive rules given in design codes. For instance, some historic concrete structures may fail to meet contemporary concrete cover requirements; in such cases a performance-based analysis may be used to justify the safety of non-compliance with the code.

\subsubsection{Regulatory Hurdles}

Any application of performance-based structural fire engineering requires a regulatory and building approvals system (i.e. both processes and stakeholders) that explicitly permits such approaches. However, formal permissibility of PBD of structures for fire is a necessary but non- 
sufficient condition for PBD to occur in real projects. In practice, even in jurisdictions where PBD for structures in fire is explicitly permitted by the building regulations (for instance in England and Wales under the Approved Document B [DCLG 2013], implementing PBD for fire can be difficult because those individuals involved in the regulatory and approvals process are not sufficiently technically competent to credibly assess detailed performance based (so-called 'fire engineered') designs; and also because the regulatory system is unused to the formalized process of third-party expert reviews of fire-engineered designs that are needed in these cases.

Thus, in addition to the technical challenges associated with credibly performing performancebased structural fire engineering of concrete elements and structures, considerable economic challenges specific to concrete structures exist (as discussed in Section 2.3.1), as well as considerable social/regulatory/competence challenges associated with properly managing, verifying, and approving performance-based designs.

One specific jurisdiction that appears to have effectively implemented performance-based design of structures for fire is London, UK (and more recently other UK cities). In these jurisdictions, steel framed multi-story buildings in particular can be structurally fire engineered to ensure optimized and robust whole structure response to fire. This appears to have been enabled in practice by a combination of:

1) building codes that explicitly permit the use of a PBD approach to building design for fire;

2) technically competent structural fire engineering consultancies;

3) technically competent and fully engaged fire and rescue services with in-house fire engineering experts who can advise regulators and approving authorities in areas where technical competence is lacking; and

4) a credible expert third-party review system through which performance-based fireengineered designs can be assessed and verified before being implemented.

In most jurisdictions, one or all of the above conditions may be missing, and in such cases effective application and implementation of PBD of structures for fire may be very difficult indeed.

\section{Knowledge Gaps}

The preceding sections have briefly outlined the current state-of-the-art in testing and analysis for the performance in fire of reinforced concrete structures. On this basis the following sections outline knowledge gaps, with a particular emphasis on those gaps that are relevant to PBD of concrete structures for fire.

\subsection{Full-Scale Experiments}

Section 2.1 outlined available knowledge from large-scale experiments and real fires in concrete buildings. The following gaps in knowledge were identified or are considered relevant. 


\subsubsection{Fire Exposure}

For various reasons, the standard temperature-time curve is not representative of a real fire in a real building [Bisby et al., 2013]. To truly understand the response of concrete buildings in fires, tests of concrete structures and structural elements are required under a range of credible design fire exposures. This may require experimental consideration of localized, compartmentalized, horizontally and/or vertically travelling, smoldering, or hydrocarbon fires, all of which have the potential to introduce structural actions or interactions that are not captured by standard fires, and all of which may have particular importance for different types of concrete structures (e.g. localized heating or travelling fires possibly being critical for UPT slabs, or high heating rates in hydrocarbon fires probably being more critical for spalling-prone concretes).

\subsubsection{Structural Interactions and Asymmetry}

The limited data available from large-scale fire tests and experience of real fires in concrete buildings cover a small fraction of all possible structural configurations. Structural fire tests conducted to date have generally studied regular, symmetric, idealized structures. Modern structures increasingly make use of irregular floor plates with varying span lengths, bay sizes, mixed construction materials (e.g. hollow core concrete slabs on cellular steel beams), etc. The influences of irregular plans and complex forms need to be investigated and understood before PBD of concrete for fire can be performed with confidence. This issue has received limited attention (through modeling) for steel-framed buildings [McAllister et al., 2012; Flint et al., 2013]; however, no serious attempts appear to have been made to understand similar issues for concrete buildings.

\subsubsection{Failure Localizations}

When concrete structures 'fail' in fires it is rarely for reasons that would be expected based on standard furnace testing. Failure is often initiated by localized failures or structural distress, such as discrete or splitting cracking in concrete, rupture of tensile steel reinforcement, connection or anchorage failure, shear or punching shear failure of concrete slabs, rupture of prestressing tendons, secondary moments or unexpected shear forces exerted on columns due to lateral expansion of floor plates, heat-induced concrete spalling, etc. These types of failure localizations fundamentally depend on the three dimensional, whole structure interactions during both heating and cooling; they cannot be simulated by conventional furnace testing. Large-scale non-standard structural fire tests on whole buildings are the only defensible means by which to observe and quantify the full suite of possible failure modes; and to then incorporate these failure modes into validated computational models to be used in PBD for fire.

\subsubsection{Compartmentation and Fire Spread}

The vast majority of large-scale structural fire testing (particularly non-standard testing) has focused almost exclusively on collapse prevention as the core performance objective; little attention has been paid to other fire safety goals such as maintaining fire compartmentation under large deformations. Considerable floor plate deflections (both vertical and lateral) and wide cracks have been observed in concrete buildings (Section 2.1). The impacts of vertical and lateral deformations of structural frames on fire stopping and both horizontal and vertical compartmentation should be studied to preserve life safety in concrete buildings, which are becoming ever more reliant on defend-in-place life-safety strategies (particularly in high rise construction). Furthermore, many fire engineers express concern regarding the quality of 
installed fire stopping between floors in multi-story buildings. Large-scale non-standard fire tests should therefore be considered to evaluate the structural impacts of fires burning simultaneously on more than one floor.

\subsubsection{Cooling Phase Behavior and Residual Capacity}

A number of localized structural failures have been observed during the cooling phase of both real fires in real buildings, in particular of concrete flat plate [Annerel et al., 2013] and hollow core slabs [de Feijter and Breunese, 2007], and non-standard heating regimes in large-scale structural fire experiments. Structural actions resulting from creep, localized and/or global plastic deformation, and thermal contraction and restraint during cooling all need to be better understood if designers are to credibly design for burnout natural fire exposures while preventing structural collapse. The importance of construction details, such as proper anchorage and grouting of hollow core slabs or other precast concrete elements, is also relevant to ensure a robust response during cooling. The residual structural capacity of fire damaged concrete structures that have undergone large deformations or experienced cracking and spalling is also not well known. The ability to predict the response of concrete structures during cooling is in its infancy.

\subsubsection{Instrumentation and Measurement}

More complete data are required from both standard and non-standard large-scale structural fire tests. Better information, in particular on strains and displacements, during testing is required to develop a more accurate understanding of response and to provide the data that are essential for credible computational model development, validation, and verification. Measurement of strain at high temperature is particularly problematic, and the development of accurate and costeffective high temperature strain measurement instrumentation would yield substantial benefits for validation of structural fire models.

\subsubsection{Data for Model Calibration, Validation and Verification}

Experimental data from realistic large-scale tests on concrete structures of various types (e.g. flat plate, UPT, hollow core, etc.) are essential for calibration, validation, and verification of both existing and emerging computational modeling techniques to simulate the response of concrete structures and structural elements in fire. This of course assumes that a relevant driver can be identified to ensure that PBD of concrete structures becomes a practical reality. The requirement for test data holds both at the material level and at the structural level. Complete hightemperature constitutive material models for concrete are needed to generate reliable input data for models and to better understand system response to fire and possible failure modes [Kodur et al., 2011]. For instance, the recovery of mechanical properties of concrete during cooling is not well known.

\subsubsection{Structural Optimization and the Use of New Materials and Systems}

Modern concrete structures are increasingly optimized, in many cases by the use of sophisticated computer analysis, in an attempt to reduce the mass, cost, environmental impact, carbon emissions, and embodied energy in buildings. Modern concrete structures also increasingly make use of high strength, high performance, and/or self-consolidating concrete, all of which have an increased propensity for heat induced spalling and suffer more severe reductions in compressive strength on heating as compared with historical concrete materials. Modern concrete buildings 
also increasingly make use of efficient structural systems such as unbonded post-tensioned flat plate slabs and precast hollow core slabs, the responses of which during fire are not well known in real buildings.

\subsubsection{Connections and Post-Installed Anchors}

A range of studies has already been performed on connection performance in fire for steel structures [e.g. Yuan et al., 2011]. However, there has been little effort to understand connection performance in concrete structures and to develop and validate computational modeling capabilities to predict connection response and suggest best practice guidance to ensure structural robustness in fire. Only Bailey and Lennon [2008] have experimentally studied details for the connection of precast concrete elements in buildings to ensure robust performance in fire. It is noteworthy that useful guidance on these issues is available in the seismic design literature [e.g. Ghosh, 2001] where robust connection design is essential; it may be appropriate to develop similar provisions for structural robustness of certain types of concrete structures in fire (precast concrete construction in particular). Research has also been performed on the response of postinstalled anchors (e.g. epoxy bonded adhesive anchors for concrete) at elevated temperature; this has shown potential problems for such anchors at only moderately increased temperatures [Pinoteau et al., 2013].

\subsubsection{Explosive Spalling of Concrete}

Structural fire design of concrete structures relies on the assumption that the concrete will not spall during fire. This assumption is based largely on data from large-scale standard fire tests of concrete elements tested in isolation in furnaces during the past 70 years [Bisby et al., 2013]. However, there is legitimate concern [Maluk, 2014] that modern concrete structures, which incorporate concrete mixes with considerably higher concrete strengths, are more susceptible to spalling than was historically the case. Whilst preliminary guidance on the means by which spalling can be addressed by designers is available in, for instance, the structural Eurocodes [CEN, 2004], additional research is needed to understand the respective roles of the various factors which are known to increase concrete's propensity for spalling [ArupFire, 2005; Bailey and Khoury, 2011] such that credible preventative actions can be taken. For instance, more specific and defensible guidance is needed on the requirement to add a certain amount of PP fibers to the concrete mix to prevent spalling. Interactions in real structures have the potential to significantly influence development of spalling in a fire, so large-scale tests under natural fires (i.e. variable time histories of heat flux) are needed to truly understand the propensity for, and the whole structure consequences of, spalling in concrete structures.

\subsection{Structural Fire Modeling}

\subsubsection{Material Models and Numerical Modeling}

The main knowledge gaps in current material models and numerical modeling tools for reinforced and prestressed concrete buildings, tunnels, and bridges can be summarized as follows:

- Current numerical modeling tools need to be validated for whole-structure performance to ensure system effects such as thermal expansion, support and restraining conditions, membrane actions, size effects, discrete cracking, rupture of tensile reinforcement and shear and structural lateral deformations are captured properly in the analyses. 
- Models need to be developed to study the response of different types of concrete structural connections, in particular for structures assembled from precast concrete elements.

- Material and computational response models need to be improved to be able to credibly predict and capture the effects of concrete spalling so that both the heat transfer and structural analyses can be performed with confidence. This must explicitly include both the effects of pore water pressure in the concrete and the development of differential thermal stress due to thermal strain (and possibly other, as yet unknown, factors which may significantly influence spalling).

- Material and computational models need to be improved to properly capture the cooling phase response and to determine the concrete residual material properties using entire structure testing to capture the potentially important system effects.

- For critical structures, such as certain types of infrastructure (notably concrete bridges and tunnels) property protection and rapid reoccupation may be essential. Current models are not validated at large-scale to obtain quantifiable structural damage levels and thresholds. Models should be developed that are useful within the context of a probabilistic performance-based framework for concrete structures in fire similar to those currently applied within the seismic design community [Lange et al., 2014]. Such an approach will also require the development of intensity measures, damage indices, performance limits, and quantification of consequences of damage [Rush et al., 2014].

- Material models and numerical modeling tools need to be updated as new structural materials emerge and find their way into practice, e.g. ultra high performance concrete, concrete structures reinforced or prestressed with FRP bars, and others [Terrasi et al., 2012].

- A test-model based certification protocol should be developed by which manufactures and producers of concrete structural materials could receive a certificate that shows performance of their product in an entire structure simulation. This could be performed by running an entire structure test for a worst-case fire scenario and estimating other identified fire scenarios using numerical modeling, after it is validated with the worst case scenario. The ability to perform such analyses is some years away.

- Hybrid testing could be developed for tests of large structures. For instance, if a ten-story structure needs to be tested in fire; the first two stories could be built and tested in the lab and the remainder of the structure, i.e. the upper stories, could be simulated simultaneously using a numerical modeling approach. This would reduce the cost of the experimentation and the required lab space, and may be possible within NIST's laboratory facilities [NIST, 2013].

\subsubsection{Spalling}

As noted above, a considerable research has been performed to investigate parameters affecting heat induced concrete spalling [Maluk, 2014]. Numerous candidate test methods have been derived and numerous attempts at computational predictive modeling have been made. However, additional research is needed before the factors leading to spalling are fully understood, or before 
credible predictive models can be put forward. All of the following (sometimes interrelated) factors are thought to increase propensity for spalling:

- Increased concrete compressive strength

- Increased in-service stress condition and moisture content

- Certain types of cement

- Certain types and shapes of aggregates and their gradation

- Fresh concrete slump or slump flow (i.e. self-consolidating, pumped, etc)

- Absence of PP fibres (PP fibre dose, diameter, aspect ratio, and distribution are all relevant)

- Absence of steel fibres (dose of steel fibres is relevant)

- Certain other concrete admixtures or supplementary cementing materials (e.g. fly ash, silica fume, water reducers, air entraining agents, etc)

- Certain methods of manufacture (e.g. precast, prestressed concrete)

- Certain internal reinforcement types, ratios, geometries

- Certain sizes/thicknesses/shapes of structural elements (larger elements typically, but not always, are assumed to be more prone to spalling)

- Certain fire exposure regimes (heating rate, fire fighting operations, cooling, etc - more rapid heating typically, but not always, is assumed to be more conducive to spalling)

Given the range of influencing parameters and the complexity of the potential thermal, mechanical, physical, and chemical drivers of spalling processes, some researchers (e.g. Maluk, 2014) have suggested that what is needed, rather than a detailed understanding of and ability to computationally predict spalling, is a means to experimentally characterize and quantify propensity for spalling of different candidate concrete mixes under different conditions of heating and thermal-mechanical stresses, with a view to eventually guaranteeing that explosive spalling will not occur for a suitably designed mix (likely by addition of an optimized dose of PP fibers); this capability is likely some years away.

\subsection{Performance-Based Design Practice}

There do not appear to be any significant knowledge gaps specifically with respect to PBD practice for concrete structures in fire, rather there is a lack of obvious drivers or incentives. As already noted, PBD of concrete structures is not widely implemented in practice, largely for nontechnical reasons, including:

- Concrete structures are widely considered to be 'inherently fire resistant' and even when specific concerns for certain types of buildings are voiced (e.g. spalling of high strength concrete columns, failures of precast prestressed hollow core slabs, tendon rupture in UPT construction) these are widely ignored due to a lack of tangible evidence (i.e. few major failures of concrete buildings).

- There are currently few obvious economic benefits of PBD for concrete. Concrete structures are unlikely to change substantially when subjected to PBD because minimum 
member dimensions are typically governed by strength and serviceability criteria, and minimum concrete cover is typically governed by bond development or corrosion prevention. Therefore PBD for concrete rarely enables further optimization or economic savings.

- An effective regulatory structure to enable PBD is not in place in most jurisdictions. Many Authorities having jurisdiction (AHJs) lack the technical expertise to assess and approve PBD submissions, and rigorous, formalized third party review procedures are not widely in place to allow credible external reviews of PBD.

- Historical inertia in the construction industry is strong, and change is typically resisted.

It is not clear at present how (or why) to address any of the above factors.

\section{Actions and Prioritization for PBD of Concrete Structures}

Based on the above discussions, an attempt is made in this section (with approximate temporal sequencing) to outline a possible future research strategy with respect to large-scale testing of reinforced concrete structures in support of PBD. This future research strategy relies on the following three fundamental assumptions:

1) suitable drivers can be demonstrated to promote funding of ongoing experimental and computational work in this area; these may be driven either by safety or property protection concerns (challenges) or by economic, sustainability, optimization, or again property protection goals (opportunities);

2) sufficient funding is made available to support the proposed research activities; and

3) the international concrete construction, fire testing, research, and regulatory communities work together to address the considerable challenges noted below, recognizing and openly acknowledging the considerable unknowns regarding the performance of concrete structures in fire, as well as the serious limitations of current approaches to structural fire testing and rational design for fire.

In considering the research program presented below, two key issues should be borne in mind at all stages:

1) All of the experiments suggested below should be modelled using the best available current modeling tools before they are performed in order to: (a) design the test samples, elements, or structures; (b) define the mechanical and thermal loads that the samples, elements, or structures should be subjected to; and (c) define the specific types and locations measurements to be made before, during, and after experiments are performed. This is an essential requirement to advance the science in this overall area.

2) Heat induced spalling of concrete can induce large differences in the thermal and mechanical responses of concrete materials, elements, and structures to fire. Attempts should be made to avoid spalling, both in the experiments suggested below and in practice, since spalling introduces uncertainties that are very difficult to rationally account for in design. Experiments with spalling should be explicitly separated from those without 
spalling. To guarantee that no spalling will occur, moisture content in the tested samples, elements, structures should be as 'realistic' as possible during testing, and PP fibers should be introduced in concretes mixes. It is noteworthy that the in-service moisture level of concrete in buildings is not well known, and research may be warranted in this area.

\subsection{Zero to Three Years}

\subsubsection{Research Needs Identification}

The first step in any future research plan must initially be to engage with all of the various stakeholders in the design, construction, and use of concrete buildings (and infrastructure) in order to determine:

- what legitimate, specific safety concerns (challenges) exist for concrete structures in fire; and

- what practical drivers (opportunities) exist for PBD of concrete structures.

At present there is a striking lack of open debate and dialogue within the concrete building community on most of the issues discussed in this report, and this will need to change for progress to be made.

\subsubsection{Materials Characterization}

The first research priority action is to improve existing material thermal and constitutive models; these are needed as inputs to any computational modeling activities. This includes:

- More reliable and complete thermal models for concretes of various types under various transient heating (and cooling) rates. Thermal property data are currently available but there is considerable scatter in the data and in general it is not clear which thermal properties should be assumed for a precise analysis. This research need holds for both historic and emerging modern, high strength, high performance, self-consolidating, and/or fiber-reinforced concrete mix designs.

- More reliable and complete mechanical property models for concretes of various types under various combinations of stress (sustained, variable), temperature (heating and cooling), and time - these should account for the effects of transient thermal strains and should be validated using tests at the material and element levels. Research should be performed to determine if transient creep strains must be explicitly accounted for to accurately predict response under various loading and heating scenarios for various types of structural elements.

- More reliable and complete mechanical property models for reinforcing materials (e.g. mild steel reinforcement, prestressing steel, and alternative materials such as fiber reinforced polymer (FRP) bars, stainless steel, etc.) - these should also account for the issues noted in the previous point.

- The development and validation of a credible, repeatable, representative, and temporally and economically efficient test method for characterization of different concrete mixes' propensity for heat-induced spalling in fire. Such a test method is needed so that results from different international testing labs can be compared and contrasted, and so that 
workable and economical concrete mixes can be developed that offer a high level of confidence that heat-induced spalling will be avoided for all credible worst-case fire scenarios relevant to a given application.

\subsection{Three to Six Years}

\subsubsection{Small Scale Structural Elements}

Small scale tests on concrete structural elements are needed to provide basic validation data for computational modeling using the thermal and mechanical properties developed in years zero to three. Such tests should initially be performed on statically determinate structural elements, as is common for contemporary structural fire resistance testing; however with considerably more attention given to appropriate measurement of relevant parameters (e.g. temperatures, strains, deformations) than is typical in standard furnace testing. Test results should be compared against the results of pre-test (a priori) computational modeling, followed by model development/redevelopment where necessary.

Issues of particular interest in these tests (and modeling) could include the effects of:

- asymmetric heating;

- localized versus global heating;

- different heating (and cooling) scenarios and rates;

- sustained and varying load levels (since restraint to thermal expansion in a building during fire would result in time-varying stresses);

- effects of bond slip between internal reinforcement and concrete at elevated temperature; and

- possible formation of air gaps and differential thermal expansion in steel-concrete composite elements.

Assuming that a credible spalling characterization test method for concrete can be developed (see Section 4.1.2), spalling tests and associated modeling should be developed to account for and understand as many of the factors listed in Section 3.2.2 as possible. Some of the key issues include:

- mix design parameters (including possible PP and steel fibre inclusion, types, and doses);

- load levels and restraint to thermal expansion;

- specimen shape and size;

- heating scenario; and

- influence of reinforcement details on spalling.

Existing numerical models for spalling need to be improved and validated in two respects:

- Models to more accurately predict occurrence of spalling in concrete during fire are needed. Such models must account for the effects of moisture and thermal and mechanical stresses. Validation is required at both the single element and whole structure levels. 
- In cases where spalling cannot be avoided, models are needed to include the effects of spalling on structural response. This would include thermal and structural effects from changes in the geometry. Alternatively it may be possible to show that spalling is not important for certain types of structures.

There is some question as to whether validated predictive models for spalling will ever be developed, given the extreme complexities of the competing processes known to be involved.

\subsubsection{Large Scale Structural Elements}

Whole structure systems are typically statically indeterminate and incorporate numerous redundancies and alternative load paths (this is particularly true of cast-in-place concrete structures); however these are highly complex and potentially difficult to understand during whole structure fire tests. Thus, large-scale structural tests are suggested which sequentially increase the complexity of structural fire testing assemblies, eventually leading to whole structure testing in years six to nine.

While it is difficult to propose the precise tests required, since these will depend on the research outcomes from earlier stages of proposed work, the tests should interrogate as many of the following issues as possible (note again that a priori computational modeling should be performed in all cases, with a focus on demonstrating the ability to quantitatively capture the important structural actions and failure modes):

- $\quad$ structural continuity;

- vertical and lateral restraint to thermal expansion;

- thermal deformations on heating (and cooling) with an emphasis on understanding the interactions between arching and thermal bowing for concrete slabs of various span-todepth-ratios;

- shear and punching shear;

- membrane actions, including both compression membrane (arching) actions and tensile membrane (catenary) actions;

- two-dimensional (one-way acting) versus three dimensional (two-way acting) response of slabs;

- response of unbonded post-tensioned reinforcement (e.g. tendon rupture) and structural elements;

- response (and possibly connection) of precast concrete elements, probably with an initial focus on hollow core prestressed precast elements; and

- effects of discrete cracking (as opposed to smeared cracking) and possible rupture of internal reinforcement at large cracks (including the effects of smooth versus deformed steel reinforcement).

Once computational modeling capability is developed and validated against an appropriate range of tests, parametric modeling studies should be undertaken to understand and assess the overall whole structure response of various types of concrete structures. This work is needed to determine which types of whole structure tests will provide the greatest benefit, either in terms 
of enhancing the fire safety of a particular type (or types) of concrete buildings, or in terms of offering opportunities for economic, sustainability, or functionality enhancement of concrete building construction.

\subsection{Six to Nine Years}

\subsubsection{Whole Structure Testing and Modeling}

The testing and modeling studies proposed above logically lead to a small number of largescale whole structure tests of 'exemplar' reinforced concrete buildings. Such tests are essential to credibly validate and corroborate testing and modeling of materials, and small scale and large scale structural elements. Such tests also provide an opportunity to observe possible additional structural interactions and failure modes that may have been overlooked during smaller scale or single element testing.

It not possible at present to define the type(s) of building that might be tested on the basis of the research performed in years zero through six. Any large-scale whole structure testing of concrete buildings should be modeled a priori (as previously) and should seek to study the effects of:

- multiple stories and multiple structural bays;

- localized (or travelling) versus global fire exposure;

- optimized, contemporary structural arrangements (including concrete flat plates, high strength concrete columns, stud rails for shear reinforcement, post-tensioned slabs (bonded and/or unbonded), high span to depth ratios, etc.); and

- if deemed appropriate from the outcomes of earlier research stages, precast concrete flooring systems (including typical structural connections between precast elements).

Models must be carefully and sequentially validated for predicting whole-structure response to fire. In general, the concrete in fire research community should seek to emulate the body of research and modeling capability that has been developed by the steel in fire research community in the wake of the large-scale Cardington fire tests in the UK performed during the 1990s.

\subsubsection{Property Protection Methodologies}

Also of interest is research to study property protection aspects of concrete buildings both during and after severe fires. Tests and models are needed to allow engineers to quantify fire damage to concrete structures after different fire exposure levels. This would involve exposing structural elements or assemblies to natural fire exposures of various severities and durations, and subsequent testing to determine the damage levels obtained. Such testing and modeling would support the development of intensity measures, damage indices, performance limits, and quantification of consequences of damage, as discussed previously.

\subsubsection{Hybrid Testing}

In the long term, validated sub-structuring methods and models need to be developed for the purpose of very large whole structure testing, when a large part of the 'test structure' is modelled in real time while a smaller portion of the structure is physically tested. For validation of the technique whole-structure tests would be required. 


\subsubsection{Test-Model Based Certification Protocols}

A long-term goal is the development of a structural certification methodology based on the whole structure response. This would be an assessment method for the purposes of certification that would be based on performing validated, credible numerical modeling of a whole structure with some minimum (as yet unknown) requirement for structural fire testing and materials characterization. This methodology needs to be developed as the test data and models become available from the studies above. The method could also include a hybrid testing method for more complex systems.

\section{Opportunities and Sponsors for Collaboration}

For the reasons noted in Sections 2.3.1 and 3.3 it is difficult to identify obvious sponsors of research intended to further enable PBD of reinforced and prestressed concrete structures. An obvious exception to this is with respect to heat-induced explosive spalling of concrete tunnel linings and structures, where there is clear evidence from real fires of potential safety and economic hazards. Other potential hazards have been identified associated with e.g. unbonded post-tensioned construction [Gales et al., 2011a, b] or precast, prestressed hollow core concrete slabs [de Feijter and Breunese, 2007], however these are not widely perceived as significant problems due in part to an absence of observed widespread failures of real structures. Opportunities and sponsors for collaboration may include the following:

- The concrete production and construction industry (broadly construed):

Opportunities may exist to optimize concrete structures for structural fire performance and to demonstrate superior property protection for concrete structures as compared with steel structures (particularly those that have been fire engineered to enable removal of applied fire protection to slab soffits and secondary beams). The concrete industry should consider supporting research to better understand the performance of concrete structures in credible worst case (rather than standard) fire exposures, with a view to demonstrating the resilience and robustness of structural concrete as compared with other types of construction.

- Critical infrastructure: This includes energy infrastructure such as within the nuclear power industry, transportation infrastructure owners, and emergency services infrastructure, all of whom rely heavily on property protection in fire rather than simply needing to meet the regulatory requirements for life safety during a fire.

- Producers of high strength and high-performance concrete: Efforts are needed to reduce or prevent the propensity for heat-induced spalling during fire.

- Producers of steel and PP fiber materials: Related to the above, application of fiber materials in concrete have showed to be effective in reducing concrete spalling. There is a financial incentive to steel and PP fiber producers to support research in this area.

- Producers of novel reinforcing materials: This includes composite materials such as FRP rebars or prestressing for application in concrete structures. Difficulty in clearly demonstrating adequate fire resistance of FRP reinforced or prestressed concrete structures remains a deterrent to their use. 
- Authorities Having Jurisdiction (AHJs): Currently there is a lack of proper calculation guide or standard in most jurisdictions for performance-based design of concrete structures in fire. Engineers may choose to use performance-based method for design of structures when the owners require a higher level of performance, e.g. property protection or rapid recovery after a fire. However AHJs currently suffer a lack of access to tools for evaluation and approval of advanced designs.

- Government departments and research centers with mandates for preserving public safety: In some cases where legitimate safety concerns might be raised, government departments should consider public funding in support of research into PBD for the specific types concrete structures in question. This includes state, national, and international research funding agencies.

- Fire safety engineering consultancies: Engineering consultancies with specific capabilities in PBD of concrete have a vested interest in increased use of PBD tools, and should consider supporting research in this area in order to promote change within the structural fire engineering community.

\subsection{Possible Partners in The Americas (possible first contact names in brackets)}

Academic partners with specific interest in fire performance of concrete (alphabetical):

- Carleton University, Canada (J. Gales)

- Lawrence Technological University, USA (E. Jensen)

- Lehigh University, USA (S. Pessiki)

- Michigan State University, USA (V.K.R. Kodur)

- Queen's University, Canada (M. Green)

Academic partners with specific interest in structural fire engineering (alphabetical):

- Lakehead University, Canada (O. Salem)

- Princeton University, USA (M. Garlock)

- Purdue University, USA (A. Varma)

- University of Michigan, USA (A. Jeffers)

- University of Texas at Austin, USA (M. Engelhardt)

Academic Partners with a specific relevant interest in fire dynamics or fire safety engineering (alphabetical):

- California Polytechnic State University, USA (F. Mowrer)

- University of Maryland, USA (J. Milke)

- University of Berkeley, USA (C. Fernandez-Paello)

- Worcester Polytechnic Institute, USA (L. Albano)

Government or pseudo-government research/testing agencies (alphabetical):

- National Institute of Standards and Technology, USA (M. Bundy)

- National Research Council of Canada (H. Mostafaei) 
Other noteworthy potential partners (alphabetical):

- American Concrete Institute - Committee 216, USA (N. Lang, National Concrete Masonry Association)

- Cement Association of Canada (R. McGrath)

- National Concrete Masonry Association (N. Lang)

- Portland Cement Association, USA (S. Szoke)

- Precast/Prestressed Concrete Institute, USA

- Underwriters' Laboratories, USA

- Underwriters' Laboratories Canada (G.A. Nanji)

\subsection{Possible Partners in Europe (possible first contact in brackets)}

Academic partners with specific interest in fire performance of concrete (alphabetical):

- Brunel University London, UK (Z. Huang)

- Czech Technical University in Prague, Czech Republic (F. Wald)

- $\quad$ ETH Zurich, Switzerland (M. Fontana)

- Imperial College London, UK (G. Khoury)

- Instituto Eduardo Torroja, Spain (Á. Arteaga)

- Politecnico di Milano, Italy (P. Bamonte)

- Technical University of Denmark (DTU) (C. Hertz)

- Université de Cergy-Pontoise (A. Noumowe)

- University of Edinburgh, UK (L. Bisby)

- University of Ghent, Belgium (L. Taerwe)

- University of Innsbruck, Austria (R. Lackner)

- University of Liege, Belgium (J-M. Franssen)

- University of Manchester, UK (M. Gillie)

- University of Naples Federico II, Italy (E. Nigro)

- University of Padua, Italy (B. Schrefler)

- Université de Pau et Pays de l'Adour, France (J-C. Mindeguia)

- University of Ulster, UK (F. Ali)

- Vienna University of Technology, Austria (M. Zeiml)

Academic partners with specific interest in structural fire engineering (alphabetical):

- Instituto Superio Tecnico Lisboa, Portugal (J. Correia)

- University of Coimbra, Portugal (A. Correia)

- University of Sheffield, UK (I. Burgess)

- University of Aveiro, Portugal (P. Villa Real)

Academic Partners with a specific relevant interest in fire dymanics or fire safety engineering (alphabetical):

- Delft University of Technology, Belgium

- Institut Nationale des Sciences Appliques (INSA) de Rennes, France

- Lund University, Sweden (P. Van Hees) 
Government or pseudo-government research/testing agencies (alphabetical):

- Architecture and Building Research Institute (ABRI), Taiwan (A. Lei)

- BRE Global, UK (T. Lennon)

- Centre d'Etudes des Tunnels (CETU), France

- Centre d'Etudes et de Recherches de l'Industrie du Béton (CERIB), France (F. Robert)

- Centre Scientifique et Technique du Bâtiment (CSTB), France (P. Pimienta)

- Centre Technique Industriel de la Construction Métallique (CTICM), France

- Efectis, Holland (R. de Feijter)

- Federal Institute for Materials Research and Testing (BAM), Germany (I. Vela)

- Netherlands Organisation for Applied Scientific Research (TNO), Holland

- SP Sweden (R. Jansson)

- Swiss Federal Laboratories for Materials Science and Technology (EMPA), Switzerland (E. Hugi)

Other noteworthy potential partners (alphabetical):

- AECOM, UK (K Anderson)

- Arup (Fire Engineering), UK (N Butterworth)

- BuroHappold FEDRA, UK (F Block)

- European Federation for Precast Concrete (BIBM)

- Promat (K Both)

- The Concrete Centre, UK (J Burridge)

\subsection{Possible Partners in Asia and Australasia (possible first contact in brackets)}

Academic partners with specific interest in fire performance of concrete (alphabetical):

- Chiba University, Japan (T. Hirashima)

- Gunma University, Japan (M. Ozawa)

- Hokkaido University, Japan (M. Henry)

- Kyoto University, Japan (K. Harada)

- Swinburne University of Technology, Australia

- The University of Tokyo, Japan

- Tongji University, China (J. Yu)

- Tsinghua University, China (L-H. Han)

- University of Canterbury, New Zealand (A. Buchanan)

- University of Queensland, Australia (J. Torero)

Government or pseudo-government research/testing agencies (alphabetical):

- Building Research Institute (BRI) of Japan

Other noteworthy potential partners (alphabetical):

- Cement Concrete \& Aggregates Australia (CCAA) (H.P.G. Bakes) 


\section{Technology Transfer and Influencing Practice}

\subsection{International Symposia}

The following international fire safety engineering symposia offer opportunities for technology transfer and influencing practice. In Structural Fire Engineering these include (in order of priority):

- $\mathrm{SiF}$ Movement.(http://www.structuresinfire.com)

- ACI 216 Special Sessions (http://www.concrete.org/Default.aspx?TabID=282\&committee_code=0000216$\underline{00})$

- International RILEM Workshops on Concrete Spalling due to Fire Exposure. (http://fire-spalling.sciencesconf.org/)

- Applications of Structural Fire Engineering Conference Series (http://fire.fsv.cvut.cz/ASFE13/)

Fire Safety Engineering:

- International Association of Fire Safety Science Symposia (http://www.iafss.org/symposium/)

- SFPE Conferences on Performance-Based Codes and Fire Safety Design Methods (http://www.sfpe.org/SharpenYourExpertise/Education/2014InternationalConfere nce.aspx)

- International Symposia on Tunnel Safety and Security (ISTSS) series (http://www.istss.se/en/about/Sidor/default.aspx)

- Interflam Conference Series (http://www.intersciencecomms.co.uk/html/conferences/Interflam/if13.htm)

- Fire and Materials Conference Series (http://www.intersciencecomms.co.uk/html/conferences/fm/fm15/fm15cfp.htm)

\subsection{Research-Active Codes and Standards Groups (alphabetical)}

- American Concrete Institute (ACI) - Committee 216 (http://www.concrete.org/Default.aspx?TabID=282\&committee_code=0000216$\underline{00)}$

- European Committee for Standardization (CEN) - Horizontal Group - Fire (http://eurocodes.jrc.ec.europa.eu/showpage.php?id=232)

- European Federation of National Associations Representing producers and applicators of specialist building products for Concrete (EFNARC) (http://www.efnarc.org/pdf/Testing\%20fire\%20protection\%20systems\%20for\%2 Otunnels.pdf)

- International Council for Research and Innovation in Building Innovation and Construction (CIB) - Working Group 14 on Fire (http://www.cibworld.nl/site/searchn/results.html?wtgtype=W\&wtgrid=1)

- Council on Tall Buildings and Urban Habitat - Fire and Safety Working Group 
(http://www.ctbuh.org/AboutCTBUH/WorkingGroups/FireSafetyGroup/tabid/98/1 anguage/en-GB/Default.aspx)

- International Federation for Structural Concrete (FIB) (http://www.fibinternational.org/comm-a-tgs)

- RILEM Technical Committee on Spalling of Concrete due to Fire (SPF) (http://www.rilem.org/gene/main.php?base=8750\&gp_id=309)

\subsection{Networks (in order of priority)}

- $\mathrm{SiF}$ Movement (http://www.structuresinfire.com)

- Concrete in Fire Forum (www.concretefireforum.org.uk)

- Steel in Fire Forum (www.steelinfire.org.uk)

- TUD COST Action TU0904 - Integrated Fire Engineering and Response (IFER) (http://www.cost.eu/domains_actions/tud/Actions/TU0904)

\section{Means for Coalition of International Research Partners}

The authors suggest that the best means for coalition of international research partners would be to 'piggy-back' on existing symposia, research-active codes and standards groups, and networks; most notably those already listed above.

\subsection{Joint International Research Funding}

Currently there is no obvious means for joint international funding between US and international research groups in the area of structural fire engineering. Such earmarked funding is urgently needed in order to support joint work between US researchers and international partners. Cofunding schemes between, for instance, the US National Science Foundation (NSF) and international science and engineering funding partners, as is routinely done in other research areas such as e.g. Materials Science, would be a positive first step in this regard.

\subsection{Potential Sponsors}

There are no obvious potential sponsors who might support coalition of research partners in the area of PBD for fire of concrete structures (for the reasons already noted).

\section{Conclusions}

This white paper has presented the current, international, state-of-the-art, large-scale experimental, modeling, and performance-based design (PBD) efforts related to structural fire resistance of concrete structures. The paper has addressed these topics with emphasis on research and development needs for large-scale experiments on fire resistance of structures to support performance-based engineering and structure-fire model validation; prioritizing those needs; phasing the needs in terms of near, medium and long term; identifying the most appropriate international laboratory facilities and collaborators available to address each need; identifying possible means to transfer the results of research to industry; and identifying a means for the coalition of international partners to review progress and exchange information on a regular basis. 


\section{References}

Abaqus FEA (2010) SIMULIA web site. http://www.appliedgroup.com/abaqus-fea/ (accessed $25^{\text {th }}$ March 2014)

Abraham O, De Robert X (2003) Non destructive testing of fired tunnel walls: the Mont Blanc Tunnel case study. NDT\&E International 36:418-441

Ali FA, O'Connor D, Abu-Tair A (2001) Explosive spalling of high-strength concrete columns in fire. Magazine of Concrete Research 53(3): 197-204

Almand K, Phan L, McAllister T, Starnes M, Gross J (2004) NISTIR 7133 - SFPE Workshop for Development of a National R\&D Roadmap for Structural Fire Safety Design and Retrofit of Structures. National Institute of Standards and Technology, Gaithersburg, MD, USA

Annerel E, Lu L, Taerwe L (2011) Punching shear tests on flat concrete slabs at high temperatures. Proceedings of the $2^{\text {nd }}$ International RILEM Workshop on Spalling due to Fire Exposure. $5^{\text {th }}-7^{\text {th }}$ October 2011, RILEM Publications S.A.R.L., Delft, pp 125-131

Annerel E, Taerwe L, Merci B, Jansen D, Bamonte P, Felicetti R (2013) Thermo-mechanical analysis of an underground carpark structure exposed to fire. Fire Safety Journal 57: 96106

ANSYS (2014) ANSYS web site. http://www.ansys.com/en_uk (accessed $25^{\text {th }}$ March 2014) ArupFire (2005) Fire resistance of concrete enclosure - Work package 2: Spalling categories. Authored for the Nuclear Safety Directorate of the Health and Safety Executive (HSE), London, UK

ASTM (2011) ASTM E119-11a: Standard methods of fire test of building construction and materials. American Society for Testing and Materials, West Conshohocken, PA, USA

Bailey CG (2002) Holistic behaviour of concrete buildings in fire. Structures and Buildings 152(3): 199-212

Bailey CG, Khoury G (2011) Performance of concrete structures in fire. MPA The Concrete Centre, UK

Bailey CG, Lennon T (2008) Full scale fire tests on hollowcore slabs. The Structural Engineer 86(6): 33-39

Bamonte and Gambarova (2014) Properties of Concrete Subjected to Extreme Thermal Conditions. Journal of Structural Fire Engineering 5(1): 47-62

Bazant ZP, Kaplan MF (1996) Concrete at High Temperatures - Material Properties and Mathematical Models. Concrete Design and Construction Series, Longman Group Ltd, UK

Beitel J, Iwankiw N (2008) NIST GCR 02-843-1 (Revision) - Analysis of Needs and Existing Capabilities for Full-Scale Fire Resistance Testing. National Institute of Standards and Technology, Gaithersburg, MD. USA

Berry R (1991) Restored concrete centre exhibits unique repairs. International Journal of Construction Maintenance and Repair 5(4): 36-39

Beyler C, Beitel J, Iwankiw N, Lattimer B (2007) NIST GCR 07-910 - Fire resistance testing for performance-based fire design of buildings. National Institute of Standards and Technology, Gaithersburg, MD, USA

Bilodeau A, Kodur VKR, Hoff GC (2004) Optimization of the type and amount of polypropylene fibres for preventing the spalling of lightweight concrete subjected to hydrocarbon fire. Cement and Concrete Composites 26(2): 163-174 
Bisby LA, Gales J, Maluk C (2013) A contemporary review of large-scale non-standard structural fire testing. Fire Science Reviews, 2(1) doi:10.1186/2193-0414-2-1

Bisby LA, Green MF, Kodur VKR (2005) Modeling the behavior of fiber reinforced polymerconfined concrete columns exposed to fire. Journal of Composites for Construction 9(1): $15-24$

Boam K, Copper D (1994) Midway links motorway viaducts; rehabilitation of a fire damaged structure. Structures and Buildings 104(2): 111-123

British Steel (1999) The behaviour of multi-storey steel frame buildings in fire. British Steel, Rotherham, UK

Buchanan AH (2002) Structural Design for Fire Safety. John Wiley \& Sons Ltd, UK

Cabrita Neves I, Brance FA, Valente JC (1997) Effects of formwork fires in bridge construction. Concrete International 19(3): 41-46

Calavera RJ (1992) Analysis and repair of a bridge damaged by fire in Granada, Spain. Proceedings of FIP Symposium, Budapest, v. 1, Environmental protection, strengthening and rehabilitation, pp. 383-398

CCAA (2010) Fire Safety of Concrete Buildings. Cement Concrete \& Aggregates Australia, St Leonards, Australia

CEN (2005) Eurocode 3: Design of steel structures - Part 1-2: General rules - Structural fire design. Brussels: European Committee on Standardization

CEN (2004) Eurocode 2: Design of concrete structures - Part 1-2: General rules - Structural fire design. Brussels: European Committee on Standardization

Concrete Society (2008) TR68: Assessment, Design and Repair of Fire-Damaged Concrete Structures. The Concrete Society, UK.

Carré H, Pimienta P, La Borderie C, Pereira F, Mindeguia JC (2013) Effect of compressive loading on the risk of spalling. $3^{\text {rd }}$ International RILEM Workshop on Concrete Spalling due to Fire Exposure, $25^{\text {th }}-27^{\text {th }}$ September 2013, Paris, France, MATEC Web of Conferences, v. 6

Connoly RJ (1995) The spalling of concrete in fires. PhD thesis, Aston University, UK

Copier WJ (1979) Spalling of normal weight and light weight concrete on exposure to fire. Report 24, Heron, Holland

DCLG (2013) Approved Document B - Fire Safety: Volume 2 - Buildings other than dwelling houses. Department of Communities and Local Government, UK

Diederichs U, Jumppanen U-M, Schneider U (1995) High temperature properties and spalling behaviour of high strength concrete. Proceedings of the $4^{\text {th }}$ Weimar workshop on highstrength concrete: material properties and design, hochschule fur architcktur und bauwesen (HAB), Weimar, Germany, October, pp 219-236

de Feijter MP, Breunese MP (2007) 2007-Efectis-R0894(E) - Investigation of Fire in the Lloydstraat Car Park, Rotterdam. Efectis, Holland

Dilek U (2007) Assessment of fire damage to a reinforced concrete structure during construction. Journal of Performance of Constructed Facilities, 21(4): 257-263

Dilek U (2005) Evaluation of fire damage to a precast concrete structure; non-destructive, laboratory, and load testing. Journal of Performance of Constructed Facilities, 19(1): 4248

Dwaikat M, Kodur VKR (2010) Fire induced spalling in high strength concrete beams. Fire Technology 46(1): 251-274 
Fletcher IA, Welch S, Torero JL, Carvel RO, Usmani A (2007) Behaviour of Concrete Structures in Fires. Thermal Science 11(2): 37-52

Fletcher IA, Welch S, Borg A, Hitchen N (2006) Performance of Concrete in Fire: A Review of the State of the Art, with a case study of the Windsor Tower Fire. Proceedings of Structures in Fire (SiF'06), Aveiro, Portugal

Flint G, Lamont S, Lane B, Sarrazin H, Lim L, Rini D, Roben C (2013) Recent lessons learned in structural fire engineering for composite steel structures. Fire Technology 49(3): 767792

Flynn DR (1999) NIST GCR 99-767 - Response of High Performance Concrete to Fire Conditions: Review of Thermal Property Data and Measurement Techniques. National Institute of Standards and Technology, Gaithersburg, MD, USA

Franssen JM (2011) User Manual for SAFIR 2011, A Computer Program for Analysis of Structures at Elevated Temperature Conditions. University of Liege, Department ArGEnCO Service Structural Engineering, Liege Belgium

Gales J, Bisby LA, Gillie M (2011a) Unbonded Post Tensioned Concrete in Fire: A Review of Data from Furnace Tests and Real Fires. Fire Safety Journal 46(4): 151-163

Gales J, Bisby LA, Gillie M (2011b) Unbonded Post Tensioned Concrete Slabs in Fire - Part I Experimental Response of Unbonded Tendons under Transient Localized Heating. Journal of Structural Fire Engineering,2(3): 139-154

Gales J, Bisby LA, MacDougall C, MacLean K (2009) Transient High-Temperature Stress Relaxation of Prestressing Tendons in Unbonded Construction. Fire Safety Journal 44: 570-579

Gawin D, Pesavento F, Schrefler B (2006) Towards prediction of the thermal spalling risk through a multi-phase porous media model of concrete. Computer Methods in Applied Mechanics and Engineering 195: 5707-5729

Ghosh, SK (2001) Seismic Design Provisions for Precast Concrete Structures. Structure, National Council of Structural Engineers Association, April 2001

Grosshandler WL (2003) The international FORUM of fire research directors: A position paper on evaluation of structural fire resistance. Fire Safety Journal 38:645-650

Grosshandler WL (2002) NISTIR 6890 - Fire Resistance Determination and Performance Prediction Research Needs Workshop. National Institute of Standards and Technology, Gaithersburg, MD, USA

Guerrieri M, Fragomeni S (2013) An experimental investigation into the influence of specimen size, in-situ pore pressures and temperatures on the spalling of difference size concrete panels when exposed to a hydrocarbon fire. $3^{\text {rd }}$ International RILEM Workshop on Concrete Spalling due to Fire Exposure, $25^{\text {th }}-27^{\text {th }}$ September, Paris, France, MATEC Web of Conferences, v. 6

Harmathy TZ (1993) Fire Safety Design and Concrete. Concrete Design and Construction Series, Longman Scientist and Technical, UK

Harmathy TZ (1965) Effect of moisture on the fire endurance of building elements. Research paper 270, Division of Building Research, National Research Council of Canada, Ottawa, Canada

Huang Z (2010) Modeling the bond between concrete and reinforcing steel in a fire. Engineering Structures 32(11): 3660-3669 
Huang Z, Burgess IW, Plank RJ (2003a) Modeling membrane action of concrete slabs in composite buildings in fire. Part I: Theoretical development. Journal of Structural Engineering 129(8): 1093-1102

Huang Z, Burgess IW, Plank RJ (2003b) Modeling membrane action of concrete slabs in composite buildings in fire. Part II: Validations. Journal of Structural Engineering 129(8): $1103-1112$

Huang Z, Burgess IW, Plank RJ (2003c) A Non-linear Beam-column Element for 3D Modeling of General Cross-sections in Fire. Research Report DCSE/03/F/1, Department of Civil \& Structural Engineering, University of Sheffield, UK

Ingham JP (2007) Assessment of fire-damaged concrete and masonry structures, evaluation and repair of the damage to concrete. Special Publication SP-92, American Concrete Institute, Detroit, USA

ISO (1999) ISO 834-1:1999: Fire Resistance Tests - Elements of Building Construction - Part 1: General Requirements. International Organization for Standardization, Geneva, Switzerland

Jansson R (2008) Material properties related to fire spalling of concrete. Licentiate thesis of Lund University of Technology, Lund, Sweden.

Jansson R, Boström L (2013) Factors influencing fire spalling of self compacting concrete. Materials and Structures 46(10): 1683

Jensen JJ, Hansen EA, Danielsen U, Seglem S (1987) Offshore concrete structures exposed to hydrocarbon fire. First International Conference on Concrete for Hazard Protection, Edinburgh, UK

Kalifa P, Chéné G, Gallé C (2001) High-temperature behaviour of HPC with polypropylene fibres: From spalling to microstructure. Cement and Concrete Research 31(10): 14871499

Kelly F, Purkiss J (2008) Reinforced concrete structures in fire: A review of current rules. The Structural Engineer 86(19): 33-39

Khoury GA (2000) Effect of fire on concrete and concrete structures. Progress in Structural Engineering and Materials 2(4): 429-447

Khoury GA, Grainger BN, Sullivan PJE (1985) Transient thermal strain of concrete: literature review, conditions within specimen and behaviour of individual constituents. Magazine of Concrete Research 37(132): 131-144

Kodur VKR, Dwaikat MMS (2012) Fire induced spalling in reinforced concrete beams. Structures and Buildings 165(7): 347-359

Kodur VKR, Sultan MA (2003) Effect of temperature on thermal properties of high-strength concrete. Journal of Materials in Civil Engineering 15(2): 101-107

Kodur VKR, Garlock MEM, Iwankiw N (2011) Structures in fire: State of the art, research and training needs. Fire Technology 48(4): 825-839

Kodur VKR, Dwaikat MB, Raut N (2009) Macroscopic FE model for tracing the fire response of reinforced concrete structures. Engineering Structures 31(10): 2368-2379

Kodur VKR, Garlock MEM, Iwankiw N (2007) NISTGCR 07-915 - Structures in fire: state of the art, research and training needs. National Institute of Standards and Technology, Gaithersburg, MD, USA

Kordina K (1997) Ueber das brandverhaltem punkthestuetzter stahlbetonplatten (Investigations on the behaviour of flat slabs under fire). DAfsib H 479:106S 
Kulkarni KS, Yaragal SC, Babu Narayan, KS (2011) An Overview of High Performance Concrete at Elevated Temperatures. International Journal of Applied Engineering and Technology 1(1): 48-60

Lange D, Jansson R (2014) Comparison of an Explicit and an Implicit Transient Strain Formulation for Concrete in Fire. $11^{\text {th }}$ Symposium on Fire Safety Science, International Association of Fire Safety Science, Canterbury, New Zealand

Lange D, Devaney S, Usmani A (2014) An Application of the PEER PBEE Framework to Structures in Fire. Engineering Structures 66:100-115

Li-Tang G, Li X, Chen L, Yuan A (2008) Experimental investigation of the behaviours of unbonded prestressed concrete continuous slabs after fire. Concrete (in Chinese) 2008-02

Lönnemark A, Ingason H (2005) Gas temperature in heavy goods vehicles fire in tunnels. Fire Safety Journal 40: 506-527

Lottman BBG, Koenders EAB, Blom CBM, Walraven JC (2013) Spalling of concrete due to fire exposure: A coupled fracture mechanics and pore pressure approach. $3^{\text {rd }}$ International RILEM Workshop on Concrete Spalling due to Fire Exposure, $25^{\text {th }}-27^{\text {th }}$ September 2013, Paris, France, MATEC Web of Conferences, v. 6

Maluk C (2014) Development and Application of a Novel Test Method for Studying the Fire Behaviour of CFRP Prestressed Concrete Structural Elements. PhD Thesis, University of Edinburgh, UK

McAllister TP, Gross JL, Sadek IH, Kirkpatrick SW, MacNeill RS, Zarghamee MS, Erbay OO, Sarawit AT (2012) Structural Response of World Trade Center Buildings 1, 2 and 7 to Impact and Fire Damage. National Institute of Standards and Technology, 18 October

Meacham B, Kim J-K, Park H (2012) Structural and Nonstructural Building System Performance during Earthquake and Post-Earthquake Fire: Fire Test Program - Full Report.

Department of Fire Protection Engineering, Worcester Polytechnic Institute.

Meyer-Ottens C (1972) Zur Frage der Abplatzungen an Betonbauteilen aus Normalbeton bei Brandbeanspruchung. PhD-thesis, Braunshweig, Germany

Mindeguia JC (2009) Contribution expérimentale a la compréhension des risques d'instabilité thermique des bétons. These de doctorat de l'université de pau et des pays de l'adour. 10 Juillet

Mindeguiaa JC, Hagerb I, Pimienta P, Carre H, Borderie C (2013) Parametric study of transient thermal strain of ordinary and high performance concrete. Cement and Concrete Research 48: $40-52$

Morales EM (1992) Rehabiltiation of a fire damaged building. Proceedings of ACI International Conference, Hong Kong, 1991, Evaluation and rehabilitation of concrete structures and innovations in design, Special Publication SP-128, American Concrete Institute, Detroit, USA

Mostafaei H (2013) Hybrid fire testing for assessing performance of structures in fire Application. Fire Safety Journal 56: 30-38

Mostafaei H (2013) Hybrid fire testing for assessing performance of structures in fire Methodology. Fire Safety Journal, 58: 170-179

Muttoni A, Furst AA, Hunkeler F (2005) Deckeneinsturzder Tiefgarageam Staldenacker in Gretzenbach, Solothurn, Switzerland, November, Medieninformation vom15.11.2005

Nene RL, Kavle PS (1992) Rehabilitation of a fire damaged structure. Proceedings of ACI International Conference, Hong Kong, 1991, Evaluation and rehabilitation of concrete 
structures and innovations in design, Special Publication SP-128, American Concrete Institute, Detroit, USA

Neville AM (1997) Properties of Concrete: Fourth and Final Edition. John Wiley and Sons, New York, USA

NIST (2013) http://www.nist.gov/el/fire_research/nfrl/project_fireresistance.cfm. Date created: November 6, 2013, last updated: December 17, 2013 (accessed 19 ${ }^{\text {th }}$ March 2014)

Ožbolt J, Bošnjak J (2013) Modeling Explosive Spalling and Stress Induced Thermal Strains of HPC exposed to High Temperature. $3^{\text {rd }}$ International RILEM Workshop on Concrete Spalling due to Fire Exposure, $25^{\text {th }}-27^{\text {th }}$ September 2013, Paris, France, MATEC Web of Conferences, v. 6

Peker K, Pekmezci B (2003) Damage Analysis for a fire exposed industrial building. Structural Engineering International 13(4): 245-248

Phan LT (1996) NISTIR 5934 - Fire performance of high-strength concrete: a report of the stateof-the-art. National Institute of Standards and Technology, Gaithersburg, MD, USA

Pimienta P, Anton O, Mindeguia JC, Avenel R, Cuypers H, Cesmat E (2010) Fire protection of concrete structures exposed to fast fires. $4^{\text {th }}$ International Symposium on Tunnel Safety and Security (ISTSS), $17^{\text {th }}-18^{\text {th }}$ March, Frankfurt, Germany

Pinoteau N, Heck JV, Rivillon Ph, Avenel R, Pimienta P, Guillet T, Rémond S (2013) Prediction of failure of a cantilever-wall connection using post-installed rebars under thermal loading. Engineering Structures 56: 1607-1619

Ring T, Zeiml M, Lackner R (2011) Large scale fire tests on concrete design and results. Poster presented at the 18th Inter-Institute Seminar for Young Researchers, September, Budapest, Hungary

Rush D, Bisby L, Ioannou I, Rossetto T (2014) Towards fragility analysis for structural fire resistance: Residual capacity of concrete columns. Proceedings of Structures in Fire (SiF'14), Shanghai, June

SAFIR (2014) SAFIR website References. www2.argenco.ulg.ac.be/logiciels/SAFIR (Accessed Feb $15^{\text {th }}$ 2014)

Salomao et Pandolfelli (2007) Polypropylene fibers and their effects on processing refractories castables. International Journal of Applied Ceramic Technology 4(6): 496-502

Schneider, U. (1986), "Properties of Materials at High Temperatures - Concrete, Second Edition, RILEM Report, Germany.

Shuttleworth, P. (2001). "Fire protection of precast concrete tunnel linings on the Channel Tunnel Rail Link." Concrete vol. 35(no 4): pp. 12-22

Sivagnanam B (2002) Damage assessment and rehabilitation of concrete structures: three case studies. Indian Concrete Journal, 76(12):764-770

Smart SAS (2006) Fire damage assessment using non-destructive site techniques - Case studies. Concrete Solutions, Proceedings of the $2^{\text {nd }}$ International Conference, St Malo, France, BRE Press, Watford, UK

Srinivasan P, Chellappan A, Annamalai S (2007) Pre-evaluation of fire-affected RC framed structure and its post-evaluation by load testing after repair; a case study. Journal of Structural Engineering 33(5): 419-427

Taerwe L, Poppe A-M, Annerel E, Vandevelde P (2006) Fire damage assessment using nondestructive site techniques - Case studies. Concrete Solutions, Proceedings of the $2^{\text {nd }}$ International Conference, St Malo, France, BRE Press, Watford, UK 
Taillefer N, Carlotti P, Lemerle C, Avenel R, Larive C, Pimienta P (2012) Ten years of increased hydrocarbon temperature curves in French tunnels. Fire Technology 49(2): 531-549

Taillefer N, Quentin C, Avenel R (2009) Spalling of concrete: a synthesis of experimental results for middle and large size tests. $1^{\text {st }}$ International Workshop on Concrete Spalling due to Fire Exposure, $3^{\text {rd }}-5^{\text {th }}$ September, Leipzig, Germany, pp. 150-167

Terrasi G, Bisby LA, Maluk C, Barbezat M (2012) Fire Experiments of Thin-walled CFRP Pretensioned High Strength Concrete Slabs under service load. $6^{\text {th }}$ International conference on Fiber Reinforced Polymer (FRP) Composites in Civil Engineering, $13^{\text {th }}$ $15^{\text {th }}$ June, Rome, Italy

Van Acker A (2003) Shear resistance of prestressed hollow core floors exposed to fire. Structural Concrete 4(2): 65-74

Van Herberghen P, Van Damme M (1983) Fire resistance of post-tensioned continuous flat floor slabs with unbonded tendons. FIP Notes, UT, pp. 3-11

Vassart O, Zhao B (2011) FRACOF Engineering Background. Report developed for the Leonardo Da Vinci Programme: Fire Resistance Assessment of Partially Protected Composite Floors (FRACOF). European Commission, Education and Culture DG, Bordeaux, France

Voeltzel A, Dix A (2004) A comparative analysis of the Mont-Blanc, Tauern and Gothard tunnel fires. Routes/Roads 324: 18-34

Wald F (2011) Large Scale Fire Tests. COST Action TU0904. Integrated Fire Engineering and Response Working Group, April 30, Prague, Czech Republic

Wong YL, Ng YW (2011) Technical Seminar - Effects of Water Quenching on Reinforced Concrete Structures under Fire. Presented to The Institution of Fire Engineers (Hong Kong Branch). Kowloon Tong Fire Station, 23 August, Hong Kong

World Road Association (1999) Fire and smoke control in road tunnels. ISBN 2-84060-064-1, http://publications.piarc.org/ressources/publications_files/2/989

Youssef MA, Moftah M (2007) General stress-strain relationship for concrete at elevated temperatures. Engineering Structures 29(10): 2618-2634

Yuan Z, Tan KH, Ting SK (2011) Testing of composite steel top-and-seat-and-web angle joints at ambient and elevated temperatures: Part 2 - Elevated-temperature tests. Engineering Structures 31(9): 2093-2109

Zeiml M, Lackner R, Mang HA (2008) Experimental Insight into Spalling Behavior of Concrete Tunnel Linings under Fire Loading. Acta Geotechnica 3:295-308

Zheng WZ, Hou XM, Shi DS, Xu MX (2010) Experimental study on concrete spalling in prestressed slabs subjected to fire. Fire Safety Journal 45: 283-297

Zukov VV (1975) Explosive failure of concrete during a fire, Translation $\mathrm{n}^{\circ} 2124$, Joint Fire Research Organisation 
II. Steel

WHITE PAPER

\section{FIRE BEHAVIOR OF STEEL STRUCTURES}

A report for the National Institute of Standards and Technology

by

Maria Garlock, Princeton University, USA

Joël Kruppa, Ismans Engineering School, France

Guo-Qiang Li, Tongji University, China

Bin Zhao, CTICM, France

Final Report

June 2014 
International R\&D Roadmap for Fire Resistance of Structures: Summary of NIST/CIB Workshop

THIS PAGE LEFT INTENTIONALLY BLANK 


\section{Contents}

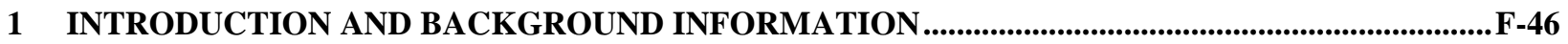

2 STATE-OF-THE-ART IN FIRE-STRUCTURE PERFORMANCE-BASED DESIGN, MODELLING,

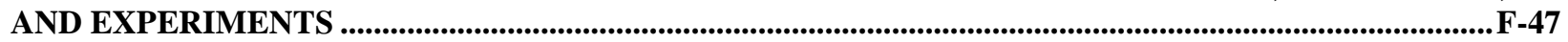

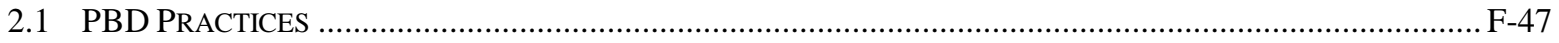

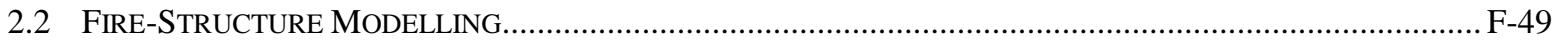

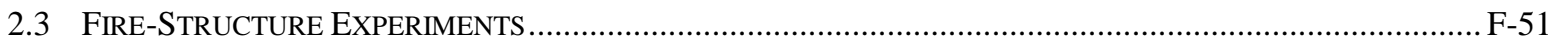

$3 \quad$ KNOWLEDGE GAPS ............................................................................................................................................5-52

$3.1 \quad$ PBD

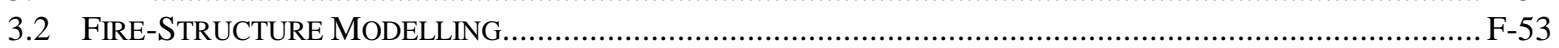

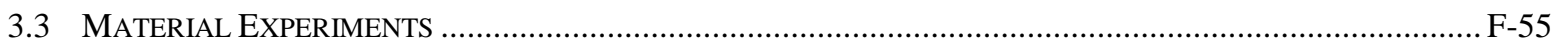

4 TOPICS 1 AND 2: IDENTIFY AND PRIORITIZE LARGE-SCALE EXPERIMENTAL NEEDS IN

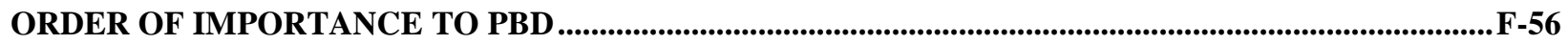

5 TOPIC 3: NEEDED RESEARCH IN A TIMELINE ..........................................................................................5-57

6 TOPIC 4: LABORATORY FACILITIES AVAILABLE TO ADDRESS EACH NEED .........................F-58

7 TOPIC 5: POTENTIAL COLLABORATORS AND SPONSORS FOR EACH NEED.............................. F-58

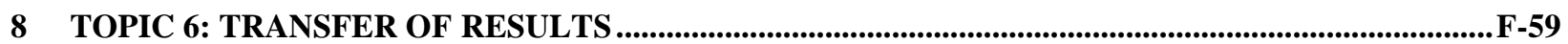

9 TOPIC 7: MEANS TO REVIEW PROGRESS AND EXCHANGE INFORMATION ..............................F-59

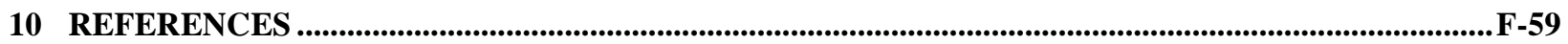




\section{Introduction and Background Information}

The National Institute of Standards and Technology (NIST) conducted its building and fire safety investigation of the World Trade Center (WTC) disaster of September 11, 2001, under the authority of the National Construction Safety Team (NCST) Act. The NCST's Final Report includes 30 recommendations that address (1) specific improvements to building standards, codes, and practices; (2) changes to, or the establishment of, evacuation and emergency response procedures; and, (3) research and other appropriate actions needed to help prevent inappropriate future building failures in fire situation. As part of NIST's plan to implement the report's recommendations regarding new methods for fire resistance design of structures, NIST intends to develop an international research and development (R\&D) roadmap on the fire resistance of structures. To support the development of the roadmap, NIST held a workshop on large-scale experimental and modelling fire resistance of structures research needs. NIST has commissioned three White Papers, to be used as the basis for technical discussions at the workshop. This effort will provide input for prioritizing and coordinating international research activities and facilitate the development of advanced validated tools for the performance-based engineering fire resistant design of structures.

This report dealing with steel structures is one of these White Papers. By steel structures it is meant both pure steel structures and composite structures in which the steel is directly exposed to fire and the concrete contributes to the loadbearing capacity of the structure. Examples of composite structures include concrete-filled steel tube column and steel beam coupled with concrete slab.

This white paper presents the state-of-the-art of large-scale experiments, modeling, and performance-based design efforts in fire behavior of steel structures. In addition, this paper discusses the seven "Topics" listed below.

- Topic 1. Research and development needs for large-scale experiments on fire resistance of structures to support performance-based engineering and structure-fire model validation;

- Topic 2. Prioritization of research and development needs in order of importance to performance-based engineering;

- Topic 3. Phasing the needed research in terms of a timeline;

- Topic 4. Most appropriate international laboratory facilities available to address each need;

- Topic 5. Potential collaborators and sponsors;

- Topic 6. Primary means to transfer the results from each series of tests to industry through specific national and international standards, predictive tools for use in practice, and comprehensive research reports; and

- Topic 7. Means for the coalition of international partners to review progress and exchange information on a regular basis.

This White Paper draws upon some information obtained from reports recently published, such as: 
- "Structures in Fire: State of the Art, Research and Training Needs" published in 2011 by Fire Technology [1]. In this paper, the state of the art is presented for (1) modeling and predictions, (2) experiments, (3) materials. It covers all materials, not just steel, and the paper is based on the input of many researchers in this field who attended a 2007 workshop, where the participants identified top 10 research and training needs.

- $\quad$ "Structural Fire Resistance Experimental Research - Priority Needs of U.S. Industry" released in 2012 by NFPA Foundation [2].

- $\quad$ "Needs to achieve improved fire protection as regards the implementation and development of the EN Eurocodes", published in 2008 by the European Commission [3].

- "State-of-the-art and Suggestion of Research on Fire-Resistance of Structures", Report on Research Development Strategy for 2011 2020 by Natural Science Foundation of China (NSFC) in 2010 [4].

It also includes new researches and needs in fire-structure interactions that have been identified since these reports were published.

\section{State-of-the-Art in Fire-Structure Performance- Based Design, Modelling, and Experiments}

Historically, the fire resistance of building structures (or other civil work) was assessed to a large extent by performing tests on isolated structural elements (beams, columns, slabs ...) under standard fires (e.g. ISO 834 [5] or ASTM E 119[6]). Thereafter, on the basis of these tests, simple calculation methods for determining fire resistive ratings for steel structures were derived. During last two or three decades, a number of numerical simulation models were developed that enable us to predict the complete history of structural response subjected to any kind of fire. These simulations are an important tool for performance-based design.

The current state of art for the behavior of steel structures includes three main topics: performance-based design (PBD) practices, fire-structure modeling, and fire-structure experiments. Each topic is developed in the sections that follow.

\subsection{PBD Practices}

The majority of fire design for structures is based on the "prescriptive approach", where the code states how the building has to be constructed and, when necessary protected, under standard fire; whereas in performance-based design (PBD) the code states how the building is to perform to meet fire safety objectives under various realistic fire conditions. In most countries, designers rely on a prescriptive approach, which is based on the results of standard fire tests on isolated structural specimens [7], or even simple calculation methods, to determine the required fire protection on steel components of buildings (e.g., ASCE/SFPE29, IBC and Structural Eurocodes $[15,16,38,73])$. However, these conventional approaches do not accurately reflect a real compartment fire time-temperature relationship nor the real behavior of an entire structure subjected to a non-uniform temperature distribution. Therefore, prescriptive building codes do not properly cover the real structural performance of a building in real fire situations.

The performance-based design approach $[8,9]$ allows the designer to consider real fire scenarios [10] and the effects of the resulting fires on the structure as a whole (as opposed to individual 
member behavior not considering the "real" boundary conditions). This approach is able to have safer and more economical choices and also to give the designer more freedom to express the architectural or industrial needs due to the activity within the building or the civil work. However, an appropriate use of PBD requires education and judgment as related to structure-fire interaction, and knowledge in structure-fire response modeling.

Considering that a performance-based fire design of a steel structure is a process as reported in the CIB publication 269 [11] or in the ISO/TS 24679 [12, 13], we have to recognize that calculation of only the critical steel temperature or the necessary thickness of fire protection material to fulfil required fire duration under standard fire (as done by the simple calculation methods like those given within the fire parts of Structural Eurocodes [14 - 16] or ASCE/SPFE29) cannot be considered as a PBD approach; it is only a way of replacing fire tests by using simple calculation formulae to predict fire resistance of steel structural members.

Generally, PBD approaches are based mainly on either advanced calculation models (numerical simulations) or analytical formulas. However, in some cases, experimental results have to be used in cases where calculation methods are not accurate enough or input data for calculation are not available.

The successful implementation of PBD into design practice will be met with the following challenges in the field of structure-fire interaction: (1) availability of accurate (simple and when necessary more sophisticated) predictive tools for practice, (2) educating the structural engineer and/or the fire protection engineer, (3) growing the knowledge. These challenges are described in more detail throughout the report.

All PBD approaches for structure-fire design to date are based on a 'first-generation' approach that uses deterministic values for the variables (e.g., high temperature material properties). However, there are inherent uncertainties in these variables. A reliability performance-based approach, which is a 'second-generation' $\mathrm{PBD}$, uses a probability distribution for the variables with uncertainties. Such an approach "improve[s]... risk decision-making through assessment and design methods that have a strong scientific basis and that express options in terms that enable stakeholders to make informed decisions."[17]. This is a new and growing area of research within the broader area of structure-fire interaction [e.g., $18-22$ ].

Multi-hazard design for fire is another complex but necessary approach to PBD. As a single event, fire is already considered as one of primary hazards for buildings and civil works. Fire could become particularly dangerous if it is caused by another hazard (a secondary event). As shown in the terrorist attacks on the World Trade Center on Sept. 11, 2001, steel buildings might be able to survive a sudden impact but subsequent fires might make the buildings unable to carry the weight of the structure leading to a failure. The events of Sept. 11 made the structural engineering profession aware that more research was needed on the response of structures to fire and since then advances in the field have been made; the vast majority of this research was applied to fire as a primary event, where the initial condition of the structure was undamaged. Fire as a secondary event, where significant structural damage exists before could happen after impact or earthquake, but the more frequent situation occurs in the case of a blast or explosion (which is more frequently happening in chemical factories). In such instances, a fire begins when the initial condition of the structure is in a damaged state, and the building could lose 
beams, columns, or be subject to permanent plastic deformations. Within this context of multihazard, some research has been developed for fire following blast and fire following earthquake [23 - 32].

\subsection{Fire-Structure Modelling}

There are essentially three components to model structures in fire: the fire model, the heat transfer model, and the structural model. A structure-fire interaction model must consider all three components; typically, all three are considered to be weakly coupled (one-way coupling). This means that the results of the former is transferred to the later as its input data in one direction only (in the direction listed above). There are no comprehensive tools to avoid this single direction communication. The deformation of the structure could have an impact on the capability of the fire separating element to limit the fire propagation from one compartment to another. Structural deformations will thus have some influence on the thermal heat flux received by structural members or the change in the fire development model, for example if a portion of a floor/roof collapses, so this has to be considered in the fire model and/or the heat transfer model.

Each of the above mentioned model components can be simple or complex. For example, for a small post flash-over compartment fire, the heat transfer model can be either 1-dimensional (1D) or 2-dimensional (2-D) with even and uneven temperature through the cross-section of the element being examined. When considering a localized fire within a large compartment, it can be a 3-D model with temperature varying along the length as well as through the cross-section of the structural element. Similarly, the structural model can be 1-D, 2-D or 3-D, and it can use bar elements, beam elements or more complex shell elements. The modeler needs to consider the level of details in the model and suitability on the structural performance that needs to be captured. The "cost" of the analysis must also be considered: the more detailed, the more computationally expensive it is in terms of setup and run-time.

Furthermore, the modeler needs to consider that significant uncertainty exists in the input, including the fire load and mechanical loads, the geometry of the structure and its constitutive elements, the thermo-mechanical material properties, which need to be considered when interpreting the accuracy of the structural analysis results. A parametric or sensitivity analysis can be employed to at least partially evaluate the range of feasible predicted outcomes.

Current practices in fire-structure modelling can be divided into the following categories: (a) finite element tools (computer modeling), (b) analytical formulas, and (c) constitutive materials and uncertainties. Each of these subjects is described in detail below.

\section{(a) Finite element tools (computer modeling)}

In the past 15 years, many advances have occurred in software dedicated to structures in fire [e.g., 33, 34]. Other general purpose and commercially available software can also be used for structure-fire modeling. [e.g., 35 - 37]. These programs are quite complex to use for everyday fire applications but when used by trained practitioners they provide a fair assessment of the reality.

Many limitations exist for modeling structures in fire in a seamless, efficient, and appropriate way. For example, the links between the fire, thermal, and structural models are not yet advanced enough. If one wants to do a 3-D computational fluid dynamics model of the fire, it is generally 
difficult to transfer that data to the heat transfer model in a seamless and efficient manner. However some research projects were performed in Europe on this topic [39] as well as in other countries $[40,41]$ The same difficulty exists if one wants to transfer data from a 3-D heat transfer model to a 3-D structural model (where typically the heat transfer model will use brick elements and the structural model will use commonly beam or shell elements). In addition, the complete analysis is typically one-way coupled as described previously.

\section{(b) Analytical formulas}

As an alternative to computational tools, simple calculations can be performed using closed-form solutions that consider equilibrium and compatibility. These closed-form solutions can provide a reasonable approximation of the structure-fire response, and they can also be used to provide some level of validation for the more complex computational solutions. For example, the fire development model can be approximated by parametric curves. The heat transfer model in steel sections with relatively thin plates can be done with a spreadsheet using a lumped mass approach that assumes the temperature of the steel is uniform or even with a simple formula developed for predicting the temperature rise of a steel component under fire curve [42]. The structural model can be a beam-element with the appropriate boundary conditions (which are assumed to be unchanged during the fire) that represent the surrounding structure.

Analytical formulas for simple elements under uniform temperature for standard fire have been developed for beams and columns and composite slabs [15, 16, 42, 43]. Both protected and unprotected steel are covered by these formulas to the extent the proper thermal properties of the protection systems are known [15, 43].

In addition, analytical formulas for assessing loadbearing capacity have been developed for beams and columns with thermal gradients [15, 44 - 50], for composite elements such as concrete filled hollow steel section or I-column or beam sections with concrete between the flanges [16, 51] and also for beam-column connections [89]. On the other hand, an analytical calculation method was developed for structural elements located outside the burning building and subjected to heat coming from external flames passing through windows $[15,16,52]$.

Limited research is available that recommends formulas that consider the structural response of elements under fire as part of a larger structural system. For example, a proposal is made for closed-form approximations of the maximum axial force in a beam considering local buckling of the beam that will develop due to the adjacent structure [53]. More recently, several projects have been conducted in the world, which have led to various analytical formulas for predicting the load-bearing capacity of steel and concrete composite floor systems subjected to both standard fire and real compartment fire conditions and behaving under membrane action [54 57].

\section{(c) Constitutive materials}

High temperature thermal and mechanical material properties of steel are available $[15,58,59]$. Most are for steels used in buildings but recent studies have been made on steels used in bridges such as A709 and A588 weathering steel $[60,61]$. However some uncertainties still exist on these thermo-physical properties. It is not clear how this uncertainty/variability affects the structural response as a whole. Probabilistic approaches are able to quantify these material property uncertainties. 


\subsection{Fire-Structure Experiments}

The discussion about fire-structure experiments is divided into the following sections: (a) standard fire tests on structural elements, (b) structural system tests, (c) material tests, and (d) hybrid testing methods.

\section{(a) Standard tests on structural elements}

Structural element tests are usually performed within a prescriptive regulation. Tests are conducted on individual structural elements or assemblies, such as beams, columns, floors or walls, of specific dimensions to standard fire exposure in a specially designed fire test furnace. Test procedures, including fire (time-temperature) curves, are specified in standards such as ASTM E119 [6], ISO 834 [5], and EN 1363 [62].

Within this section, tests on subassemblies such as girders with slabs or roof can also be considered. In North America, steel columns or subassemblies are generally not loaded during the tests; rather an alternative test procedure is employed whereby the end point (failure) criterion is based on a critical limiting temperature in structural steel.

There are many drawbacks with the structural element / subassembly tests under standard fire procedure described above, the most important being that such tests do not account for real fire scenarios (and no decay phase), structural interactions with adjacent framing, realistic load levels and restraint conditions. Further, some current test methods and their acceptance criteria do not give due consideration to various limit states, such as strength, stability, deflection, and rate of deflection for assembly failure.

\section{(b) Structural system tests}

There has been only a very limited number of fire experiments that have considered the full structural system for evaluating global response of structures. A few tests on portal frames were conducted in the 70's to 90's. Full-scale fire test of 4 story car park (20m x 30m) was conducted in Japan in 1993 [87, 88]. In France, a test on a steel structure car park of 30m x $15 \mathrm{~m}$, under real car fires, was performed in 2001 [63 - 65] and a test on a steel warehouse of $48 \mathrm{~m} \mathrm{x} 32 \mathrm{~m}$ and 12 $\mathrm{m}$ height subjected to a fire with 310 tonnes of wood over a surface of $24 \mathrm{~m} \mathrm{x} 32 \mathrm{~m}$, in 2008 [66]. In China, full-scale fire tests were conducted on two-story two-bay composite steel frames $[67,68]$. However, the most notable and significant research in full structure fire experiments was undertaken in the last decades by the Building Research Establishment (BRE) in the U.K, which conducted a series of full-scale fire tests in the Large Building Test Facility (LBTF) at Cardington [69 - 71]. The tests on multi-story steel and concrete buildings provided unique and valuable response data regarding the behaviour of both structural and non-structural elements within a real compartment subjected to real fires.

Amongst the unexpected damage in the first Cardington tests was the tension failure of the steel connections during the cooling phase of the fire. Several experiments have been done on various types of steel connections to illustrate connection vulnerability and means to improve their performance in fire [90 - 95]. 


\section{(c) Material tests}

In addition to fire tests on structural elements and systems, the temperature dependent properties of steel materials (both thermal and mechanical) are critically important for establishing an understanding of the fire-response of structures. The literature review indicates that the high temperature properties of steel (structural, reinforcing steel) are available (e.g. [72, 59]). However, there is large variability in similar data obtained from different sources. This high variation in the reported high-temperature properties of steel can be attributed to lack of standardized test methods to test high-temperature properties, and no standardized equipment to measure properties.

Regarding the capability of fire protection systems to provide an adequate protection to steel or composite structures, new test procedures were developed in Europe (see EN 13381- -4, -5, -6 \& -8 [74 - 76]) to ensure the protective material remain cohesive and coherent to its support, despite the deflection occurring at high temperature.

Also, some tests have been done on measuring the effectiveness of SFRM (Sprayed fire-resistive material) adhesion to steel following large strains related to seismic loading [77, 78].

\section{(d) Hybrid testing methods}

Hybrid fire testing (HFT) considers the effects on a whole building, but only tests individual elements or subassemblies. Computer simulations of a full structure are made, from which an element or subassembly is tested. The computer-simulation of the full structure transfers data to the actuators that represent the forces imposed by the adjacent structure in the tests. HFT therefore simulates the fire performance of the whole building at a lower cost than full-scale testing, and with more reliable results than prescriptive testing. HFT offers the possibility of investigating various fire scenarios, using selected facilities for physical testing, and running the simulation analysis remotely at different locations anywhere in the world. This is a proven method for seismic testing and is recently being adopted for fire at NRC Canada and BAM Germany [79 - 82]. However, the accuracy of these tests depend on the accuracy of the numerical simulations.

\section{Knowledge Gaps}

\subsection{PBD}

The knowledge gaps related to PBD are strongly tied to knowledge gaps in modeling and experiments as discussed in detail in the next two sections. The main PBD gaps are: (1) the discrepancy between a structural design made by prescriptive methods (considering isolated structural elements to fulfill fire resistance requirements based on the standard fire) and PBD (design of a complete structure taking into account actual fire risks), and (2) lack of knowledge in input data or calculation models leading to the need to refer to large or full scale tests results.

Regarding the discrepancy (item (1)), it is now more possible than before to develop a performance-based approach using design fire scenarios and computer code for analysis. In addition, sensitivity analysis on a large variety of buildings and activities provide guidelines for more realistic prescriptive requirements [83]. 
Regarding lack of knowledge (item (2)), for performance-based design it is necessary to know the relevant fire load during the life time and related heat release rate for different types of buildings and activities, as well as guidelines to select design fire scenarios. In addition, one needs to know fire development in various building configurations and strength or deformation design limits of structural components or systems in a fire. Of course, this matter is not a specific one for steel structures, but applicable to all structural types.

In addition, the current regulatory structure in many countries, such as the United States, does not foster performance-based design approaches. Although there are some published performance-based building codes (e.g. ICC), there is little infrastructure or tools to use them. This would include, at a minimum, agreed upon performance goals and acceptable levels of risk. For widespread implementation of performance-based design approaches, such an approach must be codified into recognized national standards. These standards generally do not exist, although some are under development. Currently, ASCE's Fire Protection committee submitted a proposal to include PBD for fire in ASCE-7. While it is still under consideration, one of the main concerns by reviewers of the profession is that there is no single comprehensive source (e.g., a book or report) to guide an engineer through the process of PBD.

And finally, PBD is an engineered approach, yet there is no clearly defined role for the structural engineer or the fire protection engineer in the design of structures for fire. And the structural engineer is typically not educated with knowledge on fire development or fire-structure interaction, and the fire protection engineer is not educated in structural behavior. Typically the architect has responsibility for the fire safety in building design. The architect may call on a fire protection engineer but recognition for the role for the structural engineer will be necessary for widespread implementation of PBD. Certainly, the fire engineer must also become an active participant in the creative, trans-disciplinary process of design. While this is not a knowledge gap, it is an important challenge to recognize.

\subsection{Fire-Structure Modelling}

The numerical models that are currently being used for predicting the response of structures under fire loading are complex and there is a clear need to validate the use of these models with experimental data. There is a need for having a database on component test results and on the other hand for performing full-scale/real-scale testing of structures under fire loading to improve the capability of these numerical models.

\section{(a) Gaps in finite element tools (computer modelling)}

The first step in structural fire response modeling is to identify the thermal loads on a structure due to fire. The thermal loads on a structure are closely coupled to the radiative and convective heating from the fires to the structure. Although some research results are already available, development of more appropriate interfaces that couple the fire dynamics to the thermal response of a structure and link the thermal models to the structural models are a critical research need for having an efficient structural fire response modeling.

Gaps also exist due to the lack of interaction between the fire development and the structural response calculations. Within the main process commonly available, calculations are conducted in a "linear and one-way" manner (see Section 2.2 - State of art in fire structure modelling). 
There is no systematic process to take into account the fact that, with the large deformation of the structure, there is a change in the heating condition of structural elements, due to:

- the change in the distance or position between a structural element and the fire source (mainly for pre-flashover conditions), e.g. a bending beam becoming closer to the floor where the fire is located;

- possible damage of fire protection materials not able to remain coherent and cohesive to the thermally protected structural elements with large deformation; and

- possible cracks in non-loadbearing separating elements, created by large deformation of loadbearing element above, which lead to hot gases passing through and the change of heating conditions.

There is also a need to harmonize the definition of failure to be used with calculation results (mainly when calculating the deformation of the structure), which has to be different from the failure criteria used for testing, since these criteria were developed to safeguard the testing facilities and not to represent specific need within a burning building. Criteria need to be differentiated when considering, e.g., the robustness of the overall structure (taking into account concepts as fire-induced progressive damage and disproportionate damage) and the reparability.

In the context of a multi-hazard computational platform, software needs to advance to consider seamless multi-hazard simulation and modeling various uncertainties (Monte-Carlo simulations). This needs to be done so that the simulation is efficient, numerically stable, accurate, and with robust algorithms that converge toward the correct solution. But to model uncertainties data are needed to form statistics for random variables, from which probability models can be developed.

Other gaps in FE modeling include:

- For steel and concrete composite structures, to take into account the bonding behavior at elevated temperatures between steel and concrete for reinforcing bars, steel tube, profile steel sheet and even I or $\mathrm{H}$ profile concreted between flanges, when the force transfer between these two materials is considered,

- To extend the knowledge in deformation capacity of various types of connections, (e.g., moment-rotation capacity at elevated temperatures),

- Improvements of calculation capabilities for geometric nonlinearity due to large structural deformation, for modeling rupture of connections and elements, as well as for considering the impact loading in case of collapse of upper floors.

(b) Gaps in simple calculations methods (analytical formulas)

Simple calculation methods for the following structural elements need to be developed:

- Composite columns partially exposed to fire (1,2 or 3 faces),

- Column and beam with steel profiles encased in concrete,

- Connections within composite structure,

- Composite floors elements (composite slabs or composite beams) with fire above and with fire on both sides (under and above), 
- Sub-assemblies (such as portal frame or part of it), and not only isolated structural elements.

\section{(c) Gaps on constitutive material models}

Improvement of knowledge needs to be achieved for following fields:

- Ductility limits for structural steel at high temperatures (given as $20 \%$ of strain in Eurocode $[15,16]$ regardless of the temperature), especially for high strength bolts and weld,

- Physical properties at elevated temperatures for high strength steel (yield stress above $500 \mathrm{MPa})$,

- Creep effects and the modeling techniques for advanced calculations, plus considering creep's influence on strain-stress relationship for simple calculation methods,

- Physical properties (stress-strain relationships, thermal properties ...) of various grades of structural steel, bolts and weld during cooling phases,

- Physical properties of fire protection materials (including reactive material such as intumescent paints), concerning thermal conductivity, specific heat, elongation/shrinkage, all versus temperature, including cooling phases, to be used for thermal analysis whatever the fire development,

- Quenching effect on the physical properties of structural steel and fire protection materials due to sprinklers or firefighting,

- Data on all relevant physical characteristics, as porosity, to enable modeling mass transfer in connection with heat transfer.

\section{(d) Traveling fires and non-structural elements under fire effects}

In order to model structures under fire loading, it is essential to fully understand how fires grow and spread from one compartment to another in case of several compartments or inside one large compartment (this matter is common for the 3 White Papers). The spread of fire can be significantly affected by the presence of partitions, doors, walls, fire load distributions, etc. (see also "gaps in finite element tools"). Furthermore, breaking of glass windows will affect the ventilation patterns and influence the growth and spread of a fire. New research activities must be initiated in the area of modeling non-structural elements, such as partitions, doors, walls, window breakage, etc.

\subsection{Material Experiments}

While the scope of the white paper focuses on large-scale experiments, it should be noted that experiments on material properties are required to understand and model the larger-scale studies. Knowledge gaps in large-scale experiments are identified in the next section.

Standardized test methods need to be developed to obtain the necessary data on materials properties of steel elements (coupon tests) focusing mainly for the future high grades of steel, fire-resistant steels (e.g., ASTM A1077), and bridge steels such as A709 weathering (including both heating and cooling phases). 
Accurate methods and standards need to be developed regarding test methods for assessing the bonding capability of fire protection systems (e.g. sprayed and intumescent material). The bonding properties of protective materials to steel need to be understood to derive the necessary thermo-physical properties that are needed for predicting the structural steel performance under fire.

\section{Topics 1 and 2: Identify and Prioritize Large-Scale Experimental Needs in Order of Importance to PBD}

Tests, at large scale and/or full scale have to be performed to provide the necessary validation data for calculation methods and to validate the simple and advanced models. Both the experiments and the models are needed to advance PBD. The subsections below identify firestructure interaction subjects that lack full-scale testing to validate performance and modeling. We also identify tools (hybrid fire testing and sensors) that need to be tested and validated and can potentially advance large-scale testing. The research needs are listed in order of importance (i.e. the first listing being the most important).

\section{(a) Develop advanced tools for large-scale testing}

As described previously, hybrid testing links a full structural system simulation with testing of a component of the structure in the lab. The simulation and experiment communicate with each other so that, for example, the proper boundary conditions are applied in the tests. This kind of testing has the potential to reduce costs associated with testing full systems, and although it is advanced and proven for seismic testing, only limited work has been done for fire simulations. There is a need to develop and validate (a1) hybrid fire testing for single events (only a fire), but it is also potentially a powerful tool (a2) for multi-hazard events as well (e.g., fire following earthquake or blast).

There is a need to develop ( $\mathbf{a} 3$ ) new sensor technology for quantifying physical behavior up to $800^{\circ} \mathrm{C}$. Sensors and measurements of interest include strains, displacements, load cells, heat flux, and optical techniques. These types of information are crucial for calibrating and verifying complex analysis models.

\section{(b) Perform large-scale steel frame tests on 3D structural systems}

The largest absence of data is in large scale 3D structural system tests. These tests are important to complement the smaller scale tests that assume boundary conditions and cannot capture the response of the adjacent structure. Examples of large scale 3D structural system to be tested with realistic fire scenarios, that are needed to validate models and advance PBD include the following: (b1) multi-story steel framed structure with semi-rigid beam-to-column connections, (b2) braced composite frame with beam-to-column hinge connections; with a set up different to the building tested in Cardington, (b3) mixed structure with high-rise steel frames and concrete core, (b4) multi-hazard of steel (and composite) structures (fire following explosion or earthquake), (b5) integrated floor system structure with different types of connections with vertical elements, (b6) tensioned-cable supported large span structure, (b7) specimens built with high grades of steel, and with "bridge" steels or fire-resistant steels, (b8) integrated floor systems (steel decking slabs with both steel and composite beams) supported by steel columns, (b9) steel structures with envelope elements such as steel roofing or façade. 


\section{(c) Perform large-scale tests on structural components}

Large scale tests to be performed (for both standard and "real" fire conditions) on structural components for which there is a lack of knowledge are, e.g.: (c1) composite columns with nonuniform heating conditions over the cross-section, (c2) mega composite columns with steel profiles encased in concrete for super-tall buildings, (c3) different types of connection for composite elements, as composite beams, composite columns, (c4) buckling-restrained braces with concrete-filled steel tube, (c5) floor with fire above and with fire on both sides, (c6) protected steel and composite elements with, e.g., intumescent material, (c7) hybrid beams (welded beam with different grades of steel for web and flanges), (c8) cellular (castellated) beams.

\section{(d) Deep plate girders and long span truss beams}

Large open spaces in buildings often require (d1) deep steel plate girders (regarding, e.g., plate buckling mechanism) or (d2) long span truss beams. Also, these plate girders or truss beams could be used for column transfer. Yet little or no information exists on how they respond in a fire. Deep plate girders are in particular susceptible to web shear buckling. Some studies have been done on this phenomenon at high temperature [84 - 86], mostly as applied to bridges; but there is still a need for experiments (d1) to be performed on girders deeper than $60 \mathrm{~cm}$.

\section{(e) Effect of structural response on non-structural elements}

The response of non-structural elements such as active and passive fire protection systems, doors, ducts, dampers, fire stops, etc., will affect the fire spread and effectiveness of egress. The large deformations experienced in a steel framed structure could affect the response of these nonstructural systems. In addition, if the structure is designed for large seismic activity, the structural design is such that large displacements and ductility is expected. This is at odds with the design of separating and fire stop elements that cannot withstand large displacements/ductility. Full-scale testing of steel frames (e1) can address these issues to provide data on maximum deformation allowed on non-structural elements and to provide knowledge for modeling such behavior of non-structural elements.

\section{Topic 3: Needed Research in a Timeline}

A timeline is presented below for the near term (less than 3 years), medium term ( 3 to 6 years) and long term (6 to 9 years). Before large-scale 3D structural system tests can be performed, we need to advance the tools (e.g., hybrid testing and sensors) so that proper measurements can be made. This can be done in the first three years. Simultaneous to this, large-scale tests on structural components and deep plate girders can be done with the available tools. Once advanced tools are developed, large scale 3D structural system tests can be done in the medium/long term. Incorporated in these tests (as a piggy-back) can be the non-structural element tests. However, large scale experimental is not an end in itself, but is incorporated in the process described in Section 8 (Topic 6). 


\begin{tabular}{|l|l|l|l|l|l|l|}
\hline \multicolumn{2}{|c|}{ less than 3 years } & \multicolumn{3}{|c|}{3 to 6 years } & \multicolumn{3}{|c|}{6 to 9 years } \\
\hline (a) Develop advanced tools & & & & & & \\
\hline & & (b) large scale 3D structural system tests & \\
\hline (c) large-scale tests on structural components & & & \\
\hline (d) Deep plate girders and long-span truss beams & & (e) Non-structural elements & \\
\hline
\end{tabular}

\section{Topic 4: Laboratory Facilities Available to Address Each Need}

The following laboratory facilities are suggested by the authors of the current White Paper for consideration, but without any specific contact with the given labs:

- Architecture \& Building Research Institute (Taiwan): a1, a2, c1, c3, c7, c8, d1, d2

- $\quad$ BAM, Berlin (Germany): a1, a2, a3, c2, c3, c4

- Braunschweig University (Germany): b7, b8, c5, c6, c7, d1, e1

- $\quad$ BRE - FRS (UK): b2, b3

- BRI (Japan): a1, a2, c1, c2, c3, c6, c7, d1, d2

- CSTB, Champs-sur-Marne (France): b1, b6, c1, c6, d1, e1

- Efectis - Maizières-lès-Metz (France): b1, b5, b6, b8, c2, c3, c4, c5, c6, c7, d1, e1

- Lehigh University (USA): a1 $\rightarrow$ a3, c1 $\rightarrow$ c6, d1

- Michigan State University (USA): a1 $\rightarrow$ a3, c1 $\rightarrow$ c6, d1

- $\quad$ NIST lab (National Fire Research Laboratory) (USA): b1, b2, b3, b4, b8, b9, c1, d1, e1

- $\quad$ NRC, Ottawa, (Canada): a1, a2, a3, b8

- TFRI, Tianjin (China): b1, b2, b3, b8, c1, c4, c5

- Tongji University, Shanghai (China): b3, b6, c1, c2 c3, c4, c5, c6, c7

- TUS (Japan): a1, c1, c3, c6, c7, d1, d2

- University of California San Diego (USA): a2

\section{Topic 5: Potential Collaborators and Sponsors for Each Need}

Potential collaborators are national research institutes with knowledge and interests on steel structures and fire behavior, such as: CTICM - France and NRC Canada. In addition, universities and their affiliated experts are potential collaborators. 
Potential sponsors are national research institutes funded by the steel construction manufacturers or by national government and steel producers, such as: AISC, AISI, ArcelorMittal, China Construction (Group) Company, European Research Fund for Coal and Steel (RFCS), Tata.

\section{Topic 6: Transfer of Results}

To be efficient, each research project should be structured as follows:

- Bibliographical study on available knowledge on the item to be tackled and identification of existing test results dealing with the item.

- If test results for the item of study are unavailable or not detailed enough, tests should be performed to cover the various expected conditions regarding the topic of the project. A database containing all detailed experimental results should be set up.

- Based on the physical phenomena identified, develop a calculation method to reproduce them and provide answers to the research item.

- Check, and if necessary improve, the accuracy of the calculation method with results of new tests to be performed.

- Then either use the calculation method to design/verify structure according to the item covered, or use the calculation method for sensitivity analysis to provide simple calculation method dealing with the item.

- Produce report for the use of the calculation method, giving boundary limits for validity.

- Produce report for simple design method or develop standard on the same matter.

\section{Topic 7: Means to Review Progress and Exchange Information}

To review progress, a progress update sheet as shown below can be located in a web site and updated regularly (but no less than twice a year). Links to all results, especially test data, and supporting documentation should be included on the website.

\begin{tabular}{|l|l|l|l|l|l|l|}
\hline $\begin{array}{l}\text { Project } \\
\text { Number }\end{array}$ & Purpose & $\begin{array}{l}\text { Interested } \\
\text { institutes }\end{array}$ & $\begin{array}{l}\text { Interested } \\
\text { laboratories }\end{array}$ & $\begin{array}{l}\text { Interested sponsors } \\
\text { (and amount of } \\
\text { financial support) }\end{array}$ & $\begin{array}{l}\text { Progress in the } \\
\text { research work }\end{array}$ & $\begin{array}{l}\text { Progress in the } \\
\text { transfer of } \\
\text { results }\end{array}$ \\
\hline 1 & & & & & & \\
\hline 2 & & & & & & \\
\hline
\end{tabular}

\section{References}

[1] Kodur, V.K., Garlock, M.E.M., Iwankiw, N. (2012). "Structures in Fire: State-of-the-Art, Research, Training Needs", Fire Technology, Vol. 48, Issue 4, pp 825-839.

[2] Kathleen H. Almand (2012). "Structural Fire Resistance Experimental Research - Priority Needs of U.S. Industry" NFPA - Fire Protection Research Foundation. 
[3] J. Kruppa, G. Sedlacek et al. (2008). "Needs to achieve improved fire protection as regards the implementation and development of the EN Eurocodes", JRC/European Commission, EUR 23523 EN.

[4] Li G-Q, Wu B, Jiang S-C (2010). "State-of-the-art and Suggestion of Research on Fire-Resistance of Structures”, Journal of Progress in Steel Building Structures, I2(5), PPI3-18, 2010. (in Chinese).

[5] ISO 834-1 (1999). Fire-Resistance Tests - Elements of Building Construction - Part 1: General Requirements, Geneva - ISO.

[6] American Society for Testing and Materials (ASTM). (2000). "Standard test methods for fire tests of building construction and materials", E 119, ASTM, 1-21.

[7] Babrauskas V., Williamson R. B.(1978). "Historical Basis of Fire Resistance Testing" Fire Technology, Vol 14, No 3/Aug 1978 (part I) and No 4 / Nov 1978 (part II).

[8] ISO 23932, Fire safety engineering - General principles - Geneva - ISO - 2009.

[9] J. Kruppa, D. Joyeux (1998). "Proposal for a Real Performance Based Code in Fire Resistance", Eurofire.

[10] ISO TS 16733 (2006). Fire safety engineering — Selection of design fire scenarios and design fires - Geneva - ISO - 2006.

[11] CIB W14 (2001). Rational Fire Safety Engineering Approach to Fire Resistance of Buildings, publication 269.

[12] ISO TS 24679 (2009). Fire safety engineering - Performance of structures in fire.

[13] J. Kruppa (2010). "Eurocodes For Fire Safety Engineering”, Conference "Code in structural Engineering" - IABSE - Dubrovnik May 3-5.

[14] EN1991-1-2: Eurocode 1: Actions on structures - Part 1-2: General rules - Actions on structures exposed to fire, Brussels, CEN, 2002.

[15] EN1993-1-2: Eurocode 3: Design of steel structures - Part 1-2: General rules - Structural fire design, Brussels, CEN, 2005.

[16] EN1994-1-2: Eurocode 4: Design of composite steel and concrete structures - Part 1-2: General rules - Structural fire design, Brussels, CEN, 2005.

[17] ATC (2004). "Engineering Design Parameters for Structural Framing Systems”, ATC-58 Project Task Report, Phase 2, Task 2.2.

[18] Ellingwood, B. (2009). “Ch3, Decision Framework for Fire Risk Mitigation” in Best Practice Guidelines for S.F.R of Concrete and Steel Buildings (Draft for Public Comments), NISTIR 7563, NIST, Gaithersburg, MD.

[19] Elhami Khorasani, N., Garlock, M.E.M., Gardoni, P. (2013). "Fire Load: Survey Data, Recent Standards, and Probabilistic Models for Office Buildings", Engineering Structures, Elsevier, in press: http://dx.doi.org/10.1016/j.engstruct.2013.07.042.

[20] Sanctis, G. De, Fischer, K.; Kohler, J.; Fontana, M.; Faber, M.H. (2011). “A probabilistic framework for generic fire risk assessment and risk-based decision making in buildings" Proceedings of the 11th Int. Conf. on Applications of Statistics and Probability in Civil Engineering, p 2000-2007. 
International R\&D Roadmap for Fire Resistance of Structures: Summary of NIST/CIB Workshop

[21] Shi, Kaihan, Guo, Qianru; Jeffers, Ann (2013). "Stochastic analysis of structures in fire by Monte Carlo simulation”, Journal of Structural Fire Engineering, v 4, n 1, p 37-46, March 1, 2013.

[22] Thauvoye C. et al. (2010). "Method for calculating heat fluxes from a warehouse fire SFPE, 8th International Conference on Performance-Based Codes and Fire Safety Design Methods, Lund, Sweden 16-18 June.

[23] J.Y. Richard Liew, and Hong Chen (2004). "Explosion and Fire Analysis of Steel Frames Using Fiber Element Approach", Journal of Structural Engineering, 130 (7), pp9911000, 2004.

[24] J.Y. Richard Liew (2008). Survivability of steel frame structures subject to blast and fire, Journal of Constructional Steel Research Vol.64, p.854-866.

[25] Della Corte, G, Landolfo, R, Mazzolani, FM. (2003). "Post-earthquake fire resistance of moment resisting steel frames," Fire Safety Journal, 38:593-612.

[26] Scawthorn, C, Eidinger, J.M., and Schiff, A.J. (2005). Fire Following Earthquake, Technical Council on Lifeline Earthquake Engineering, Monograph No. 26, Published by ASCE, January.

[27] Scawthorn, C. (2008). "The Shake Out Scenario - Fire Following Earthquake" Prepared for United States Geological Survey, Pasadena, CA and California Geological Survey, Sacramento, CA, March 3.

[28] Lee, S., Davidson, R., Ohnishi, N., and Scawthorn, C. (2008). "Fire Following Earthquake-Reviewing the State-of-the-Art of Modeling." Earthquake Spectra: November 2008, Vol. 24, No. 4, pp. 933-967.

[29] Mousavi, S., Bagchi, A., Kodur, V.K.R. (2008). "Review of post-earthquake fire hazard to building structures", Canadian Journal of Civil Engineering, v 35, n 7, p 689-698, July 2008.

[30] Yassin H., Iqbal, F., Bagchi, A., and Kodur, V.K.K.R. (2008). “Assessment of Postearthquake Fire Performance of Steel-Frame Buildings", Proceedings of the 14th World Conference on Earthquake Engineering, October 12-17, 2008, Beijing, China.

[31] Neal, M., Garlock, M.E.M., Quiel, S.E., Marjanishvili, S. (2012). "Effects of Fire on a Tall Steel Building Designed to Resist Progressive Collapse", Proceedings of the ASCE Structures Congress, ASCE, Chicago, March.

[32] Quiel, S.E. and Marjanishvili, S. (2012). "Fire Resistance of a Damaged Steel Building Frame that has been Designed to Resist Progressive Collapse," Journal of Performance of Constructed Facilities, Vol. 26, No. 4, pp. 402-409.

[33] Franssen J.-M. (2005). "SAFIR: A thermal/structural program for modeling structures under fire.” Engineering Journal, AISC, 42(3), pp. 143-158.

[34] http://www.vulcan-solutions.com/software.html

[35] http://www.ansys.com/

[36] Craveur J.C., Jetteur Philippe (2009). "Numerical simulation of fire resistance of ship steel decks" NAFEMS - Benchmark - July. 
International R\&D Roadmap for Fire Resistance of Structures: Summary of NIST/CIB Workshop

[37] ABAQUS version 6.8 Documentation, DS-Simulia, 2008.

[38] International Building Code (2012). International Code Council, Suite 600, 5203 Leesburg Pike, Falls Church, VA 22041.

[39] S. Kuma, B. Zhao et al.(2008). "Integrating advanced three-dimensional modelling methodologies for predicting thermo-mechanical behaviour of steel and composite structures subjected to natural fires" European Commission - EUR 23200 EN.

[40] LI G.Q. and WANG P.J. (2013). Advanced analysis and design for fire safety of steel structures, Zhejiang University Press, Hangzhou and Pringer-Verlag, Berlin Heidelberg, 2013.

[41] Yu, Xiaojun, Jeffers, Ann E. (2013). “A comparison of subcycling algorithms for bridging disparities in temporal scale between the fire and solid domains", Fire Safety Journal, v 59, p 55-61.

[42] Joël Kruppa, Daniel Joyeux, Bin Zhao (2005). " Scientific Background to the Harmonization of Structural Eurocodes" Heron (NL) VOLUME 50, No. 4.

[43] CECS200 (2006). Code for Fire Safety of Steel Structures for Buildings. China.

[44] Dwaikat, M.M.S., Kodur, V.K.R., Quiel, S.E., Garlock, M.E.M., (2011). "Experimental Behavior of Steel Beam-Columns Subjected to Fire-Induced Thermal Gradients", Journal of Constructional Steel Research, Elsevier, v67, n 1, p 30 - 38.

[45] Garlock, M.E.M. and Quiel, S.E. (2007). "Mechanics of Wide-Flanged Steel Sections with Thermal Gradients Due to Fire Exposure," International Journal of Steel Structures, Korean Society of Steel Construction, 7(3), 153-162.

[46] Garlock, M.E.M. and Quiel, S.E., (2008). "Plastic Axial Load - Moment Interaction Curves for Fire-Exposed Steel Sections with Thermal Gradients", Journal of Structural Engineering, ASCE 134(6).

[47] Quiel, S.E., Garlock, M.E.M., Paya-Zaforteza, I. (2011). “Closed-form Procedure for Predicting the Capacity and Demand of Steel Beam-Columns under Fire", Journal of Structural Engineering, ASCE, 137(9), p.967-976.

[48] Agarwal, Anil, Choe, Lisa; Varma, Amit H. (2014). "Fire design of steel columns: Effects of thermal gradients", Journal of Constructional Steel Research, v 93, p 107-118, February.

[49] Lawson R M , Mullett D L and Rackham (1997). Design of asymmetric slim floor beam using deep composite decking, SCI Publication 175, The Steel Construction Institute, Ascot, UK.

[50] Mullett D L and Lawson R M (1999). Design of slimflor fabricated beam using deep composite decking, SCI Publication 248, The Steel Construction Institute, Ascot, UK.

[51] J. M. Aribert, Ch. Renaud and B. Zhao (2008). "Simplified fire design for composite hollow-section columns", Proceedings of the Institution of Civil Engineers Structures \& Buildings 161 December Issue SB6, Pages 325-336.

[52] S. Desanghere (2007). "Development of A Simplified Model Aimed At Predicting External Members Heating Conditions" - Interflam. 
[53] Selamet, S., and Garlock, M.E.M. (2012). "Predicting the maximum compressive Beam Axial Force during Fire considering Local Buckling”, Journal of Constructional Steel Research, Elsevier, V.71, p.189-201.

[54] Bailey C.G. and Moore D.B., (2000). The structural behaviour of steel frames with composite floor slabs subjected to fire: Part 1: Theory and Part 2: Design.

[55] Vassart O. and Zhao B. (2013). "Membrane action of composite structures in case of fire", ECCS, Technical document, No.132.

[56] Li G.Q., Guo X.S. and Zhou H.S. (2007). "Modeling of membrane action in floor slabs subjected to fire", Structural Engineering, 29.

[57] Zhao B. (2011). "A new design method for calculating the fire protection of composite (steel and concrete) structures", EUROFIRE 2011 - "FSE - Trends and practical Applications" 25-27 May.

[58] Lie, T.T. (1992). Structural Fire Protection: Manual of Practice. ASCE Manuals and Reports of Engineering Practice. No. 78. American Society of Civil Engineers.

[59] Luecke, W.E., Banovic, S. and McColskey, J.D. (2011). "High-Temperature Tensile Constitutive Data and Models for Structural Steels in Fire". NIST Technical Note 1714. U.S. Department of Commerce. National Institute of Standards and Technology. November.

[60] PennDOT (2011). "Effects of Fire Damage on the Structural Properties of Steel Bridge Elements", PennDOT, April 30.

[61] Labbouz, S., Glassman, J., Garlock, M.E.M., Ricles, J. (2014). "Evaluating Weathering Steel Performance at Elevated Temperatures: The I-195 Bridge Fire Case Study", Proceedings of the 7th International Conference on Structures in Fire, Shanghai, China, June 11-13.

[62] "Fire resistance tests", part 1 - EN 1363-1 - CEN - March 1999.

[63] Zhao B. and Fraud C. (2004). "Fire resistance analysis of open car parks with composite structures under real car fire", Conference on composite construction - July, South Africa.

[64] Joyeux D. (1997). "Natural fires in closed car parks - Car Fire Tests", CTICM report INC96/294d - DJ/NB - August.

[65] Bin Zhao and Joel Kruppa (2004). "Structural behaviour of an open car park under real fire scenarios", Fire and Materials.

[66] Thauvoye C. et al. (2010). "Method for calculating heat fluxes from a warehouse fire SFPE, 8th International Conference on Performance-Based Codes and Fire Safety Design Methods, Lund, Sweden 16-18 June.

[67] Dong Y. L., Prasad K. (2009). "Thermal and structural response of a two-story, two bay composite steel frame under fire loading", Proceedings of the Combustion Institute, 32, 2543-2550.

[68] Dong Y. L., Zhu E. C.,Prasad K., (2009). “Thermal and structural response of two-storey two-bay composite steel frames under furnace loading", Fire Safety Journal, 4. 
International R\&D Roadmap for Fire Resistance of Structures: Summary of NIST/CIB Workshop

[69] Bailey, C.G., Lennon, T., and Moore, D.B. (1999). "The behavior of full-scale steel-framed buildings subjected to compartment fires." The Structural Engineer, Vol. 77, No. 8, pp. $15-21$.

[70] Lennon,T., and Moore, D. (2004). Results and observations from full-scale fire test at BRE Cardington, 16 January 2003.

[71] Gille, M., Usmani, A.S., Rotter, J.M., (2002). "A structural analysis of the Cardington British Steel corner test", Journal of Constructional Steel Research, Vol. 58, No. 4, pp. 427-442.

[72] Luecke, W.E., McColskey, J.D., McCowan, C.N., Banovic, S.W., Fields, R.J., Foecke, T., Siewert, T.A., and Gayle, F.W. (2005). "Federal building and fire safety investigation of the World Trade Center disaster: Mechanical properties of structural steel." Technical Report NCSTAR 1-3D, National Institute of Standards and Technology. Available online at http://wtc.nist.gov.

[73] ASCE/SEI/SFPE 29-05 (2005). Standard Calculation Methods for Structural Fire Protection, Structural Engineering Institute, American Society of Civil Engineers, Reston, VA.

[74] EN 13381-4 \& 8 "test method for determining the contribution to the fire resistance of structural members: by applied protection to structural elements".

[75] EN 13381-5 "test method for determining the contribution to the fire resistance of structural members: by applied protection to concrete/profiled steel sheet".

[76] EN 13381-6 "test method for determining the contribution to the fire resistance of structural members: by applied protection to concrete filled hollow steel columns".

[77] Braxtan, N.J.L., Pessiki, S.P. (2011). "Post-earthquake Fire Performance of Sprayed Fire Resistive Material on Steel Moment Frames”. Journal of Structural Engineering, ASCE, 137(9), p.946-953.

[78] Ryder, N.L., Wolin, S.D., and Milke, J. (2002). "An Investigation of the Reduction in Fire Resistance of Steel Columns Caused by Loss of Spray-Applied Fire Protection", Journal of Fire Protection Engineering, Vol 12, February, p. 31-44.

[79] Mostafaei, H. (2009). “A Hybrid Fire-Resistance Test Method for Steel Columns, NRCCNRC Report \# IRC-RR-292, November.

[80] Mostafaei, Hossein (2013). "Hybrid fire testing for assessing performance of structures in fire - Application" Fire Safety Journal, v 56, p 30-38, 2013

[81] Mostafaei, Hossein (2013). "Hybrid fire testing for assessing performance of structures in fire - Methodology” Fire Safety Journal, v 58, p 170-179.

[82] Correia, António M.; Rodrigues, João Paulo C.; Korzen, Manfred (2012). “Experimental research on the load-bearing capacity of partially encased steel columns under fire conditions", Journal of Structural Fire Engineering, v 3, n 1, p 81-94, March.

[83] Henneton N., Kruppa J. and Zhao B. (2011). "Fire risk assessment for people in steel structure warehouses”, EUROSTEEL, September, Budapest, Hungary. 
International R\&D Roadmap for Fire Resistance of Structures: Summary of NIST/CIB Workshop

[84] Payá-Zaforteza, I, Garlock, M. (2012). "A numerical investigation on the fire response of a steel girder bridge”, Journal of Constructional Steel Research, Elsevier, V. 75, p.93-103. 59.

[85] Glassman, J., Garlock, M.E.M. (2014). "Shear buckling behavior of steel plate girders at elevated temperatures", Proceedings of the ASCE Structures Congress, ASCE, Pittsburgh, PA, May.

[86] Glassman, J., Garlock, M., (2014). "Elevated temperature evaluation of an existing steel web shear buckling analytical model." Accepted for publication in Journal of Constructional Steel Research, Elsevier.

[87] T. Kitano, O. Sugawa, H. Masuda, T. Ave \& H. Uesugi, (2000). "Large Scale Fire Tests of 4-Story Type Car Park (Part 1: The behavior of structural frame exposed to the fire at the deepest part of the first floor)", Proceedings of the Fourth Asia-Oceania Symposium on Fire Science and Technology, May.

[88] Hirashima, T., Wang, Y. and Uesugi, H., (2003). "Large Scale Fire Tests Of A 4-story Type Car Park Part 2 Analysis Of The Thermal Stresses And Deflections" Fire Safety Science 7: 655-666. doi:10.3801/IAFSS.FSS.7-655.

[89] Chen-Hung Lee, Yaw-Jeng Chiou, Hsin-Yang Chung, Chien-Jung Chen (2011). "Numerical modeling of the fire-structure behavior of steel beam-to-column Connections" Journal of Constructional Steel Research Vol.67 p.1386-1400.

[90] Hsin-Yang Chung, Chen-Hung Lee, Wun-Jie Su, Rih-Zeng Lin (2010). “Application of fireresistant steel to beam-to-column moment connections at elevated temperatures", Journal of Constructional Steel Research Vol. 66, p. 289-303.

[91] Kuo-Chen Yang, Sheng-Jin Chen, Ming-Chin Ho (2009). "Behavior of beam-to-column moment connections under fire load”, Journal of Constructional Steel Research, Vol. 65, p.1520-1527.

[92] Pakala, P., Kodur, V., Selamet, S., and Garlock, M.E.M. (2012). "Fire behavior of shear angle connections in a restrained steel frame", Journal of Constructional Steel Research, Elsevier, Volume 77, Pages 119-130.

[93] Buick Davison, J.; Burgess, Ian W.; Plank, Roger J.; Yu, Hongxia; Hu, Yin (2010). "Ductility of simple steel connections in fire", Proceedings of SDSS' Rio 2010: International Colloquium Stability and Ductility of Steel Structures, v 1, p 441-448.

[94] Guanyu Hu; Engelhardt, M. (2012). "Studies on the Behavior of Steel Single-Plate Beam End Connections in a Fire", Structural Engineering International, v 22, n 4, p 462-9, Nov. 2012.

[95] Selden, K., Fischer, E., Varma, A. (2012). "Experimental Evaluation of Composite Beams Subjected to Fire Loading", Proceedings of the7th International Conference on Structures in Fire, Shanghai, China, June 11-13. 
III. Timber

\author{
WHITE PAPER
}

\title{
FIRE RESISTANCE OF TIMBER STRUCTURES
}

A report for the National Institute of Standards and Technology

by

Andrew Buchanan, University of Canterbury, New Zealand

Birgit Östman, SP Wood Technology, Sweden

Andrea Frangi, ETH Zurich, Switzerland

Final report

28 June 2014
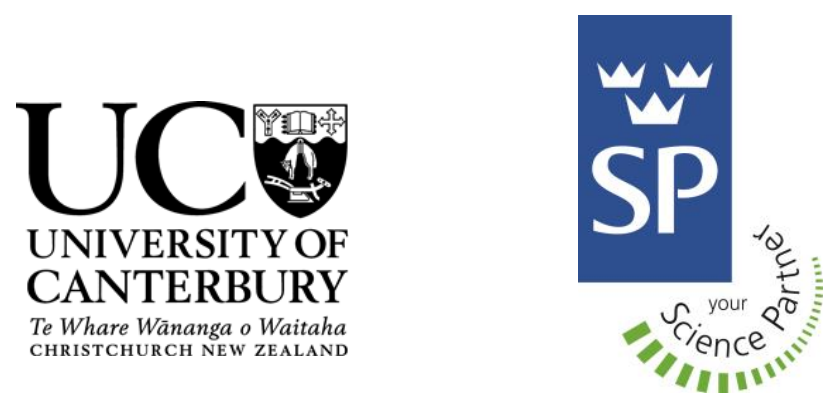

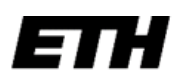

Eidgenössische Technische Hochschule Zürich Swiss Federal Institute of Technology Zurich 
International R\&D Roadmap for Fire Resistance of Structures: Summary of NIST/CIB Workshop

THIS PAGE LEFT INTENTIONALLY BLANK 


\section{Contents}

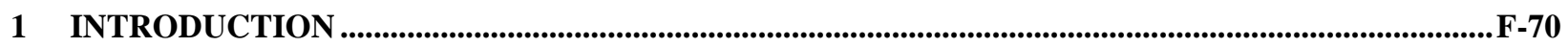

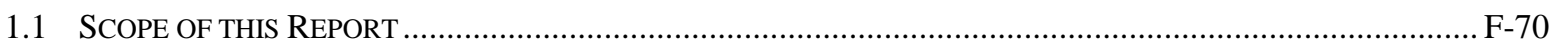

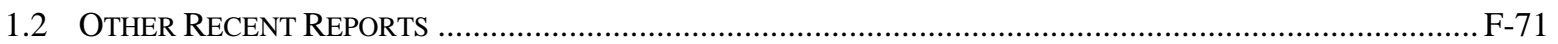

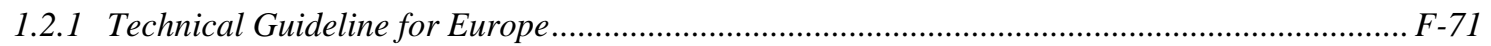

1.2.2 Fire Safety Challenges of Tall Wood Buildings ..................................................................... F-71

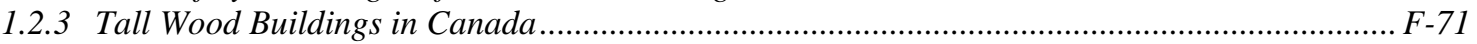

1.2.4 Use of Timber in Tall Multi-Story Buildings..................................................................... F-72

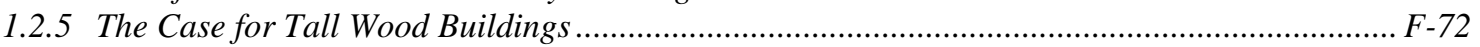

1.2.6 The Timber Tower Research Project ................................................................................... F-73

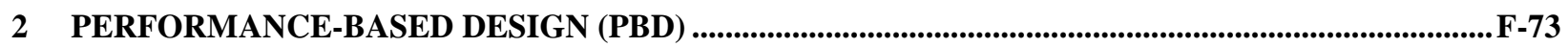

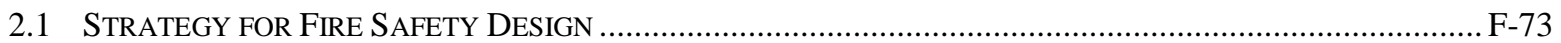

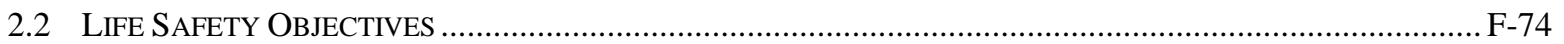

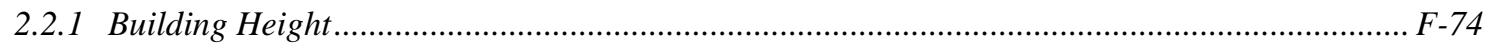

2.2.2 Performance Statements Related to Building Height ……….................................................... F-75

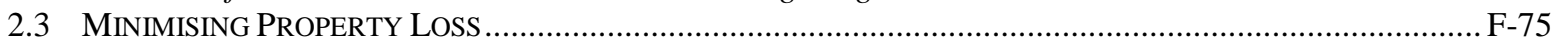

2.4 ESTABLISHING THE DESIGN LEVEL OF FIRE RESISTANCE ……......................................................... F-76

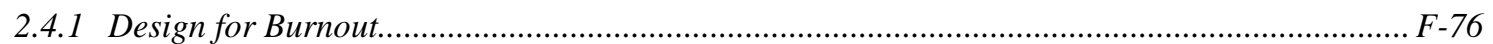

3 CURRENT STATE-OF-THE-ART .....................................................................................................................

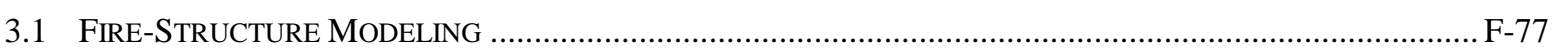

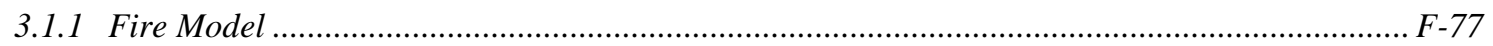

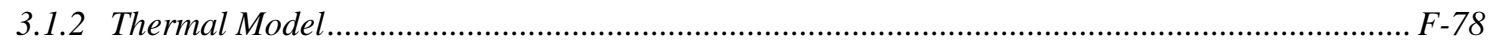

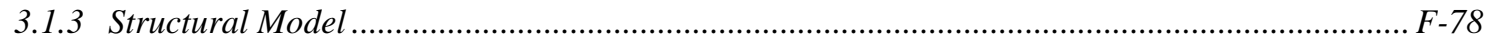

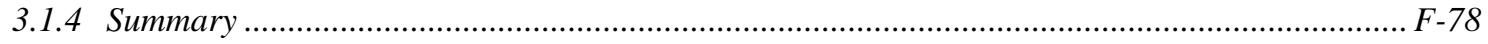

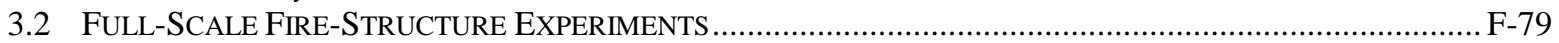

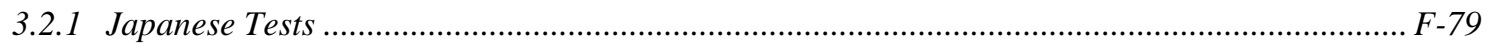

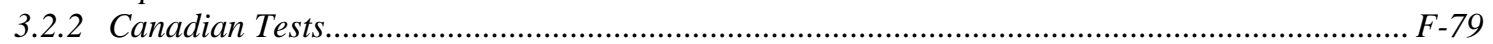

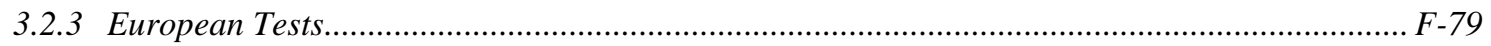

3.3 EXPERIENCE FROM FIRE ACCIDENTS IN TIMBER STRUCTURES....................................................... F-80

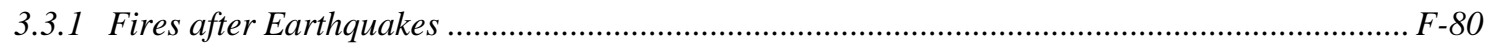

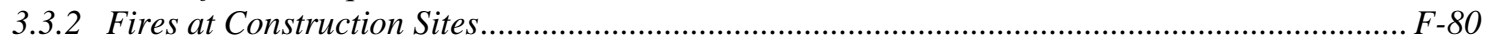

3.3.3 Fire Spread Caused by Poor Structural Detailing................................................................ F-80

4 IMPROVING THE FIRE PERFORMANCE OF TALL TIMBER BUILDINGS ..................................... F-80

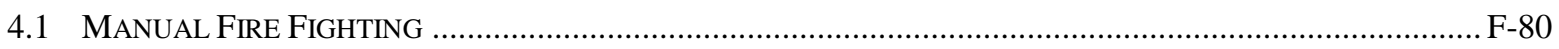

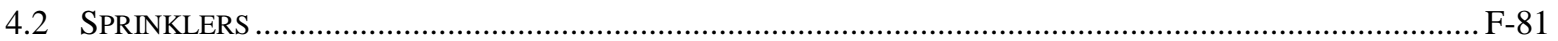

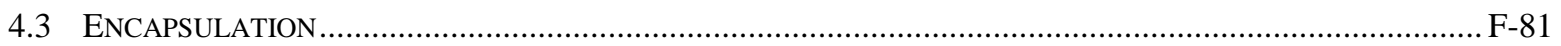

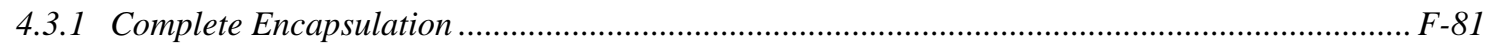

4.3.2 Limited Encapsulation ……………………..................................................................... F-81

4.3.3 Layered Encapsulation …………………….................................................................. F-81

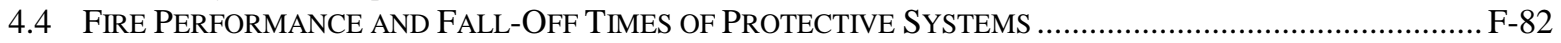

4.5 Fire PERFoRMANCE OF CONNECTIONS BETWEEN STRUCTURAL TIMBER ELEMENTS ................................ F-82

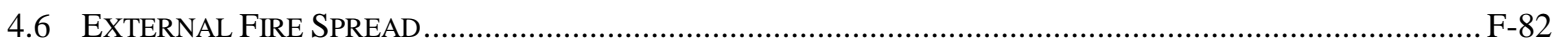

4.7 DETAILS TO PREVENT INTERNAL SPREAD OF FIRE .......................................................................... F-83

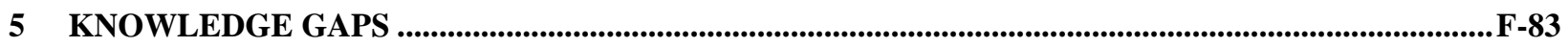

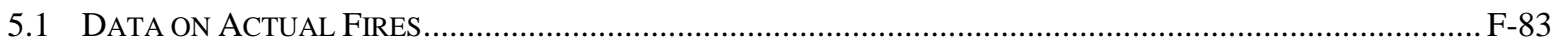

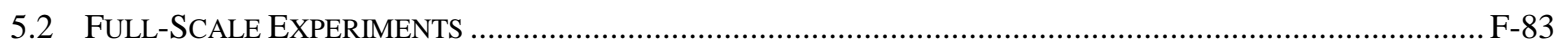




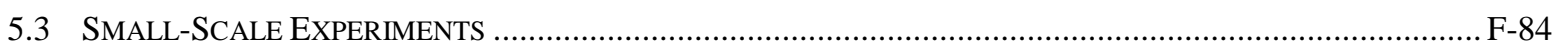

5.4 EVALUATION OF EXISTING FIRE TESTING EXPERIENCE …….................................................... 84

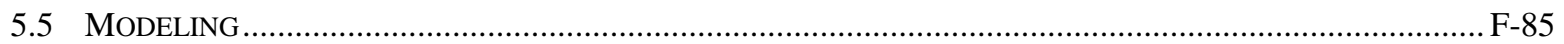

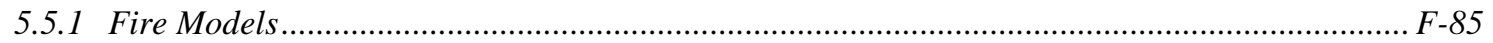

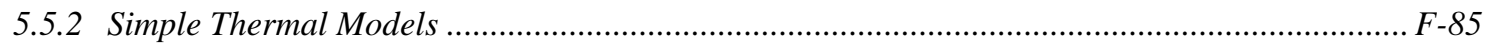

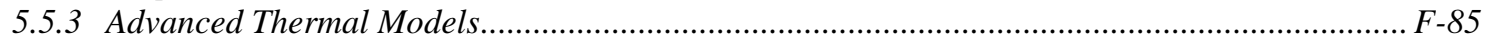

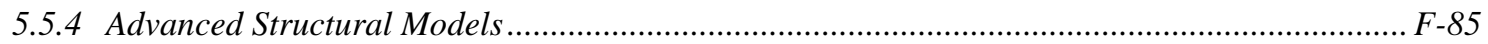

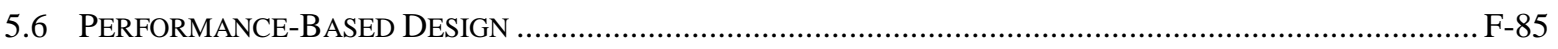

6 HOW BEST TO ADDRESS THE SEVEN FOCUSED TOPICS IN THE SCOPE OF WORK .............. F-86

6.1 IDENTIFY R\&D NEEDS FOR LARGE-SCALE EXPERIMENTS .................................................................. F-86

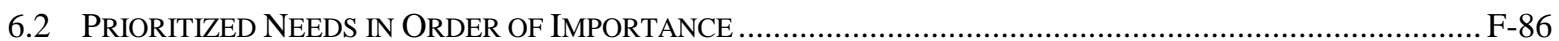

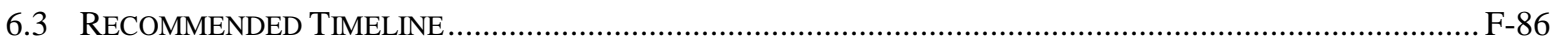

6.4 THE MOST APPROPRIATE INTERNATIONAL LABORATORY FACILITIES ................................................ F-87

6.5 POTENTIAL COLLABORATORS AND SPONSORS ……...........................................................................

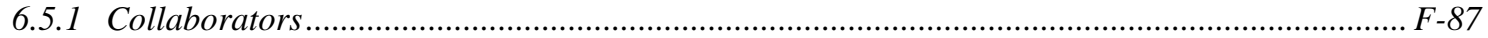

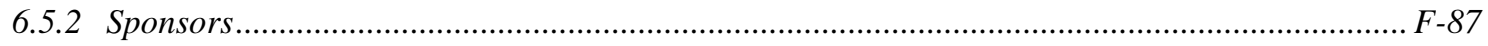

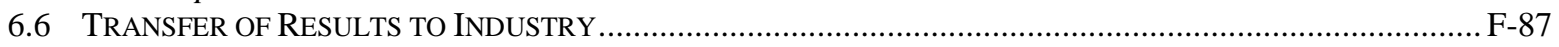

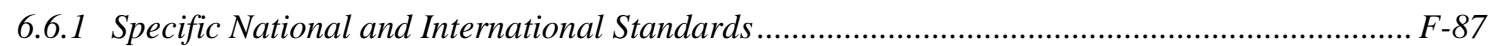

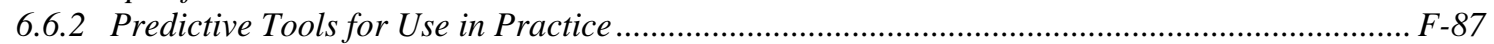

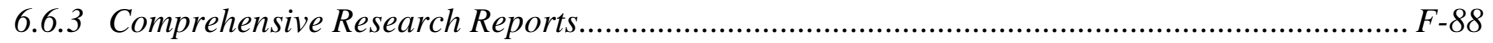

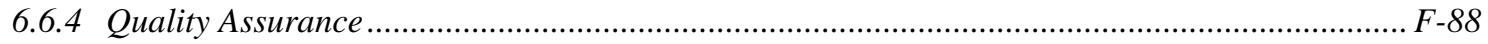

6.7 INTERNATIONAL COALITION TO REVIEW PROGRESS .......................................................................... F-88

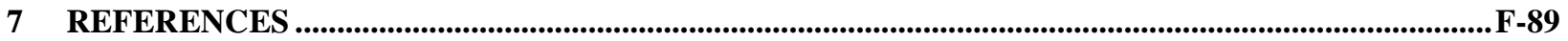




\section{Introduction}

Timber structures have experienced a renaissance during the recent few decades due to their environmental credentials, and societal goals striving for sustainable development with lower energy demands and less pollution in all sectors including the construction sector that stands for a major part of the overall community economy.

However, the combustibility of timber still limits its use as a building material by restrictions in building regulations in most countries, especially for higher and larger buildings. Several research projects on the fire behaviour of timber structures have recently been conducted worldwide aimed at providing basic data on the safe use of timber. The results have been relaxations introduced during recent years, especially in Europe.

Overall, the research and basic understanding of timber structures in fire is limited compared to traditional building materials, since large timber structures have been forbidden for a long time. The developed design concepts and models are mostly limited to standard time-temperature exposure (e.g. ISO 834-1 and ASTM E119). The need for further studies of the fire behaviour of timber structures is therefore large, in particular with regard to the global structural behaviour of realistic buildings exposed to natural fires.

\subsection{Scope of this Report}

Fire resistance of timber structures is a very large field. In order to keep this document relatively small, the scope of is limited as follows:

- This report attempts to define a Performance-Based framework for the fire safety design of multi-story timber buildings.

- The report concentrates on medium-rise multi-story timber buildings from 3 stories to 10 stories tall, which are likely to be most popular and technical feasible. Taller buildings are discussed briefly.

- The report concentrates on "mass timber" buildings, constructed from large timber posts and beams (from LVL or glulam) and large wood panel construction using cross-laminated timber (CLT) or other heavy timber panels. Light wood frame buildings protected with gypsum plasterboard ( 2 by 4 construction) have been covered elsewhere and are not considered to be feasible for building above about 6 stories.

- The report concentrates on the fire resistance of structural elements and assemblies, and does not include early fire safety issues such as ignition and flame-spread on wood surfaces. It does not address broader fire safety issues such as fire safety systems, fire fighting, or evacuation.

- External fire spread via building facades and windows is partly included, since wooden façade claddings are considered by many architects to be an essential feature of timber buildings, at least up to 8-10 stories.

- Automatic fire sprinkler systems are discussed briefly, since the combination of active and passive fire protection is considered to be an important way to provide fire safety for tall timber buildings. 
- Fire resistance of timber connections is included briefly, including both mechanical fasteners and glued connections. The influence of adhesives on the fire behaviour of bonded structural timber elements is discussed briefly.

\subsection{Other Recent Reports}

There are a number of excellent recent international publications on fire safety in timber buildings. These publications are summarised below.

\subsubsection{Technical Guideline for Europe}

A comprehensive European report (Östman et al., 2010) describes the work of a multi-national committee which produced "Fire Safety in Timber Buildings - Technical Guideline for Europe". This comprehensive 200 page document gives the background and design methods for designing timber buildings to have similar fire safety to buildings of other materials. The report refers mainly to fulfilling requirements according to the recent European system for fire safety in buildings (CPD), but the basic principles are all applicable in North America and elsewhere.

This excellent report has chapters on fire safety objectives, wood products as linings, flooring and facades, fire stops, service installations and active fire protection. Advanced calculation methods are provided for both separating timber structures and load-bearing timber structures with and without layers of gypsum board protection. Performance-based fire design is discussed with reference to methods of quantitative risk assessment.

\subsubsection{Fire Safety Challenges of Tall Wood Buildings}

More recently the Fire Protection Research Foundation (Gerard et al., 2013) has produced "Fire Safety Challenges of Tall Wood Buildings" which has an extensive literature list and case studies of modern timber buildings around the world.

The report also gives a comprehensive gap analysis, leading to recommendations for future research and testing:

- Fire testing of new and innovative timber and hybrid solutions

- Full-scale / large-scale fire testing of mock up tall timber frames

- Natural fire testing in full-scale / large-scale tall timber frames

- Economic analysis to quantify construction, operation and costs of tall timber buildings

- Emphasis on effective risk communication and education.

\subsubsection{Tall Wood Buildings in Canada}

FPInnovations (2013) has recently published a 90\% draft of the "Technical Guide for the Design and Construction of Tall Wood Buildings in Canada". Chapter 5 (Fire Safety and Protection) covers much of the same material from a Canadian perspective in 60 pages. Understandably, this report is strongly related to the objective-based National Building Code of Canada (NBCC), with much attention on providing an "alternative design" which meets the minimum fire performance implied by the "acceptable solution" of the prescriptive Division B of the NBCC. Unfortunately this concentration on the NBCC draws attention away from the basic principles of fire safety design. 
The report gives recent examples of heavy timber construction in Canada, with useful sections on the fire resistance of penetrations and concealed spaces, façade spread, and flame spread rating of exposed timber surfaces, with a useful summary of risk assessment methods for fire safety.

Section "5.12 Consideration of Major Natural Disasters" describes the need to design some buildings for extreme scenarios where water supplies and emergency services may not be available. Such events have very low probability but potentially high consequences, especially for tall buildings. Design for such disasters requires design for complete burnout including the decay phase of any compartment fire, hence stringent measures such as "complete encapsulation" of the timber structure and provision of an emergency on-site water supply.

To provide fire safety equivalent to non-combustible steel or concrete construction, the report promotes "complete encapsulation" of wood to provide two hours of fire resistance before any charring of the underlying wood occurs. Some situations may be satisfactory with "limited encapsulation" and others with fully exposed timber surfaces, provided that the building code requirements are met. This is discussed in more detail later in this report.

\subsubsection{Use of Timber in Tall Multi-Story Buildings}

The International Association for Bridge and Structural Engineering (IABSE) has recently published a Structural Engineering Document (SED) on the Use of Timber in Tall Multi-Story Buildings (Smith and Frangi, 2014). The document addresses a reawakening of interest in timber and timber-based products as primary construction materials for relatively tall, multi-story buildings. Emphasis throughout is on the holistic addressing of various issues related to performance-based design of completed systems, reflecting that major gaps in know-how relate to design concepts rather than technical information about timber as a material.

Special consideration is given to structural form and durability aspects for attaining desired building performance over lifespans that can be centuries long. Chapter 3 describes fire safety concepts for tall buildings, based on the scenario that occupants located in upper parts of buildings cannot leave during fires, and fires cannot be extinguished so they may continue until all combustible material in any affected fire compartments has burned. Based on this scenario, fire requirements for building elements are formulated as follows:

- Separating elements shall be designed in ways that sustain a full burnout, thereby preventing uncontrolled spread of fire to other parts of buildings throughout the duration of a fire

- Load-bearing building elements shall be designed in ways that prevent their structural collapse during full burnout without intervention of the fire fighters.

Thus, for tall multi-story timber buildings, the authors put emphasis on the concept of "encapsulation" of the timber structure and/or the use of hybrid structural elements (e.g. timberconcrete composite slabs).

\subsubsection{The Case for Tall Wood Buildings}

This current interest in tall wood buildings has led to two major feasibility studies for tall buildings. Vancouver architect Michael Green (2012) has produced possible designs for 10, 20 
and 30 story timber buildings in "The Case for Tall Wood Buildings - How Mass Timber Offers a Safe, Economical, and Environmentally Friendly Alternative for Tall Building Structures”.

The report covers many important aspects of fire safety, but falls short of a clear strategy to meet all the Canadian Code requirements, especially for very tall buildings.

The main thrust for fire safety design is to design in such a way that the timber building can be equivalent to non-combustible construction; that is to achieve "an equal level of performance to that outlined in the acceptable solutions to the Building Code". This is to be achieved with reliance on sprinkler systems, together with the predictable charring rate of heavy timber, and encapsulation where necessary.

The report does not suggest designing for complete burnout of a fire compartment. It covers the possibility of sprinkler failure by providing a 2-hour fire resistance rating to critical structural elements. In extreme events it is expected that "fire department resources would be dispatched and able to suppress the fire condition before the 2-hour fire duration is achieved." It does not adequately cover the case of a post-earthquake fire where the fire-fighting services may be unavailable, other than saying that more research is needed on built-in fire protection systems and their reliability in post-earthquake fire scenarios.

\subsubsection{The Timber Tower Research Project}

Skidmore Owings and Merrill (SOM, 2013) has produced a feasibility study for a 42 story timber building in Chicago, "The Timber Tower Research Project," based on an existing reinforced concrete tower of the same size. Fire safety is addressed with broad principles but no details. It blithely states that "fire burnout time should be considered" and "fire cannot be allowed to jump between floors" (page 23). It also recommends "flammability tests ... to verify that fires will self-extinguish" (page 44). Unfortunately this report does not provide much confidence regarding occupant safety in a 42 story timber building in the event of an unwanted fire, especially if the sprinklers do not work for any reason.

\section{Performance-Based Design (PBD)}

\subsection{Strategy for Fire Safety Design}

Performance-based design (PBD) is becoming the long-term objective of code-writers and designers, not only for fire safety. In simple terms this means designing to a target level of performance rather than simply meeting the requirements of a prescriptive building code.

The actual specification and adoption of performance-based design is very different in various countries, depending on the national fire code environment.

PBD for fire safety can mean many different things. For example, any of these could be called PBD:

- Providing the code-specified levels of fire resistance

- Providing the same level of fire safety as the prescriptive code requirements

- Providing a fire safety equivalent to a code-complying steel or concrete structure 
- Providing specific levels of fire performance, such as meeting a specified time for escape and/or fire-fighting

- Providing fire resistance to a complete burnout in the absence of fire-fighting

All of these can be specified either on a deterministic basis, or a probabilistic basis using quantified risk assessment tools. Most structural design codes (for non-fire conditions) use a semi-probabilistic approach to provide a design that meets a target failure probability, which could be extended to design for fire safety. Full-scale structural fire risk assessment is still in its infancy, so more research in this area is required (De Sanctis et al., 2014).

The authors of this report suggest that modern building codes should move towards performance-based design for fire safety. A clear definition of performance-based fire design is needed, as this will be of great benefit to code-writers and building designers. Ideally this should have the same basic philosophy for all building materials in all jurisdictions.

\subsection{Life Safety Objectives}

The over-riding objective of fire engineers is to ensure life safety (occupants and fire fighters). This is achieved either by allowing people to escape, or by protecting them in-place with guaranteed containment of the fire and prevention of structural collapse.

The European Construction Products Directive (CPD) has introduced essential requirements on fire safety that structures must be designed and built such that, in the case of fire:

- Load-bearing capacity can be assumed to be maintained for a specific period of time

- The generation and spread of fire and smoke is limited

- The spread of fire to neighbouring structures is limited

- Occupants can leave the building or be rescued by other means

- The safety of rescue teams is taken into consideration

\subsubsection{Building Height}

Building height is critical. For low-rise buildings life safety can be achieved by ensuring that all occupants have time to escape the building. Once everyone has escaped, it may be acceptable to allow a building to burn to the ground, depending on the size and value of the building and its contents.

Escape cannot be relied on for tall buildings with many people living or working above the fire floor. For buildings up to about 8 stories (the maximum achievable height of fire-fighting ladders) there is a possibility of fire-fighting and rescue via ladders, but both become very difficult as building height increases above 3 or 4 stories.

The taller the building, the greater the possibility of a fire occurring on an upper floor and people being trapped above the fire floor - a potentially disastrous combination. Tall buildings require a long escape time, and they have slow internal access for fire fighters. It is likely that full encapsulation may be required in order to meet the performance requirements for timber buildings taller than about 8 stories. 
If people are to remain safe in tall buildings, it is essential to contain the fire, and prevent structural collapse. If the fire is above the height of fire-fighting ladders, there needs to be total reliance on fire resistance for a complete burnout. There is also danger of vertical fire spread via windows, which is addressed in relation to wooden façade claddings in this report.

This discussion is somewhat beyond the initial scope of the report, but it is included to show the vital importance of providing fire resistance for complete burnout for very tall buildings. This then becomes a critical research need for tall timber structures.

\subsubsection{Performance Statements Related to Building Height}

Combining the points above, it is suggested that rational performance requirements for all tall buildings should be related to the height of the building and the location with height in the building.

The performance requirements will increase with the height of the building, for the reasons given above. In the most general form, for timber buildings, the requirements might be based on this type of hierarchy:

\begin{tabular}{|l|l|l|}
\hline & \multicolumn{1}{|c|}{ Possible level of specified performance: } & \multicolumn{1}{|c|}{$\begin{array}{c}\text { Possible design strategy } \\
\text { for timber elements: }\end{array}$} \\
\hline Low-rise buildings & $\begin{array}{l}\text { Escape of occupants with no assistance } \\
\text { No property protection }\end{array}$ & No encapsulation \\
\hline Mid-rise buildings & $\begin{array}{l}\text { Escape of occupants with no assistance } \\
\text { Some property protection }\end{array}$ & No encapsulation \\
\hline Taller buildings & $\begin{array}{l}\text { Escape with firefighter assistance } \\
\text { Burnout with some firefighting intervention }\end{array}$ & Limited encapsulation \\
\hline Very tall buildings & $\begin{array}{l}\text { Protect occupants in place } \\
\text { Complete burnout with no intervention }\end{array}$ & Complete encapsulation \\
\hline
\end{tabular}

The definitions of building height need work, and may be different in different jurisdictions. In all cases, active fire-safety precautions like sprinklers will help to reduce the risk of serious damage, supplemented by on-site water storage in special cases. The level of safety may need to be assessed by a probabilistic fire risk assessment, especially for very large or very tall buildings.

For the very tall buildings, the performance statement might be:

"Very tall buildings shall be designed in such a way that there is a very low probability of fire spread to upper floors and a very low probability of structural collapse, at any time during a fire regardless of whether or not the fire can be controlled by fire-fighting services and/or suppression systems".

\subsection{Minimising Property Loss}

Property losses are often not included in national building regulations, since the main focus is life safety. However, insurance companies have been increasingly interested in this topic during 
recent years, since they have insufficient information of property losses in larger and taller timber buildings. The risk for property losses increases with the size of the building.

Property losses are out of scope for this paper, but should be handled separately, preferably by careful risk and cost benefit analysis, leading to additional performance requirements.

\subsection{Establishing the Design Level of Fire Resistance}

Once the performance requirements have been established, it becomes necessary to provide an appropriate level of fire resistance. Buchanan (2001) outlines four criteria that are considered when determining the level of fire resistance, depending on the size and importance of the building:

- Time for occupants to escape from the building

- Time for fire-fighters to carry out rescue activities

- Time for fire-fighters to surround and contain the fire

- A complete burnout of the fire compartment with no fire-fighter intervention

For very tall or important buildings, the design strategy must be a design for complete burnout of the fire compartment, with no spread of fire to other parts of the building. Design methods (and codification of design methods) for burnout are not well advanced. Some national building codes allow buildings to be provided with levels of fire resistance which would allow failure of the building before complete burnout occurs. For very tall buildings, this could lead to the possibility of some disastrous fires in the future, although the probability is very low if other precautions such as automatic sprinklers are provided.

\subsubsection{Design for Burnout}

The most common way of designing for burnout is to use a time-equivalent formula to estimate the equivalent fire severity (exposure to a standard fire) for the complete process of an uncontrolled fire from ignition through fire growth, flashover, burning period and decay to final extinguishment. Such time-equivalent formulae assume that the fire severity is a function of the fire load, the available ventilation, and the thermal properties of the surrounding materials of the fire compartment. These values should be determined on a probabilistic basis, with higher safety factors for increasingly tall buildings.

The requirement of safety equivalence has some problems, especially when requiring the equivalence of performance-based design approaches to prescriptive design criteria. The reason is that the safety level of prescriptive approaches depends on building properties and varies for different buildings (De Sanctis et al., 2014).

More research is required to assess the applicability of current time-equivalent formulae for use in multi-story timber buildings. The fire severity, hence the time-equivalent formula, will depend on whether the wood structure has no protection, limited encapsulation or complete encapsulation. 


\section{Current State-of-the-Art}

\subsection{Fire-Structure Modeling}

Modern structural design methods require the use of sophisticated computer modeling to predict the actions from applied loads or fire exposure, and to predict the capacity of structures and structural members to resist those actions. Large scale or small scale experiments are necessary to calibrate and verify computer models.

The main components of such a model are shown in Figure 1 (Buchanan, 2008). As with all structural materials, any advanced modeling of the fire resistance of timber structures must include both thermal modeling and structural modeling, integrated as far as possible, but all is dependent on an accurate fire model.

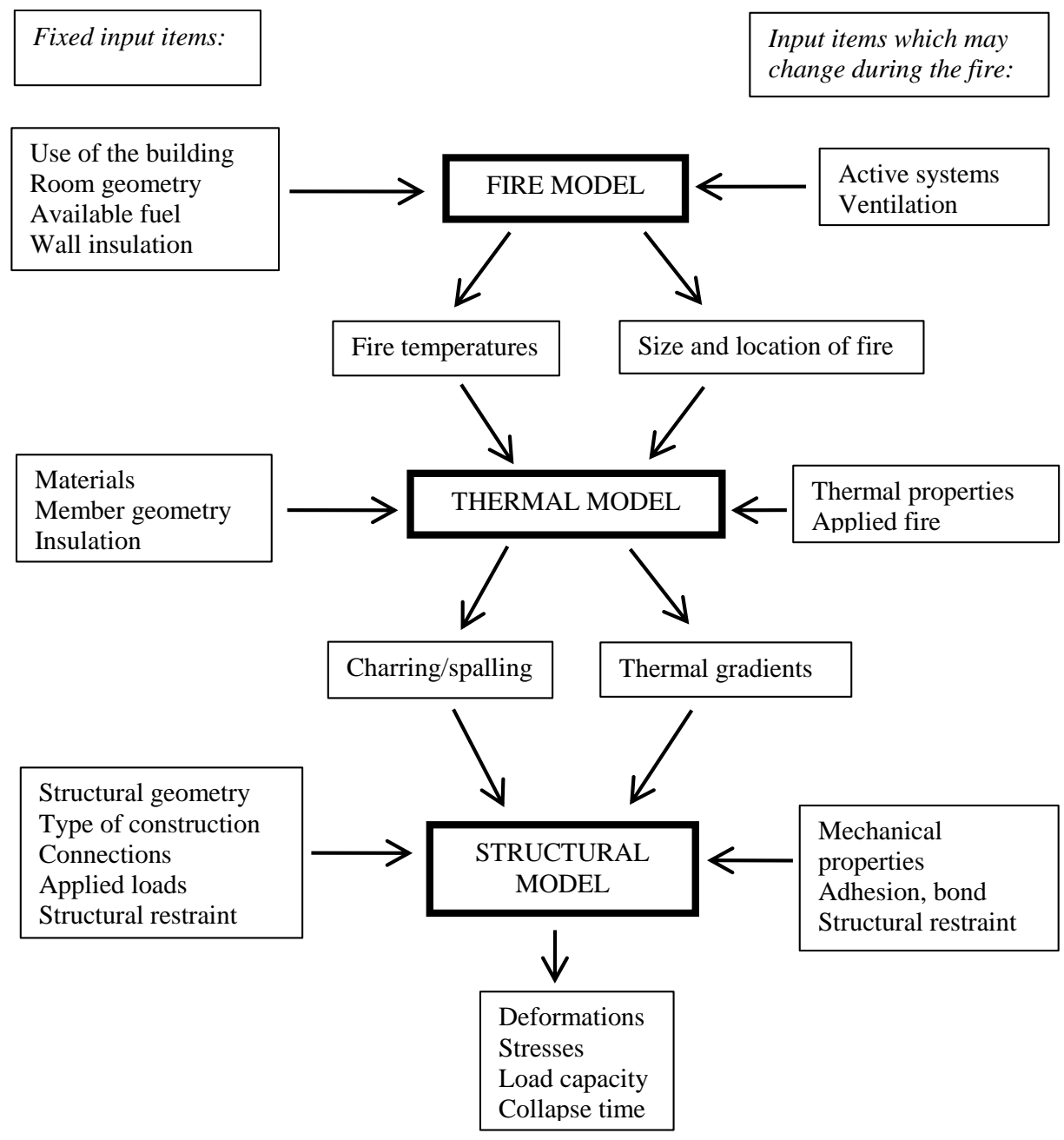

Fig. I. Flow Chart for Predicting Structural Fire Performance

\subsubsection{Fire Model}

An accurate fire model is a fundamental part of fire-structure modeling. Accurate models are still not available for post-flashover fires in non-combustible compartments. There is even less 
accuracy for compartments with combustible structural materials available to fuel the fire. More work on this is proceeding, and any new models will need to be verified with large-scale tests. Results are awaited from Canada of current research "intended to provide fire time-temperature curves that are more realistic to expected fire behavior" (Gerard et al., 2013).

VTT has recently published a report (Hietaniemi \& Mikkola, 2010) on design fires appropriate for use in Fire Safety Engineering (FSE) design in general and thus applicable also for buildings with wood. The initial fire growth is quantified using heat release rates which are dependent on the usage of the building. Assessment of fire growth and spread is based on the capability of the FDS fire simulator to make conservative estimations of how rapidly and to how large a fire may grow within a given space. Existing fire models need to be expanded to include changes in ventilation conditions as the fire grows, and to include travelling fires in large spaces. For timber structures, they also need to include the contribution of combustible building materials.

\subsubsection{Thermal Model}

The thermal model is essential for timber structures exposed to fires, because this is the model which predicts the rate of charring as a function of fire exposure. This is relatively easy for large elements of timber exposed to the standard time-temperature exposure (e.g. ISO 834-1 and ASTM E119) because many tests have shown predictable charring rates for different types of wood products and wood species exposed directly to standard fires. For initially protected timber elements, different charring rates should be applied during different phases of fire exposure, before and after falling off of the protective boards (König and Walleij, 1999). The predictable behaviour of heavy timber in fires allows simple excel calculations based on charring rate to predict the fire resistance of most structural timber elements such as beams, columns, walls and floors. However this is much more complicated for non-standard fire exposure, and for timber structures which are fully or partially protected with other materials. The thermal model needs to allow for the decay phase of the fire, and the possibility or not of self-extinguishment after the available fuel is consumed.

\subsubsection{Structural Model}

Wood structures are generally easier to structurally model than steel or concrete structures because of the low conductivity of wood and the lack of significant thermal expansion. The heataffected layer below the char layer is generally very thin $(\sim 20-40 \mathrm{~mm})$ so that the structural performance of the wood below this layer is essentially the same as wood at ambient temperatures. Advanced FEM methods are not often required because the simple calculations based on charring are sufficiently accurate.

\subsubsection{Summary}

The major obstacles to fire-structure modeling in realistic fires are:

1. Knowing the expected temperatures in fully developed fires

2. Knowing the charring rate as a function of fire exposure

3. Knowing the temperature and moisture dependent thermal and mechanical properties of heated timber

4. Knowing the self-extinguishment properties of charred wood 
5. Predicting the fire performance and fall-off times of protective systems (e.g. gypsum plasterboards)

6. Predicting story to story fire spread via combustible façade cladding

7. Predicting the effectiveness of details to prevent internal spread of fire

8. Predicting the fire performance of connections between structural timber elements

\subsection{Full-Scale Fire-Structure Experiments}

Very few large scale experiments have been carried out on large timber buildings. Large scale tests are very expensive, so the objectives of any such tests must be clearly defined before starting. Some of the information needed is summarised above in Section 3.1.4.

Tests have been carried out in several different countries. Unfortunately many of these tests have attempted to answer too many questions, so that the test results are of limited use.

\subsubsection{Japanese Tests}

Three recent tests on Japanese 3-story school buildings have been performed (Hasemi et al., 2014). The aim was to demonstrate to the national authorities that the fire safety goals can be achieved. This goal seems to have been reached by the latest test (Japanese full-scale fire tests, 2012-2013).

Several full-scale fire tests of whole timber buildings have been performed in Japan in the late 90s, most of them first being subjected to a simulated earthquake (Hasemi, 1989). These tests, mostly of light timber frame buildings protected with gypsum plasterboard, have demonstrated limited fire damage.

\subsubsection{Canadian Tests}

Tests have been performed in Canada on single rooms constructed from CLT panels (protected and unprotected). Some tests had a second flashover during the decay phase. Results are presented by McGregor (2013).

\subsubsection{European Tests}

Room fire tests with and without encapsulated timber structures were performed in a Nordic project (Hakkarainen, 2002) showing that the room temperature during fire was similar in all cases, but that the non-encapsulated timber structures caused heavy flames out of the windows. These were caused by unburnt gases being produced in the room due to lack of oxygen. Similar results have been obtained in tests performed in Switzerland (Frangi and Fontana, 2005). Further, it was demonstrated that by protecting the timber structure adequately, a complete burnout of the fire compartment with no fire-fighter intervention can be achieved, without any significant damage to the timber structure. A series of tests performed with activated sprinklers confirmed that with a fast response sprinkler system the influence of a combustible structure on the fire safety was compensated and the fire safety objectives can be fulfilled with combustible timber structures. Despite a fast fire development, the structure was undamaged because the sprinkler system extinguished the fire at an early stage. 
A full-scale test on a 3-story building made of CLT panels was performed under natural fire conditions to check the global performance and find possible weaknesses of the timber structure (Frangi et al., 2008). The CLT panels were protected by one or two layers of non-combustible gypsum plasterboards. The test confirmed that with pure structural measures it is possible to limit the fire spread to one room even for timber structures. However, the fire was suppressed by the fire-fighting intervention after one hour.

\subsection{Experience from Fire Accidents in Timber Structures}

Some examples of fire accident types are highlighted in order to supply background information to the need for extended knowledge and research.

\subsubsection{Fires after Earthquakes}

The biggest danger of fires after earthquakes is the lack of water for fire-fighting and poor access for fire-fighting vehicles. This is a serious threat to timber buildings, especially light timber frame structures. The most well-known recent examples of severe fires after earthquakes are probably the 1989 earthquake in Kobe, Japan, and the 2011 Japanese earthquake and tsunami (Sekizawa et al., 2014). The 2010 and 2011 earthquakes in New Zealand caused very few fires in any kinds of buildings, even though thousands of light timber frame houses suffered severe shaking damage (Baker et al., 2012).

\subsubsection{Fires at Construction Sites}

Fires at construction sites with timber frame structures have been gaining large publicity recently, mainly in the UK and the US. They seem to have been associated mainly with large areas of construction work without any fire separation and without the final fire protection systems having been installed yet. This topic is not directly included in this report, but as it may influence the further use of timber structures, some guidance should be given.

\subsubsection{Fire Spread Caused by Poor Structural Detailing}

Structural details in buildings are always very important for the total fire safety of buildings and insufficient detailing may have larger consequences in timber buildings. A recent example is a small kitchen fire at the top floor of a student residential building that caused a total damage of a five story timber building in Sweden. The main reasons were inferior kitchen ventilation, large attic space without fire separation and most importantly insufficient fire stops in the multi story vertical voids between the fire cells.

\section{Improving the Fire Performance of Tall Timber Buildings}

\subsection{Manual Fire Fighting}

The risk of severe fires will be reduced if there is prompt action to suppress the fire, either by the building occupants or by the fire brigade. According to EN 1991-1-2 intervention of the fire brigade is considered by reducing the characteristic fire load. This reduction in fire load has been calibrated by Schleich and Cajot (2002) for steel structures, and the same approach could be allowed for structures of any other materials including timber. A similar approach can be used for automatic fire detection or for automatic fire sprinkler systems, as described below. On-site 
emergency water supplies for manual or automatic suppression systems may also reduce the risk of major losses.

\subsection{Sprinklers}

Automatic fire sprinkler systems are the most effective way of improving the fire safety in all buildings. They are especially recommended for use in tall timber buildings.

Some building codes (e.g. Switzerland) allow for a reduction in the fire resistance if automatic fire sprinkler systems are installed. A reduction of fire resistance to $60 \%$ of the normal value is included in Eurocode 1 for sprinklered buildings. For an individual building owner this may be important, but the potential benefits of sprinklers require a quantitative fire risk assessment be taken into account, also including risks from earthquakes, maintenance, and an overwhelmed water system. The New Zealand Building Code allows a 50\% reduction in fire resistance for sprinklered buildings under certain conditions.

It should be noted that the reliability of sprinkler systems usually are much higher than for many systems of passive fire protection, fire doors probably being the most obvious example with reliability levels down to $70 \%$ (BSI PD, 2013). Sprinkler installations may also allow for a wider use of visible wood on internal and external building surfaces. This has been verified by risk analysis (Nystedt, 2011, 2012).

\subsection{Encapsulation}

The FP Innovations report (2013) and the IABSE SED (Smith and Frangi, 2014) give a lot of emphasis to encapsulation, in two categories, either complete encapsulation or limited encapsulation. The purpose of encapsulation is to ensure that structural timber does not contribute to the fire load, and also to ensure that the fire does not continue to burn after the combustible contents of any fire compartment have been completely burned away. The Japanese concept of "Fire Resistive Construction" has similar objectives, as explained in Section 5.4.

\subsubsection{Complete Encapsulation}

Complete encapsulation provides sufficient thickness of gypsum plasterboard or other similar material to prevent any charring of the wood in a complete burnout, thereby providing the same level of fire resistance as a totally non-combustible material. It is suggested in FPInnovations (2013) that two layers of Type X gypsum board will prevent the onset of charring for 2.0 hours exposure to the standard fire, giving total fire resistance of up to four hours in many cases. This claim needs to be verified because it depends on the thickness, the fixing details, and they type of gypsum board.

\subsubsection{Limited Encapsulation}

Limited encapsulation is a more economical solution which will prevent any involvement of the structural timber in the fire until well into the burning phase, but may not guarantee complete burnout with no onset of charring.

\subsubsection{Layered Encapsulation}

Layered encapsulation refers to timber structural elements made up of layers of wood and noncombustible materials. In some cases this may be a timber member with limited encapsulation, 
covered with an additional wood layer to improve the appearance and the fire resistance. Many different combinations of materials are possible, all requiring more research and testing.

\subsection{Fire Performance and Fall-Off Times of Protective Systems}

Protective layers such as gypsum plasterboards are often used to protect timber structures from fire. For the verification of fire resistance, full-scale testing or calculation using design models can be used. The latter needs input values which describe the contribution of the cladding (lining) to the overall fire resistance of the construction. Fall-off time of the cladding is one of the parameters needed, but it is seldom monitored properly in full-scale fire tests, although it has large impact on the fire resistance (Just et al., 2010). Further, fall-off time of the cladding based on standard time-temperature exposure (e.g. ISO 834-1 and ASTM E119) may not reflect the fire behaviour for non-standard fire exposure (Frangi et al., 2008).

A related problem is the variability between different types of gypsum plasterboard from different manufacturers in different countries. The contribution to the fire resistance of gypsum plasterboards is not specified in standards such as the European product standard for gypsum plasterboards (EN 520) or for gypsum fibreboards (EN 15283) nor the design standard for timber structures, Eurocode 5, part 1-2, (EN 1995-1-2). Hence important characteristics are lacking as input for the design models.

A methodology (routine) has to be developed to obtain input values for design models, such as the model in the fire part of Eurocode 5. These need to be verified by full-scale tests. The methodology developed should be implemented in an official document (e.g. national or international standards) and used by notified bodies to certify material characteristics not covered by other standards. Currently, a European standard (prEN 13381-7) is under development, providing test methods for determining the contribution to the fire resistance of applied protection (e.g. gypsum plasterboards) to timber structural members.

\subsection{Fire Performance of Connections between Structural Timber Elements}

Prior to the 1990s, knowledge of the fire performance of timber connections was limited. At that time, there was no method for assessing the behaviour of wood joints exposed to fire, nor for calculating their load carrying capacity in fire (Carling, 1989). In the last two decades, this area has received large attention and several research efforts have been devoted to the analysis of the fire performance of timber connections. So far, extensive experimental and advanced numerical studies have been performed (Noren, 1996; Moss et al., 2009; Cachim and Franssen, 2009; Erchinger et al., 2010; Frangi et. al., 2010; Peng et al., 2010, Audebert et al., 2013); however, simple models for design in fire are still limited. Further, current knowledge is limited to standard time-temperature exposure (e.g. ISO 834-1 and ASTM E119).

\subsection{External Fire Spread}

The main risk for external fire spread is from big flames coming out of windows in a fully developed compartment fire and spreading upwards along the façade. Such flames usually reach the story above independent of building material and this is accepted in most building regulations. But there is no consensus or procedures on how to determine the risk for the external flames reaching two stories above the compartment fire. The issue is handled differently and 
only on a national basis. For timber structures, the main interest is to verify that wooden facades can be used in a fire safe way, also as façade claddings on, e.g., concrete or steel buildings.

There are also risks for fire spread between adjacent buildings. These risks are considered to be independent of the structural building system used, although the contribution of combustible cladding materials should be included.

\subsection{Details to Prevent Internal Spread of Fire}

The execution of construction works is critical to good building performance; inappropriate practices can lead to critical building damage, which can generally only be rectified at considerable financial expense.

In order to achieve the required fire safety level, the fire behaviour of the building construction, service installations, and additional safety measures must be reviewed and assured. The evaluation factors are interlinked, and interfaces (assembly of wall or ceiling configurations) with related fire resistance requirements as well as reaction to fire performance of encapsulated combustible load-bearing structure must be quantified.

Fire spread can be minimized with internal fire stops as well as at interfaces, for example with penetration seals for the electric installation or heating systems, or additional safety measures such as preventive structural measures, but also the application of specific active fire protection systems such as sprinklers or smoke detectors.

Connections of wall, ceiling and roof elements have a significant influence on the fire behaviour, the danger being uncontrolled spread of smoke, hot gases and fire. Poorly designed connections affect evacuation, life, and property safety (e.g. spread of CO to neighbouring rooms).

Penetrations through fire-rated walls and floors for ventilation, pipes and other building services can provide paths for spread of fire and smoke. Careful attention to detailing and quality control is required.

\section{Knowledge Gaps}

Knowledge gaps are explored below, based on the text above.

\subsection{Data on Actual Fires}

There is a lack of statistical information on the fire performance of real timber buildings, in all countries. In order to develop probabilistic design methods, it is necessary to have data on the number and severity of fires, and the effectiveness of automatic and manual fire suppression.

\subsection{Full-Scale Experiments}

Many more full-scale tests are needed to provide information on fire severity. These must be large scale, so they will be expensive. Because of the trend to multi-story timber buildings, it is important to address the influence of combustible materials carefully, in particular when no encapsulation or sprinklers are provided. Some examples are given: 
- Determine the contribution of massive timber elements (e.g. CLT) to fire severity for non-standard fire exposure (interesting also for standard fire exposure)

- Determine fall-off times of claddings for non-standard fire exposure (also required for standard fire exposure)

- Determine the load bearing capacity and stability at fire exposure of timber building elements 3-10 $\mathrm{m}$ high - interesting also for standard fire exposure

- Determine the relevant fire exposure conditions for different types of fire stops in voids in timber structures

- Determine the influence of wooden façade claddings on the exterior fire spread of multistory buildings with flames coming out from a broken window after flashover

- Determine the influence of active (e.g. sprinkler) fire protection on structural fire performance and external spread of flame in a building

\subsection{Small-Scale Experiments}

Small-scale experiments are needed to:

- Establish the charring rates of different types of wood and wood-based products under different levels of thermal radiation

- Establish the self-extinguishment properties of different types of wood and wood-based products after different levels of fire exposure

- Determine the performance of different types of fire stops according to fire exposure conditions and procedures to be determined, see above

- Determine the performance of different types of connections according to fire exposure conditions and procedures to be determined, see above

- Investigate the charring rates of engineered wood products such as glulam, CLT, LVL and hybrid products, considering the effects of any gaps and the effects of different types of adhesive

\subsection{Evaluation of Existing Fire Testing Experience}

Japan has requirements on extended time after fire resistance testing of combustible structures in order to evaluate possible continued charring and loss of load-bearing capacity. Their experience should be consulted before starting further studies on this topic.

In summary, Japanese building codes have been adapted to ensure self-extinguishment of certain types of timber elements, and fire testing methods have been modified to assess the performance of encapsulation and self-extinguishment. Two types of fire resistance grade are defined in Japan:

1. "Fire Resistive Construction" requires structural stability of structural elements during and after a fire, including the entire cooling phase.

2. "Fire Preventive Construction" and "Quasi-fire Resistive Construction" both require 
structural stability for a specific fire duration. For example, $30 \mathrm{~min}, 45 \mathrm{~min}$, or $60 \mathrm{~min}$.

Fire resistance tests of "Fire Resistive Construction" must demonstrate the self-extinguishment of structural timber elements. The duration of each fire test depends on the type of material. If the structural elements are non-combustible material, a 3 hour cooling phase is nominally required after a 1 hour fire resistance test. If the structure is combustible, the duration of the cooling phase might be as long as 24 hours. Test operators in fire laboratories do not predetermine the duration before the fire tests, because they will only stop the test when charred wood of the specimen do not glow and the temperatures of all measurement points decrease below the decomposition temperature of the material.

\subsection{Modeling}

\subsubsection{Fire Models}

Existing fire models need to be expanded to include changes in ventilation conditions as the fire grows, and to include travelling fires in large spaces. For timber structures, they also need to include the contribution of combustible building materials.

\subsubsection{Simple Thermal Models}

Simple thermal models can be used for the design of large timber structures provided that the charring rate of wood is known under different thermal exposures. The charring rate is well known under standard fire exposure but it is important to know the change in charring rate under more realistic fire exposure. More research, including large scale experiments, is required to provide the charring rates needed for simple calculation models to be applied to realistic fires.

\subsubsection{Advanced Thermal Models}

Advanced thermal modeling can be done using the finite element method (FEM). These advanced methods are important for the development of simple charring models, but they are not normally required for design. For development of more advanced thermal calculation models, the problem is obtaining accurate time-dependent and temperature-dependent thermal properties of materials.

\subsubsection{Advanced Structural Models}

Complete fire-structure modeling based on FEM requires coupled thermal and mechanical analysis, which is difficult because of the large number of unknown input values. For standard ISO fire exposure tremendous improvements have been achieved (O'Neill et al., 2014; Schmid et al., 2010; and Klippel, 2014). However much needs to be done to provide accurate input data before the performance of timber structures exposed to natural fires can be predicted accurately.

The development of more advanced structural calculation models requires accurate timedependent and temperature-dependent mechanical properties of wood-based materials.

\subsection{Performance-Based Design}

An international agreement is needed on the overall approach of performance-based design (PBD) for fire safety (and fire resistance), consistent for all materials. It should be based on design fires for different types and sizes of buildings and occupancies. This needs to include the 
development of probabilistic or semi-probabilistic design methods for fire safety, to encourage building designs that meet target failure probabilities specified in modern building codes.

\section{How Best to Address the Seven Focused Topics in the Scope of Work}

\subsection{Identify R\&D Needs for Large-Scale Experiments}

Large-scale experiments on timber structures are needed to support PBD and structure-fire model validation. The main needs are to develop a design strategy for "burnout of fire compartments" to prevent structural collapse and to control vertical spread of fire, also to understand the interaction between active and passive fire protection systems. This needs to be focused on the development of advanced computer modeling, followed by, and supported by, experiments.

\subsection{Prioritized Needs in Order of Importance}

1. Agreement on relevant design fires / parametric fires to be used for the structural fire performance of buildings - these should be the same for all structural materials.

2. Determine the contribution of massive timber elements (e.g. CLT) to fire severity for nonstandard fire exposure.

3. Determine charring rates as a function of fire exposure (design fires) - does not need large scale facilities.

4. Determine conditions for self-extinguishment of charred wood, and reusability of the timber structure after a fire. This will require tests to compare the relative performance of different species and products.

5. Determine the performance of encapsulated timber elements, including the fall-off times of protective boards for non-standard fire exposure.

6. Determine the performance of different types of connections for non-standard fire exposure.

7. Determine the relevant fire exposure conditions for different types of fire stops in voids in timber structures.

8. Determine the influence of wooden façade claddings on the exterior fire spread of multistory buildings with flames coming out from a broken window after flashover in an apartment.

9. Determine the influence of passive (e.g. non-combustible claddings) and active (e.g. sprinkler) fire protection on the items above.

10. Quantitative fire risk assessment to determine the balance between active and passive fire safety measures in tall timber buildings.

\subsection{Recommended Timeline}

All of these items are urgent. They should be investigated as soon as there is money available. 


\subsection{The Most Appropriate International Laboratory Facilities}

It is very important to distinguish between standard fire test facilities (mainly for commercial tests of building elements) and non-standard facilities (for research of whole buildings or parts of buildings).

Every country has standard fire test facilities, and results are largely transferable between labs because all the international standards for fire resistance are similar. These facilities can be used for much of the research testing required.

Large-scale special-purpose research testing is required on an international scale, with test results shared between countries. Test facilities for large-scale special-purpose research testing are much more difficult to find. In North America, large scale laboratory facilities are available at NIST, also at FM Global, the National Research Council of Canada, and Carleton University in Ottawa. Other large scale testing facilities are available in France, Japan, and Australia. Some facilities used in the past are no longer available, such as those at Cardington in the UK.

Very large special purpose testing may be carried out in the open, not needing huge laboratories. This has been done recently in Japan, with destructive tests on several three-story timber school buildings.

\subsection{Potential Collaborators and Sponsors}

\subsubsection{Collaborators}

Potential collaborators include: university and government researchers (national and international), international conferences, the "Structures in Fire (SiF) community, and ISO meetings.

\subsubsection{Sponsors}

Potential sponsor include: US timber industry, Canadian suppliers, insurance industry, and government funding aimed at promoting sustainable development of the construction sector.

\subsection{Transfer of Results to Industry}

\subsubsection{Specific National and International Standards}

It will be very useful to have international guidance on ways to fulfil different requirements based on international standards for specific national codes. Codes must be based on a scientific response to consistent objectives. It will be easiest to start with Europe where a harmonised system for requirement classes and methods is in force, even if the different countries still may choose different levels of performance.

It is essential to maintain international standardisation, through organisations such as the International Standardisation Organisation (ISO), in particular ISO TC 92.

\subsubsection{Predictive Tools for Use in Practice}

The hard part is establishing the performance requirements. Once those are in place, a fire model and a structural model are both needed. The development of an accurate fire model for realistic fires needs experimental research. Once the fire model has been developed, and the charring 
rates established, the structural calculation tools can be relatively simple for wood, provided that the necessary input data is available.

\subsubsection{Comprehensive Research Reports}

All test and research results must be supported by comprehensive research reports. These will provide the international guidance needed to develop national and international standards. All reports must include case study buildings and worked examples.

\subsubsection{Quality Assurance}

Quality assurance is essential, at many levels, if research results are to produce safer buildings. This includes design calculations and specifications, documentation of designs, code enforcement and inspection of on-site construction.

Timber frame construction often consists of a combination of several different materials, which are designed and installed to fulfil multiple performance functions such as fire safety and acoustic performance. The methods used for assembling/erecting these multiple layers are vital to ensuring adequate performance. The sourcing and manufacture of all materials must meet the specified requirements.

Although the assembly sequences may differ, the requirements for ensuring adequate performance levels are identical. As an example, insulation (e.g. mineral wool) must be mounted carefully and must be in direct contact with wooden beams and girders to ensure adequate fire performance. Empty voids can lead to premature exposure of wooden elements in the event of a fire, and can lead to earlier charring and therefore decreased fire resistance. Careful installation of insulating products is particularly important in nominally empty attic areas, where the insulation can tend to be less carefully installed due to the non-occupied state of the roof space.

Fasteners used for securing claddings are also essential for the fire resistance. If nails or screws are too short, the cladding will be prone to premature delamination (fall-off), and wooden beams and girders will be exposed to fire at an earlier stage. This will lead to earlier charring and can reduce fire resistance times.

The installation of fire stops within the building as well as in façade gaps or voids, the erection and connectivity of penetrations and building services systems at the construction site are essential to ensure the fire performance of a timber structure. The appropriate installation of such details can be checked only during the construction period, and the quality of workmanship of such details should be monitored closely by the responsible contractor.

Self-monitoring by the contractor is an important process, and should be mandated and formalised whenever possible. The responsibilities of interacting trades must be clearly stated, and overarching project management processes communicated and enforced at the beginning of a project. In larger buildings third party control by building inspectors is essential.

\subsection{International Coalition to Review Progress}

The international coalition should be built on the existing network FSUW, Fire Safe Use of Wood. FSUW is originally a European network with mainly research and industry partners. The main result so far from FSUW is the very first European guideline on Fire Safety in Timber 
International R\&D Roadmap for Fire Resistance of Structures: Summary of NIST/CIB Workshop

Buildings (Östman et al, 2010). The network has recently been extended to include partners from Australia, Canada, Japan and New Zealand and should be further extended to include US participants.

\section{References}

Audebert, M., Dhima, D., Taazount, M. and Bouchaïr, A. 2013. Thermo-mechanical behaviour of timber-to-timber connections exposed to fire, Fire Safety Journal 56: 52-64.

Baker, G.B., Collier, P.C.R., Abu, A.K., Houston, B. 2012. Post-Earthquake Structural Design for Fire - a New Zealand Perspective. Zurich, Switzerland: 7th International Conference on Structures in Fire $(\mathrm{SiF})$.

BSI PD 7974-7, 2003. Application of fire safety engineering principles to the design of buildings - Part 7. British Standard.

Buchanan, A.H., 2001. Structural Design for Fire Safety. West Sussex, UK: John Wiley and Sons. 421pp.

Buchanan, A.H., 2008. The Challenges of Predicting Structural Performance in Fires. Ninth International Symposium on Fire Safety Science, Karlsruhe, Germany. September, 2008. pp. 77-90. doi:10.3801/IAFSS.FSS.9-79

Cachim, P.B. and Franssen, J.M., 2009. Numerical modeling of timber connections under fire loading using a component model, Fire Safety Journal 44: 840-853.

Carling, O., 1989. Fire resistance of joint details in load bearing timber construction - a literature survey. BRANZ Study Report SR18, Building Research Association of New Zealand, New Zealand.

CPD, Construction Products Directive. Official Journal OJ L40 of 11.2.1989, as amended by Council Directive 93/68/EEC, OJ L220 of 30.8.1993. European Commission.

De Sanctis, G., Faber, M.H. and Fontana, M., 2014. Assessing the Level of Safety for Performance Based and Prescriptive Structural Fire Design of Steel Structures. Proceedings, $11^{\text {th }}$ International Symposium on Fire Safety Science, Christchurch, New Zealand.

EN 1991-1-2. Eurocode 1. Action on structures. Part 1-2 General action - Actions on structures exposed to fire. European standard. CEN, Brussels, 2002.

EN 1995-1-2. Eurocode 5. Design of timber structures. Part 1-2 General - Structural fire design. European standard. CEN, Brussels, 2004.

EN 520:2004, Gypsum plasterboards - Definitions, requirements and test methods. European Standard, CEN, Brussels, 2004.

prEN 13381-7. Test methods for determining the contribution to the fire resistance of structural members - Part 7: Applied protection to timber members, European Standard, Draft, CEN, Brussels.

EN 15283-2:2008, Gypsum boards with fibrous reinforcement - Definitions, requirements and test methods - Part 2: Gypsum fibre boards, European Standard, CEN, Brussels, 2008. 
International R\&D Roadmap for Fire Resistance of Structures: Summary of NIST/CIB Workshop

Erchinger, C., Frangi, A. and Fontana, M., 2010. Fire design of steel-to-timber dowelled connections, Engineering Structures 32: 580-589.

FPInnovations, 2013. Technical Guide for the Design and Construction of Tall Wood Buildings in Canada. 90\% draft. Chapter 5 - Fire Safety and Protection (pp 223-282). FPInnovations, Vancouver, Canada.

Frangi, A. and Fontana, M., 2005. Fire Performance of Timber Structures under Natural Fire Conditions, Fire Safety Science 8: 279-290.

Frangi, A., Bochicchio, G., Ceccotti, A. and Lauriola, M.P., 2008. Natural Full-Scale Fire Test on a 3 Story XLam Timber Building, Proceedings of $10^{\text {th }}$ World Conference on Timber Engineering (WCTE), June 2-5, 2008, Miyazaki, Japan.

Frangi, A., Schleifer, V., Fontana, M. and Hugi E., 2008. Fire performance of gypsum plasterboards, Proceedings of 5th International Conference on Structures in Fire, May 28-30, 2008, Nanyang Technological University, pages 619-631.

Frangi, A., Erchinger, C. and Fontana, M., 2010. Experimental fire analysis of steel-to-timber connections using dowels and nails, Fire and Materials 34: 1-19.

Gerard, R., Barber, D. and Wolski, A., 2013. Fire Safety Challenges of Tall Wood Buildings. Arup North America Ltd. San Francisco, CA, and Fire Protection Research Foundation Quincy, MA, U.S.A. 162pp.

Green, M., 2012. The Case for Tall Wood Buildings - How Mass Timber Offers a Safe, Economical, and Environmentally Friendly Alternative for Tall Building Structures. mgb ARCHITECTURE + DESIGN, Vancouver, Canada.

Hakkarainen T., 2002. Post-Flashover Fires in Light and Heavy Timber Construction Compartments, Journal of Fire Sciences 20: 133-175

Hasemi, Y. 1989. Recent Japanese Studies on the Fire Safety of Timber Framed Residential Buildings. COST Action E5 Workshop on Fire Safety of Medium-Rise Timber Frame Residential Buildings. VTT Technical Research Centre of Finland.

Hasemi, Y., Yasui, N., Kato, K., Itagaki, N., Izumi, J., Osaka, Y., Kaku, T., Naruse, T., Hagiwara, I., Kagiya, K. and Suzuki, J., 2014. Full-Scale Fire Tests of 3-Story Wooden School Building. 2014 World Conference of Timber Engineering, Quebec City, Canada,

Hietaniemi, J. and Mikkola, E., 2010. Design Fires for Fire Safety Engineering, VTT Working Papers 139.

Japanese full-scale fire tests, 2012-13. www.nilim.go.jp/lab/bbg/kasai/h25/video/video06.wmv

Just A, Schmid J, König J. Gypsum plasterboards used as fire protection - Analysis of a database. SP Report 2010:29, Stockholm, 2010

Klippel M., 2014. Fire safety of bonded structural timber elements, PhD Thesis, ETH Zurich.

König J. and Walleij L., 1999. One-dimensional charring of timber exposed to standard and parametric fires in initially protected and non-protected fire situations, Trätek - Swedish Institute for Wood Technology Research, Report No. I 9908029, Stockholm. 
McGregor, C.J., 2013. Contribution of Cross Laminated Timber Panels to Room Fires. M.App.Sci thesis, Department of Civil and Environmental Engineering, Carleton University, Canada.

Moss, P.J., Buchanan, A.H., Fragiacomo, M., Lau, P.H. and Chuo, T., 2009. Fire performance of bolted connections in laminated veneer lumber, Fire and Materials 33: 223-243.

Nystedt F. Verifying Alternatives in Buildings with Fire Sprinkler Systems. Department of Fire

Safety Engineering and Systems Safety. Lund University, Sweden. Report 3150, 2011.

Nystedt F. Case Studies on the Verification of Fire Safety Design in Sprinklered Buildings. Report 7035, Department of Fire Safety Engineering and Systems Safety, Lund University, 2012.

Noren, J., 1996. Load-bearing capacity of nailed joints exposed to fire, Fire and Materials 20: $133-143$.

O’Neill, J.W., Abu, A.K., Carradine, D.M., Moss, P.J., and Buchanan, A.H., 2014. Predicting the Fire Performance of Structural Timber Floors. Proceedings, Structures in Fire Symposium, Shanghai, China.

Östman, B. et al, 2010. Fire Safety in Timber Buildings - Technical Guideline for Europe. SP Report 2010:19. Stockholm, Sweden.

Peng, L., Hadjisophocleous, G., Mehaffey, J. and Mohammad, M., 2010. Fire resistance performance of unprotected wood-wood-wood and wood-steel-wood connections: A literature review and new data correlations. Fire Safety Journal 45: 392-399.

Sekizawa, A., Sasaki, K., 2014. Study on Fires Following the Great East-Japan Earthquake. Proceedings, $11^{\text {th }}$ International Symposium on Fire Safety Science, Christchurch, New Zealand.

SOM, 2013. The Timber Tower Research Project. Skidmore, Owings and Merrill LLP, Chicago. $66 \mathrm{pp}$.

Schmid J, König J, Köhler J. 2010. Fire-exposed cross-laminated timber-Modeling and tests. World Conf. on Timber Engineering 2010, Riva del Garda, Trentino, Italy.

Schleich, J-B and Cajot, L-G, 2002. Competitive steel buildings through natural fire safety concepts, ECSC.

Smith, I. and Frangi, A. 2014. Use of Timber in Tall Multi-Story Buildings, Structural Engineering Document SED 13, International Association for Bridge and Structural Engineering IABSE, 2014. 